\title{
SCHOOL SIZE AND YOUTH VIOLENCE: POTENTIAL MEDIATING AND MODERATING ROLE OF SCHOOL CONNECTEDNESS
}

\author{
Adam M. Volungis \\ Submitted to the faculty of the University Graduate School \\ In partial fulfillment of the requirements \\ for the degree \\ Doctor of Philosophy \\ in the Department of Counseling and Educational Psychology of, \\ Indiana University \\ January 2011
}


Accepted by the Graduate Faculty, Indiana University, in partial fulfillment of the Requirements for the degree of Doctor of Philosophy.

\section{Doctoral Committee}

Date of Oral Examination

December 10, 2010
Susan C. Whiston, Ph.D.

Chair

Ellen L. Vaughan, Ph.D.

Jeff Daniels, Ph.D.

Janet P. Near, Ph.D. 
Copyright (C) (2011)

Adam M. Volungis 
To my parents and wife:

for their continued support, especially during the most difficult of times. 


\section{Acknowledgements}

Much thanks goes to my chair, Sue Whiston. Her support and patience "through it all" was invaluable and admirable. Thanks also go to my dissertation committee members Ellen Vaughn, Jeff Daniels, and Janet Near for their guidance, advice, and time in assisting this project to its full fruition. Stephanie Dickinson at the Indiana Statistical Consulting Center provided much needed guidance and insight on the statistical procedures and interpretation of results. Thank you to Jeremiah Byrd and the Education Technology Services for their cooperative assistance in establishing a secure network for data analysis.

I am most thankful for those closest to me whose faith in my ability to complete this endeavor was unwavering. My parents endured all the trials and tribulations of this journey, while always being available for support whenever I needed it. Finally, my wife, whose consistent support and unconditional love provided the much needed hope and determination to continue moving forward. 


\section{Adam M. Volungis}

\section{SCHOOL SIZE AND YOUTH VIOLENCE: POTENTIAL MEDIATING AND}

\section{MODERATING ROLE OF SCHOOL CONNECTEDNESS}

Youth violence continues to be considered a public health concern in the United States. Extant research indicates school size is positively associated with youth violence. School connectedness (i.e., the quality of perceived relationships between students and school personnel) has been found to be inversely associated with youth violence. This study utilized longitudinal data to test the possible mediating and moderating effects of school connectedness between school size and youth violence. The participants were obtained from Waves I and II of the National Longitudinal Study of Adolescent Health (Add Health), a nationally representative ongoing survey of $7^{\text {th }}$ through $12^{\text {th }}$ grade students in the United States. A series of multilevel models using Hierarchical Linear Modeling (HLM6) procedures were compared.

Results did not support school connectedness as a moderator; however, results did support school connectedness as a mediator between school size and youth violence. Although no direct relationship was found between school size and youth violence, there was a significant inverse relationship between school size and school connectedness and a significant inverse relationship between school connectedness and youth violence. These findings highlight the importance of how the quality of individual student-school personnel relationships can play a role in preventing violence both within and outside of the school setting. Furthermore, increasing school student population appears to 
play a role in creating challenges in the development of quality relationships between students and school personnel, which in turn impedes prevention of youth violence. In addition to contributing to the literature on preventing youth violence, this study also underscores the need for future research to take caution in research design and measurement with Add Health data, and further exploration in alternative contextual relationships that may prevent youth violence.

Susan C. Whiston, Ph.D. Chair

Ellen L. Vaughan, Ph.D.

Jeff Daniels, Ph.D.

Janet P. Near, Ph.D. 


\section{Table of Contents}

$\begin{array}{lll}\text { Chapter } 1 & \text { Introduction and Literature Review } & 1\end{array}$

$\begin{array}{lll}\text { Chapter } 2 \text { Methods } & 30\end{array}$

$\begin{array}{lll}\text { Chapter } 3 & \text { Results } & 43\end{array}$

$\begin{array}{lll}\text { Chapter } 4 & \text { Discussion } & 65\end{array}$

$\begin{array}{lr}\text { References } & 86\end{array}$

$\begin{array}{ll}\text { Appendices } & 101\end{array}$ 


\section{List of Tables and Figures}

Table 1: Youth Violence Skewness Pre/Post Log-Log Transformation

Table 2: Correlations Between Level 1 Variables

Table 3: Correlations Between Level 2 Variables

Table 4: Variance Explained for Key Variables

Table 5: Hypothesis Model Equations without Controls (A-E)

Table 6: Hypothesis Models without Controls (A-E) Final Estimation of Fixed Effects

Table 7: Hypothesis Model Equations with Controls (F-I)

Table 8: Hypothesis Models with Controls (F \& G) Final Estimation of Fixed Effects

Table 9: Hypothesis Models with Controls (H \& I) Final Estimation of Fixed Effects

Figure 1. Predicted mediating effect of school connectedness between school size and youth violence.

Figure 2. Predicted moderating effect of school connectedness between school size and youth violence.

Figure 3. Predicted interaction effect resulting school connectedness moderation 


\section{Appendices}

Appendix A: Tables

Appendix B: Figures

Appendix C: Curriculum Vita 


\section{Chapter 1}

\section{Introduction and Literature Review}

\section{Youth Violence}

Violence in some form has always existed in our schools and communities, but the highly publicized shootings in the 1990s, such as Littleton, Colorado, Jonesboro, Arkansas, and Paducah, Kentucky received extensive media attention resulting in an increase in public awareness and concern (Modzeleski et al., 2008). In 2001, the Surgeon General released a report in order to designate youth violence as a public health concern in the United States (U. S. Department of Health and Human Services, 2001). Although this report showed that youth violence was less lethal than it was in 1993 , violent behaviors involving adolescents showed trends of increasing. In fact, violent crimes committed by adolescents have dramatically increased (Federal Bureau of Investigation, 1999) to the point that this population commits more violent crimes than any other age group (Pastore \& Maguire, 2002). Also of concern are the findings that adolescent problem and criminal behaviors are related to future adult illegal behaviors (Loeber \& Hay, 1997; Sampson \& Laub, 1990). Furthermore, compared to all other age groups, children and adolescents are most likely to be the victims of crimes (Furlong \& Morrison, 2000). Youth violence is the second leading cause of fatal injuries for adolescents and in 2009 over 300,000 youth received emergency treatment for nonfatal injuries resulting from violence (Centers for Disease Control and Prevention, 2009).

The tragedies of the aforementioned school shootings in the $1990 \mathrm{~s}$ received intense media coverage, which resulted in many individuals having 
emotions such as shock, fear, helplessness, frustration, and anger (O'Toole, 2000). Although these feelings should not be downplayed, it is important to point out that school homicides are relatively rare. From July 1, 1992 to June 30, 2000, there were 234 school homicides of school-aged youth (ages 5-19), whereas there were 24,406 homicides of school-aged youth in locations other than schools (DeVoe et al., 2003). Thus, youth are at least 70 times more likely to be killed outside of school than in school. Overall, youth homicides appear to be a concern both in school and, even more so, within the community.

It is important to note that there are many other acts of youth violence besides homicides. For example, looking solely at homicides as a gage to determine youth violence can be somewhat deceiving. Although homicides are obviously significant, nonfatal violent acts can also result in significant physical and psychological trauma (Hyman, Cohen, \& Mahon, 2003; Hyman, Zelikoff, \& Clarke, 1988). When observing nonfatal crimes, there is a tendency for students ages 12 to18 to be at high risk both in school and away from school. As an example, in 2001, DeVoe et al. (2003) reported 2 million nonfatal crimes (i.e., theft, robbery, rape, sexual assault, aggravated and simple assault) of students in school and 1.7 million nonfatal crimes away from school. Findings from the 2009 Youth Risk Behavior Survey, a nationally representative sample of students in grades 9 through 12, indicated that $31.5 \%$ had engaged in a physical fight in the past year and $17.5 \%$ had carried a weapon in the past 30 days (Centers for Disease Control and Prevention, 2010). Additionally, although not considered a crime in the legal sense, DeVoe et al. reported a 3\% increase in school bullying from 1999 to 2001. In fact, the same 2009 Youth Risk Behavior Survey findings 
indicated that $19.9 \%$ of students reported being bullied on school property at least once over the past year (Centers for Disease Control and Prevention, 2010). There is substantial research that reflects that bullying is highly correlated with a negative school environment and is predictive of future youth violent behaviors (Ericson, 2001).

Besides the more visible consequences of youth violence (i.e., injury or death), there are also other consequences that may not be immediately apparent. Research has demonstrated that over time violence exposure and violence victimization is associated with risk factors and risk-taking behaviors (e.g., posttraumatic stress disorder [PTSD], depression, smoking, high-risk sexual behaviors, unintended pregnancy, substance abuse; Buka, Stichick, Birdthistle, \& Earls, 2001; Hammond, Haegerich, \& Saul, 2009; Kia-Keating \& Ellis, 2007; Ludwig \& Warren, 2009), along with some of the leading causes of death (e.g., suicide, heart disease, sexually transmitted diseases; Hammond et al., 2009). Moreover, there appears to be a general theme of youth violence being related to feelings of distress, anger, hopelessness, and shame from youth witnessing or experiencing violence (Martinez \& Richters, 1993; Ludwig \& Warrn, 2009; Osofsky, Werers, Hann, \& Fick, 1993). Buka et al.'s review of the literature on youth exposure to violence found that these individuals were more likely to experience higher rates of posttraumatic stress, depression, aggression, and other acting out behaviors. Similarly, Martinez and Richters found significant relations between violence exposure and distress, including sleep problems, worrying about re-exposure, intrusive thoughts, and nervousness. More specifically, KiaKeating and Ellis found that exposure to violence in a sample of youths 
significantly predicted $29 \%$ of the variance in PTSD symptoms and $14 \%$ of the variance in depression severity. Schwab-Stone et al.'s (1999) longitudinal study found that violence exposure at time 1 was related to adolescents' externalizing behaviors $\left(6^{\text {th }}\right.$ to $8^{\text {th }}$ grade and $8^{\text {th }}$ grade to $10^{\text {th }}$ grade) and internalizing symptoms ( $6^{\text {th }}$ to $8^{\text {th }}$ grade only) two years later. Overall, there appears to be legitimate concern of not only the physical well-being of adolescents after violence exposure, but also the social, emotional, and psychological well-being, which can sometimes have long term effects.

An additional concern of youth exposure to community violence tends to be a resulting cycle of violence where the victims become the perpetrators (Osofsky et al., 1993). Brookmeyer, Fanti, and Henrich (2006) in their analysis of data from the National Longitudinal Study on Adolescent Health (Add Health) found that simply being exposed to violence is a significant predictor of subsequent increases in violent behavior. In other words, exposure to violence increases the likelihood that youth will learn and apply these behaviors to their interactions with others. Hyman et al. (2003) also proposed that youth feel the constant need to defend themselves to ensure their safety, which may be used to justify their counter-aggression. Sampson and Laub (1990) found in a longitudinal study of delinquent and non-delinquent males from childhood to age 32 that youth delinquent/criminal behaviors were linked to adult crime , alcohol abuse, social deviance, economic dependency, and unemployment. Thus, the physical and psychological injury incurred by adolescent victims of violence often spreads to victimization of other adolescents. 
Finally, in addition to the public health concerns of youth violence, there are also social/economic costs to society. Nation et al. (2003) argued that one of the driving forces for the need for effective youth violence prevention programs are the costs associated with social, therapeutic, and rehabilitative services. For example, Cohen (1998) estimated that an adolescent who grows up to be a "career criminal" costs society $\$ 1.7$ to $\$ 2.3$ million in costs to victims, court costs, and costs of incarceration and treatment. Cohen argued that this is how much money society could save for each individual who is prevented from following a path of violence and crime.

Regardless of how the aforementioned youth violence statistics are viewed, it is difficult to minimize the impact that violent acts have on students, teachers, administrators, families, and community members (Daniels, Bradley, \& Hays, 2007; Hyman et al., 2003; Hyman et al., 1988). Unfortunately, a common reaction by many school systems and communities is to resort to stricter school policies and security precautions; even to the point of "profiling" students. These approaches are presumed to be effective with the goal of preventing violence. However, profiling students tends to be ineffective, susceptible to judgment and confirmation bias, and often stigmatizes many nonviolent students (Reddy et al., 2001; O’Toole, 2000). Additionally, extreme hypervigilance and "zero tolerance" approaches also have been found to produce minimally positive results and can potentially negatively influence the school atmosphere or climate (e.g., Blum, McNeely, \& Rinehart, 2002; McNeely, Nonnemaker, \& Blum, 2002). Zero tolerance policies were first created by the federal government as a means to enforce drug laws (Skiba \& Peterson, 1999). However, zero tolerance drug 
programs are now minimally used because often severe consequences were given for many relatively minor crimes. Paradoxically, as the federal government began phasing out zero tolerance polices because of their ineffectiveness, public schools soon began embracing this approach (Skiba \& Peterson, 1999).

McNeely et al. (2002) found that schools mandating harsh punishment through "zero tolerance" polices (typically expulsion), compared to schools with lenient discipline policies, had poorer student-teacher relationships. Thomas and Smith (2004) also found that most students in their study held strong negative feelings towards zero tolerance policies, especially punishments that were perceived to be disproportionate to the behavior. Hyman and Perone (1998) argued that such measures as strip searches, undercover agents, and corporal punishment may constitute psychological maltreatment and contribute to youth violence. Thus, schools that utilize zero tolerance policies to make schools safer may be doing the opposite; putting schools and communities at risk for violence. Blum et al. (2002) found less reactive efforts that understood potential risk and protective factors produced more robust and long-term preventative results in regards to youth violence.

In summary, it appears that youth violence is a significant problem and has negative impacts ranging from physical (e.g., serious injury, death), to psychological (e.g., posttraumatic stress, depression, substance abuse), and to economic, across schools, communities, and society as a whole (Bonny, Britto, Klostermann, Hornung, \& Slap, 2000; Cohen, 1998; McNeely \& Falci, 2004; Shochet, Dadds, Ham, \& Montague, 2006; Smith \& Sandhu, 2004). As discussed, research has shown that some adolescents engage in a significant 
number of violent behaviors both in school and the community (Farrington, 2004). Furthermore, the prevalence and public concern about youth violence suggests that additional research is needed to find effective means of prevention through key risk and protective factors (see Jimerson, Morrison, Pletcher, Furlong, 2006), rather than reacting after the occurrence of violent events or labeling youth who "might" be violent. As Hammond et al. (2009) stated: "Violence is experienced acutely by individuals, but its consequences and potential solutions affect society in general" (p. 254).

\section{Predicting Violence vs. Preventing Violence}

As the statistics and consequences discussed above demonstrate, youth violence is a significant public health concern that needs to be addressed. However, it is important to first distinguish between predicting violence and preventing violence, as these are two distinct approaches with arguably different goals and outcomes. As it will be discussed, preventing violence in this context often refers to creating an environment that minimizes risk factors and strengthens protective factors related to youth violence (e.g., Daniels et al., 2007; Daniels et al., 2010; Nation et al., 2003; Sullivan, Farrell, Betencourt, \& Helms, 2008). On the other hand, predicting violence is determining if a youth is a potential perpetrator of violence based on stereotypical behaviors and personality characteristics. Predicting violence is not an easy process and can have significant negative ramifications (Derzon, 2001; Mulvey \& Cauffman, 2001) similar to profiling students, as discussed earlier (e.g., Reddy et al., 2001; O’Toole, 2000). 
A major obstacle in predicting violent behaviors is that the process of identifying those who are violent often results in identifying many false positives (Hart, Webster, \& Menzies, 1993). On the surface, some individuals may not be concerned about the number of false positives (e.g., "better safe than sorry"). However, particularly in a zero-tolerance context, a false positive has been shown to be stigmatizing and limit future opportunities (Derzon, 2001; Mulvey \& Cauffman, 2001). Even if the label of a potential violent offender is formally removed, it does not mean the ramifications of the label are eliminated. An important point made by Mulvey and Cauffman is that oftentimes school violence not only reflects the individual factors, but also environmental factors. Thus, predicting, or targeting, specific students does not address changing the school environment that also may be contributing to the propensity of violent behavior.

Derzon's (2001) meta-analysis of 58 studies related to violence prediction identified other difficulties related to only focusing on individual factors in attempting to predict future violent behavior. Derzon found that $60 \%$ of individuals who were involved in antisocial behavior or engaged in substance use did not commit a crime against another person. Furthermore, $66 \%$ of individuals who did not engage in prior antisocial behavior did commit a later crime against another person. Additionally, O’Donnell, Hawkins, and Abbot (1995) found that aggressiveness ratings by teachers of students ages 10 and 11 did not predict future aggressive behavior and maladaptive outcomes at ages 13 and 14 . Considering the possible negative effects of falsely predicting an individual's propensity to commit a future crime (i.e., false positives) and the high number individuals who did commit a future crime but were "missed" in the prediction 
(i.e., false negatives) minimizes the confidence one can have in predicting future violence based on intrapersonal factors.

The following highlights some of Vossekuil, Fein, Reddy, Borum, and Modzeleski (2002) major findings related to predictability of violence from the safe school initiative: (a) there is no accurate "profile" of students who engage in targeted violence, (b) most attackers had no history of prior violent or criminal behavior, and (c) most attackers did not threaten their targets directly prior to the attack. Therefore, it appears that attempting to predict student violence based upon profiling is minimally effective.

As an alternative to predicting violence, or labeling students who might be violent, many prevention efforts and research recommendations are being suggested to help ameliorate this physically and psychologically traumatic cultural phenomenon. In fact, in 2002, the $49^{\text {th }}$ World Health Assembly declared that violence is a leading public health problem world-wide, and in turn, preventing violence should be a leading public health priority (Krug, Dahlberg, Mercy, Zwi, \& Lozaneo, 2002). Additionally, O’Toole (2000) cited multiple research recommendations from a National Center for the Analysis of Violent Crime symposium that included possible school dynamics as risk factors for violence, which could be used to develop effective prevention approaches. Furlong and Morrison (2000) asserted there is a crucial need for future research on youth violence to move beyond simple associations and consider specific contexts and potential precursors that may lead to violent behaviors. Similarly, Hoagwood (2000) emphasized the importance of considering extra-individual and transactual factors (e.g., social settings, social networks) as being the most 
logical approach to understanding youth violence. Finally, Hawkins et al. (2000) argued that in order to identify factors that prevent youth violence, researchers should conduct longitudinal studies that focus on violence or protective predictors. This is a significant point in that the majority of the research examining youth violence cannot determine directionality because of their crosssectional designs (Chávez, 1999). Therefore, research tends to indicate it is important to examine violence within a contextual framework while also identifying specific predictors/precursors' role in increasing or preventing youth violence.

The Centers for Disease Control (CDC) has responded to these calls for focusing on precursors to violence within a social context by developing a violence prevention agenda, which has focused on primary prevention (Hammond, Whitaker, Lutzker, Mercy, \& Chin, 2006). Simply stated, the goal is to prevent violence before it occurs. The CDC emphasized the importance of reducing risk factors and increasing protective factors to minimize the chances of youth becoming perpetrators of violence. Sullivan et al. (2008) presented a series of necessary core competencies for youth violence prevention. One of these competencies was an emphasis on the protective factor of "prosocial connectedness," which initially centered on looking at the role of secure attachment and family support. Vossekuil et. al's (2002) overview of the safe school initiatives indicated that relationships between students and school personnel may be particularly salient in preventing youth violence because: (a) many of the attackers felt bullied, persecuted or injured by others prior to the attack; (b) prior to most incidents, other people knew about the attacker's idea 
and/or plan to attack; (c) most attackers engaged in some behavior, prior to the incident, that caused others concern or indicated a need for help; and (d) despite prompt law enforcement responses, most attacks were stopped by means other than law enforcement intervention (i.e., students and/or teachers). Oftentimes perpetrators, or would-be perpetrators, share their plans of a violent act with other students before it takes place (O’Toole, 2000). However, students who would normally feel uncomfortable in "ratting out" a peer, and keeping this information to themselves, may be more prone to inform an adult (e.g., teacher) of a potential plan for violence if they trust and feel connected with this individual. In other words, students may be more likely to break the "code of silence" with a trusted adult.

Sullivan et al. (2008) suggested that the concept of prosocial connectedness can be generalized to broader systems, such as schools and communities. Furthermore, Nation et al.'s (2003) review of principles of effective prevention programs found that it was critical for children and adolescents to have at least one strong relationship with an adult. There appears to be strong relationships between student/youth outcomes and having a positive adult role model. Smith and Sandhu (2004) commented that this growing body of literature on relationships between students and adults has now been generalized into the school setting and studied as "school connectedness." As the discussed literature noted, there is a push for further research in preventing youth violence, especially primary prevention that takes into account important youth relationships (i.e., school personnel). Furthermore, school connectedness 
happens to be an area of growing interest and research may find that school connectedness is an effective mechanism in preventing youth violence.

Although there appears to be some relationship between school connectedness and youth violence, little research has examined the complexities of this relationship. There are most likely other variables that may be influencing the relationship of school connectedness and youth violence and there have been calls for additional research in this area (e.g., Blum et al., 2002; Loukas et al., 2006). One particular variable, school size, has also been linked to youth violence. Some research has shown that incidents of youth violence are associated with increasing school size (e.g., Ferris \& West, 2004; Kaiser, 2005; Leung \& Ferris, 2008). However, empirical research is relatively sparse on the relationship between school size and youth violence, and especially between school size and school connectedness. Thus, the interrelationship between school size, school connectedness, and youth violence is an area of research in need of more exploration.

\section{Youth Violence and School Size}

There has been the assumption for some time that larger schools are more economical and academically superior compared to smaller schools (Lindsay, 1982). In other words, bigger is always better. This assumption that bigger is

always better was advanced in 1959 when James B. Conant, past president of Harvard University, argued that small school size (schools with less than 100 students in the graduating class) was the primary obstacle in providing the highest quality of education (Kaiser, 2005; Lindsay, 1982). Conant argued for a comprehensive curriculum, which he believed smaller schools could not 
effectively provide. There was even a time when school districts would lose state aid if they deviated from the optimal large school size (see Cohn, 1975). Hence, even though the population in the United States has continued to increase, the number of schools has decreased. After World War II, there was a 70\% decrease in number of schools, while the average size of schools became five times larger (Rotherham, 1999). More specifically, in 1940 there were approximately 200,000 public and elementary schools, but by 2005 this number was decreased to 65,000 (Kaiser, 2005). This decrease in the number of schools took place while the population increased by $70 \%$.

There is, however, a growing body of literature that shows the size of the schools (as measured by number of students) may significantly impact student functioning. More specifically, in the past 30 years, there has been growing empirical support that as school size increases, students tend to have less participation in school activities, higher absenteeism, and higher dropout rates (Cotton, 1996a, 1996b; Fowler \& Walberg, 1991; Jones, Toma, \& Zimmer, 2008; Kearney, 2008; Lindsay, 1982; Pittman \& Haughwout, 1987;). Students in larger scores also tend to have lower levels of academic achievement, lower rates of attending college, and poorer self-reports of equity (Cotton, 1996a, 1996b; Galletti, 1999; Pittman \& Haughwout, 1987; Ready, Lee, \& Welner, 2004). Many studies show these domains of functioning to be superior in smaller schools, with few results indicating that larger schools are "equally" effective at best (Lindsay, 1982).

When it comes to establishing meaningful relationships within schools there is some evidence in favor of small schools. For example, some research 
findings have shown that as school size increases, students tend to report lower levels of school satisfaction and poorer interpersonal relationships with teachers (Bowen, Bowen, \& Richman, 2000; Cotton, 1996a, 1996b; Fowler \& Walberg, 1991; Lindsay, 1982; Resnick et al., 1997). Some studies have also found school connectedness to be inversely related to school size (Crosnoe, Johnson, \& Elder, 2004; Kearney, 2008; McNeely et al., 2002; Thompson et al., 2006). Similar to school connectedness, some of the more recent literature on school size and violence has shown larger school size associated with higher rates of youth violence (Ferris \& West, 2004; Kaiser, 2005; Leung \& Ferris, 2008).

Although sparse, some of the more recent literature on school size has indicated that as school size increases so do rates of youth violence. Some researchers (see Cotton, 1996a, 1996b) have shown that behavioral and delinquency problems are more prevalent in larger schools. However, there are only four known studies that have specifically examined school size and violence. Using Add Health data, Brookmeyer et al. (2006) found increasing rates of school size to be associated with increasing rates of youth violence. Three other studies also examined school size and youth violence, in terms of aggressive and fatal outcomes. Ferris and West (2004) approached this concern with an economic perspective through considering the external costs of school violence. They found that once schools reached an enrollment of 1000 or more students, there was a dramatic increase in serious violent incidents (e.g., from physical altercations to use of guns/knives). Leung and Ferris (2005) in their economic approach to school size and youth violence found that adolescents who attended schools with more than 2000 students had a $22 \%$ greater chance of engaging in violent 
behavior than those students who attended schools with less than 1,00o students. Finally, in an interesting neurobiological approach, Kaiser (2005) found that 14 of the 17 school shootings that were investigated took place in schools with grade enrollments larger than 150. In addition, of the 13 high school shootings, seven involved total school enrollments of more than 1,00o students. Kaiser contended that adolescents do not have the biological cognitive ability to adaptively function in grade sizes over 150 students.

Generally speaking, the studies previously discussed have used various levels of school enrollment to determine the optimal school size. Although there is no consensus, a few researchers have found that once schools reach above 1,00o students enrolled there appears to be a dramatic increase in youth violence (Ferris \& West, 2004; Kaiser, 2005). Others educators have advocated for a range of 400 to 800 (Galletti, 1999) or 600-900 (Ready et al., 2004), whereas, others have advocated for no more than 150-200 students per grade level (Kaiser, 2005). Devoe et al. (2003) also supported this position with statistical data. Smaller schools (400-600) compared to larger schools (enrollments above 600) experienced one-eighth the rate of serious crimes (4\% vs. 33\%) and one-tenth the rate of physical attacks with weapons ( $2 \%$ vs. $20 \%$ ). Interestingly, these size numbers are also consistent with research demonstrating that 600 or fewer students is the optimal school size for increasing school connectedness (Blum et al., 2002). Furthermore, Dunbar's $(1992,1993)$ work on natural group size suggested that once a group exceeds 150 individuals, there is a greater chance for social conflict and the formation of smaller groups within larger groups. When the natural group size of 150 students per grade (600 total students for grades 9- 
12) there are increases in aggressive behaviors as group splintering becomes more prominent (Dunbar, 1993). Overall, although there is no "magic number," it seems to appear that as school size gradually increases incidences of youth violence increases.

The ambiguity of what constitutes optimal school size may be due to varying contextual school and individual factors. Such factors may mitigate or enhance the effect of school size on youth violence. In particular, school connectedness, may be a significant linking factor between school size and youth violence. As stated earlier, some studies have found school size to be inversely related to school connectedness (e.g., Crosnoe et al., 2004; Kearney, 2008; McNeely et al., 2002; Thompson et al., 2006). Additionally, research has also shown school connectedness to be inversely related to youth violence (e.g., Herrenkohl et al., 2003; Resnick et a., 1997; Wilson 2004). Thus, it appears that the next logical step is to further examine the relationship between school size and youth violence within the context of school connectedness.

\section{Youth Violence and School Connectedness}

Within the past decade, youth violence has been studied from multiple perspectives in an effort to understand the causes and how to prevent these traumatic and sometimes deadly, violent events. One possible factor that has emerged from this research is the quality of relationships between students and school personnel (e.g., faculty, staff, and administrators); often referred to as school connectedness, which may influence violent incidents within and outside the school. The need to belong, or feel accepted, has been found to significantly affect emotional adjustment and related cognitive processes (Baumeister \& Leary, 
1995). Stated differently, interpersonal attachments can be a significant motivational factor in making decisions and corresponding behavioral responses. School connectedness appears to influence multiple domains of student social and emotional well-being. In one of the first studies to explicitly examine this construct, Resnick et al. (1997) found that school connectedness was the only school-related variable that was protective of eight student health risk. This finding spurred additional studies and state health agencies began to examine the important roles of school connectedness in relation to health outcomes (McNeely, 2003).

Researchers have found that adolescents who tend to feel nurtured, supported, and accepted within such contexts as peers, school, and community are more likely to: engage in fewer health risk behaviors, have higher levels of commitment, attend school regularly, graduate, and experience improved performance in school (Hawkins et al., 2000; Karcher, 2004; Kearney, 2008; Resnick et al., 1997; Shochet et al., 2006; Thompson, Iachan, Overpeck, Ross, \& Gross, 2006). Furthermore, studies have indicated that students who feel connected to their teachers and peers are more likely to seek help with interpersonal issues (McNeely et al., 2002; Townsend \& McWhirter, 2005). Moreover, experiencing a level of school connectedness as a result of trusting relationships with school personnel may also positively affect academic achievement, well-being, and resiliency (Catalano, Haggerty, Oesterle, Fleming, \& Hawkins, 2004; Shochet et al., 2006; Smith \& Sandhu, 2004). Although it has not been explored extensively, school connectedness may also play an important 
role in preventing youth violence (e.g., Catalano et al., 2004; Derzon, 2001; McNeely et al., 2002; Resnick et al., 1997).

McNeely et al. (2002) found that schools mandating harsh punishment through "zero tolerance" polices (typically expulsion), compared to schools with lenient discipline policies, had lower levels of school connectedness. Using data from the National Longitudinal Study on Adolescent Health (Add Health), Blum et al. (2002) found that students tended to display lower levels of school connectedness when discipline policies were perceived as overly harsh or punitive. In fact, Blum et al. recommended school administrators should not punish mistakes whenever possible, but rather turn them into learning opportunities. Whitlock's (2006) study of youth perceptions of life at school found that students who were allowed input into school policies and class materials reported higher levels of school connectedness. Edwards (2001) suggested that students may be more connected to their schools and less prone to violence when they have a role in determining certain rules and consequences.

Results from research studies have also indicated that the more connected students feel within their school the less likely they are to engage in negative, disruptive, antisocial behaviors (Battistich \& Hom, 1997; Brookmeyer et al., 2006; Miller, Breham, \& Whitehouse, 1998; O’Donnell et al., 1995; Ozer, 2005). In fact, alienation from family and peers and lack of school connectedness have been shown to be significant predictors of adolescents involved in weapon violence (Henrich, Brookmeyer, \& Shahar, 2005; Karcher, 2004). In a sample of high school students, Resnick, Harris, and Blum (1993) compared students with high connectedness scores to those with low connectedness scores. Those 
students reporting high levels of school connectedness were found to have significantly lower rates of emotional distress, suicidal ideation/behavior, and risky/delinquent behaviors than students with low levels of school connectedness. Resnick et al. (1997) obtained similar results based upon crosssectional analysis of interview data from over 12,000 adolescents (grades 7-12) that participated in the National Longitudinal Study on Adolescent Health (Add Health). More specifically, Resnick et al. found that students with high levels of school connectedness reported lower levels of distress, risk behavior, and aggression compared to students who reported low levels of school connectedness. Also using Add Health data, Franke (2000) found school attachment (a variation of school connectedness) to play a role in preventing violence against both property and people. In fact, students with high levels of school connectedness as compared to students with low levels of school connectedness have been found to be less likely to be perpetrators, or victims, of violence (Wilson, 2004). In Resnick, Ireland, and Borowsky's (2004) Add Health study, students who reported higher levels of school connectedness at initial assessment had much lower reports of violent behavior one year later, compared to those reporting lower levels of school connectedness. This trend remained relatively consistent even for those students exposed to other risk factors. Furthermore, Herrenkohl et al. (2003) found in their prospective study that even youth who experienced aggression at a young age had a lower probability of violence at age 18 if they later were exposed to protective factors such as school connectedness. 
In one of the few studies to look at school connectedness as a mediator, Loukas, Suzuki, and Horton (2006) found school connectedness to mediate the relationship between three school climate variables (i.e., perceived friction, perceived cohesion, and overall class satisfaction) and future conduct problems one year later. Jenkins (1997) also found school connectedness to mediate the relationships of personal background characteristics and family involvement in schooling with delinquent/violent school behaviors. Thus, school connectedness not only appears to have a direct relationship with youth violence, but also may have an indirect or mediation effect.

An interesting finding by Dornbusch, Erickson, Laird, and Wong (2001) using Add Health data was distinguishing that school connectedness had a stronger influence on preventing initial involvement in deviant/violent behavior than reducing deviant/violent behavior once it has already occurred. In other words, it appears more challenging to stop an adolescent with a history violent behavior than it is to prevent violence in an adolescent with no history. This finding reflects the importance of school connectedness' primary preventative role of violence.

The research linking the connection between establishing student school connectedness and youth violence has sometimes been viewed as a "call' to school personnel (e.g., teachers, counselors, and administration) to recognize that they can have a significant impact on preventing youth violence simply by establishing trusting relationships. Hunt et al. (2002) emphasized the importance of considering school connectedness as a primary preventative approach to youth violence, rather than secondary or tertiary. It also has been argued that in order 
to support nonviolence, schools need to encourage a climate of genuine acceptance and caring and trusting relationships among students and school personnel (Edwards, 2001). The concept of preventing youth violence can often be perceived as a daunting problem to be handled by formal protocols. If school connectedness is found to prevent youth violence, then all educational personnel can be involved in prevention strategies.

Although there are a few studies that indicate that school connectedness and school size may be separately related to youth violence, there has been very little research that has examined both factors together. This is somewhat surprising considering the robust literature in demonstrating relationships between school connectedness, school size, and other outcomes. Although some of these studies may have included both school connectedness and school size variables, no known research has directly examined both variables concurrently in terms of their role in predicting youth violence as an outcome.

Conceptualizing the role of school size, school connectedness, and youth violence together appears to be the next appropriate step for empirical examination. Currently, many of the studies examining theses variables use cross-sectional data and/or do not include all three simultaneously. Hawkins et al. (2000) argued more studies using longitudinal data are needed in order to identify protective factors of violence. This study use longitudinal data by way of measuring the predictor variables at time 1 and the outcome variable at time 2 . Therefore, this study's design and analyses may be able to provide added knowledge of the contextual relationship of preventing youth violence over time. 
Additionally, it seems important to examine whether school connectedness is a mediator and/or moderator of the relationship between school size and youth violence. Such an approach is based upon not only the demonstrated literature supporting the relationship among these constructs but also on recommendations of scholars in this field. For example, Hoagwood (2000) encouraged researchers to consider possible mechanisms that contribute to the development of aggressive behavior. More specifically, Blum et al. (2002) recommended considering possible school characteristics that may predict school connectedness (i.e., school size), which in turn may help prevent youth violence. Very few studies have actually directly tested school connectedness as a mediator between other school variables (Loukas et al., 2006). Crosnoe et al. (2004) further stated that future studies should explore the mediating role of interpersonal climate (i.e., school connectedness) between school size and academic achievement. Hence, it is believed that this study's examination of potential mediating and moderating roles of school connectedness between school size and youth violence is a potentially important contribution to the existing research related to youth violence.

There is a plethora of extant research demonstrating that a variety of characteristics such as biological sex, race/ethnicity, and socioeconomic status are associated with higher rates of violence. For example, males tend to have significantly higher rates of aggression compared to females (Centers for Disease Control and Prevention $[C D C], 2010)$. Ethnic minorities have also been shown to have higher rates of violence (CDC, 2010). However, it is important to note that oftentimes socioeconomic status is typically found to be the more significant 
predictor of violence, rather than race/ethnicity (Crouch, Hanson, Saunders, Kilpatrick, \& Resnick, 2000; Foster, Brooks-Gunn, \& Martin, 2007). More specifically, lower levels of socioeconomic status tends to be associated with higher rates of violence (Crouch et al., 2000). Even such school characteristics as urbanicity (i.e., rural, suburban, urban) and school type (public vs. private) have shown differences in rates of violence (Ferris \& West, 2004; Leventhal \& BrooksGunn, 2000). Many studies that have examined youth violence, school connectedness, and school size (either together or separately) have controlled for such variables as biological sex, race/ethnicity, socio-economic status (SES), urbanicity, and school type (e.g., Fowler \& Walberg, 1991; Leung \& Ferris, 2008; Lindsay, 1982). Therefore, in examining the mediating and moderating influence of school connectedness on the relationship between school size and violence, it also seemed important to control for these variables in order to understand the mediating or moderating influences.

\section{Research Questions and Hypotheses}

The goal of this study is to consider an alternative, multivariable approach towards preventing youth violence utilizing longitudinal data. First, school personnel (e.g., school teachers) may specifically enhance/foster schoolconnectedness through their relationships, which may play a role in decreasing youth violence. Second, school size by itself seems to also influence school connectedness and other similar factors such as interpersonal relationships with teachers.

The research questions associated with the present study emerged as an unexplored area within the larger context of research related to youth violence, 
school connectedness, and school size. The first research question proposes school connectedness as a partial mediator. The second research question proposes school connectedness as a moderator. These two questions resulted in five hypotheses that were tested using an existing dataset from Add Health. In order to test these hypotheses multiple multilevel models were used for conceptualization and analyses. Conceptually, schools size and school connectedness were the independent (i.e., predictor) variables and youth violence was the dependent (i.e., outcome) variable. The third research question proposes that any relationships found in the first two questions will still hold after controlling for pertinent student and school characteristics.

Research Question One: Does school connectedness partially mediate the effects of school size on youth violence?

Hypothesis 1: School size would be positively associated with youth violence.

Hypothesis 2: School size would be inversely associated with school connectedness.

Hypothesis 3: $\mathrm{H}_{3 \mathrm{a}}$ : School connectedness would be inversely associated with youth violence. $\mathrm{H}_{3}$ : School connectedness would be inversely associated with youth violence, while controlling for the effects of school size.

Hypothesis 4: School connectedness would partially mediate the effects of school size on youth violence. (See Figure 1.) Research Question Two: Does school connectedness moderate the effects of school size on youth violence? 
Hypothesis 5: Student connectedness would moderate the effect of school size on youth violence. (See Figures 2 and 3).

\section{Research Question Three: Will the relationships found in the first two research questions still hold after controlling for pertinent student and school characteristics?}

Hypothesis 6: School size would be positively associated with youth violence controlling for student and school characteristics.

Hypothesis 7: School size would be inversely associated with school connectedness controlling for student and school characteristics.

Hypothesis 8: School connectedness would be inversely associated with youth violence controlling for student and school characteristics.

Hypothesis 9: School connectedness would partially mediate the effects of school size on youth violence controlling for student and school characteristics. (See Figure 1.)

Hypothesis 10: Student connectedness would moderate the effect of school size on youth violence controlling for student and school characteristics. (See Figures 1 and 2.)

\section{Operational Definitions of Key Variables}

\section{Youth Violence}

Like all constructs, it is crucial for researchers investigating youth violence to be clear on how it is operationally defined, including corresponding measurement approaches. The World Health Organization defined violence as "the intentional use of force or power, threatened or actual, against oneself, another person, or against a group or community, that either results in or has a 
high likelihood of resulting in injury, death, psychological harm, maldevelopment, or deprivation" (World Health Organization Global Consultation on Violence \& Health, 1996, p. 3-4). Furlong and Morrison (2000) explained that "youth violence" is often used as a term that encompasses violence that takes place in the schools and out in the community by individuals under the age of 18. Chavez (1999) provided a review and conducted a meta-analysis of 43 articles on how youth violence is operationally defined in empirical research. Overall, Chavez found the definitions of "youth" and "violence" to be inconsistent, abstract, and not explicit. Self-reports of violence are the most frequently used measures due to pragmatic and ethical reasons (Rosenblatt \& Furlong, 1997). Although alternatives like police and school records may not be subject to memory accuracy from self-reports, these indices also have their own problems in terms of only indicating who actually get caught and could be subject to gender and racial/ethnicity bias (Dornbusch et al., 2001). Thus, although not perfect, Dornbusch et al. asserted that self-reports remain the preferred source of information to measure youth violence.

There appears to a range of definitions and methods to assessing levels of youth violence. Regardless of the variability in definitions of this construct, it is important to be explicit in how youth violence is defined, reported, measured, and appropriately fits the research questions. Lack of clarity in defining youth violence can have significant empirical implications in generalizability and complicate recommendations for future research and practice. Youth violence in this study included $7^{\text {th }}$ to $12^{\text {th }}$ grade students self-reported experiences of violence, 
including variations of threatening to use a weapon on someone, getting in a physical fight, and shooting or stabbing someone.

\section{School Connectedness}

Reviews of the literature appear to indicate that school connectedness is also a construct with many names and definitions (see Libbey, 2004; Maddox and Prinz, 2003). This makes it difficult to develop definitive conclusions about school connectedness and impedes school personnel's ability to apply the research in this area. Libbey (2004) addressed this construct concern with an extensive review of the multiple terms and definitions for school connectedness in the literature. Libbey found the following terms were commonly used in the health and education literature: positive school orientation, school attachment, school bonding, school climate, school connection, school context, school engagement, school involvement, student satisfaction with school, student identification with school, and teacher support. Libbey concluded that although there are many terms and methods used to measure school connectedness, there are many shared definitional components. These components are (a) academic engagement, (b) belonging, (c) discipline/fairness, (d) extracurricular activities, (e) likes school, (f) student voice, (g) peer relations, (h) safety, and (i) teacher support

In their executive summary of the special edition of the Journal of School Health devoted to school connectedness, Blum and Libbey (2004) stated that the construct is dependent on students experiencing high expectations for (relational) success, feeling supported by school personnel, and feeling safe while in school. They argued that any measure of school connectedness should include 
these three pertinent themes. This study will use Resnick et al.'s (1997), and other related studies (e.g., Dornbusch et al., 2001; McNeely, 2003), conceptualization of school connectedness where individual-school environment interactions and perceptions of safety are of primary interest. This includes adolescents needing to feel respected and cared for, having a perception of belonging, and a sense of safety and fairness. Although there are some concerns about self-report measures, this is the most common measurement method for assessing school connectedness. School connectedness in this study will be examined using student self-report measure.

\section{School Size}

How school size is operationally defined is a methodological consideration that should not be taken for granted. Kimberly's (1976) review of organizational size noted that about $80 \%$ of the studies included number of employees as a measure of organizational size. What is unique about the school size literature is that number of employees (i.e., teachers, administrators, school counselors) has very rarely been considered. Rather, researchers in this domain have solely focused on what Kimberly refers to "organizational inputs or outputs" - number of students enrolled within a school.

Regardless of how school size is operationally defined, it is important to be clear and explicit in how the construct is measured. Different measures of school size can possibly provide different results and corresponding conclusions (Bowen et al., 2000; Kaiser, 2005; Lindsay, 1982; McNeely et al., 2002; Fowler \& Walberg, 1991). Overall, research on the relationship between school size and youth violence appears to be most robust using total student population (Ferris \& 
West, 2004; Resnick et al., 1997; Leung \& Ferris, 2008). This study will use the conventional school size measure of student population as reported by school administrators from each school.

\section{Summary}

Significant acts of youth violence continue to occur in the U.S., which can cause significant physical harm, emotional trauma, and economic strain. What has been presented here is an empirical approach to examining the interrelationship of school size, school connectedness, and youth violence. This is the first known study and conceptual approach to consider these variables concurrently with multilevel modeling. Understanding the potential mediating and/or moderating role of school connectedness between school size and youth violence may be key to prevention. These knowledge gains could inform such individuals as teachers and mental health professionals, along with administrators and politicians when advocating for positive school climate programs (e.g., anti-bullying). The results of implementing such programs may not only be economically advantageous, but most importantly, benefit the academic and socio-emotional well-being of our students. 


\section{Chapter 2}

\section{Methods}

This chapter contains the procedures for the present study. Participants, variables, instrumentation, and the statistical analysis to address the research questions are reviewed.

\section{Participants}

The 11,777 participants from this study came from Waves I and II of the National Longitudinal Study of Adolescent Health (Add Health), a nationally representative ongoing survey of $7^{\text {th }}$ through $12^{\text {th }}$ grade students in the United States beginning during the 1994-95 school year (Harris et al., 2009).

The primary sampling frame included all high schools in the United States that had an $11^{\text {th }}$ grade and at least 30 students in the school $(n=26,666)$. A systematic random sample of 80 high schools was selected with probability proportional to enrollment size and stratified based on region, urbanicity, school type, and racial composition. Fifty-two of the 80 selected high schools were eligible and agreed to participate. The remaining 28 schools were replaced by similar high schools by sorting the frame by eight variables: school size, school type, level of urbanicity, percent white, grade span, percent black, consensus region, consensus division. This resulted in the replacement school matching the school it was meant to replace on all eight characteristics. Each sample school was then matched to its largest feeder school. A feeder school was typically a school with a $7^{\text {th }}$ grade (i.e., middle school) that sent at least 5 of their graduates to the entering class of the high school. Four high schools had no eligible feeder because students came from multiple middle schools. Twenty-four high schools 
had their own feeder due to having grade ranges that included $7^{\text {th }}$ or $8^{\text {th }}$ grades. The size of the schools ranged from fewer than 100 to more than 3,000 students. Overall, $79 \%$ of the schools contacted agreed to participate, resulting in a total of 132 schools (8o high schools and 52 feeder schools). School administrators completed a questionnaire of key school demographics during Wave I. The analyses for this study only included schools that answered key demographic questions (e.g., schools size), and schools that were given sample weights $(N=$ 115).

Wave I consisted of a total sample of 20,745 students who completed the in-home interview (79.8\% response rate). However, 1,821 cases were not given sampling weights, resulting in a total of 18,924 students for Wave I. The sample for Wave II was composed of those who participated in Wave I of the in-home interview except for the $12^{\text {th }}$ graders and a few select subsamples. The overall response rate for the second wave was $88.2 \%$, yielding a total sample of 14,738 . Overall, the analyses for this study included students who responded to both Wave I and Wave II surveys and answered key construct questions (e.g., school connectedness, youth violence), and students that were given sampling weights at both waves $(N=11,777)$.

\section{Procedures}

Add Health was designed to provide an extensive examination of healthrelated behaviors among adolescents. Add Health takes into account characteristics of the individual, family, peer group, school, and community as having important roles and determinates in the lives of adolescents' health status. This dataset was chosen for its longitudinal nature and extensive inclusion of 
individual and organizational characteristics, which best fit this study's research questions and statistical analyses.

The data used in this study was from the first two waves of the Add Health full contractual restricted-use dataset (Harris, 2009). All study protocols received Indiana University Institutional Review Board approval. Precautions were taken to maintain confidentiality and to prevent deductive disclosure of students' identities. This process included signed contractual agreements by investigators with access to the data, creation of a separate secure windows server, use of individualized passwords to access the data, and locked storage of the physical (i.e., software) data.

The focus of this study was the in-home survey/interview of Wave 1 and Wave 2 and school administrator questionnaire of Wave 1. The first wave of the in-home interviews was conducted from April 2005 to December 2005. Informed consent was obtained from a parent or legal guardian of the adolescent by a trained research assistant who assisted in the administration of the in-home interview. Most of the interviews took place in the adolescents' home and took one to two hours to complete. All responses were recorded on a laptop with more sensitive questions being pre-recorded and listened to through earphones. All of the students who were in the participating schools' directory were eligible for selection. Students from each school were stratified by grade and sex. Approximately 17 students were randomly chosen from each stratum resulting in a total of about 200 students selected from each of the 80 high schools and 54 feeder schools. There were special over-samples of black adolescents with college-educated parents, Cuban and Puerto Rican adolescents, Chinese 
adolescents, and physically disabled adolescents. (The sample also included Mexican-Americans, Nicaraguans, Japanese, South Koreans, Filipinos, and Vietnamese.) There was also familial oversampling for genetic siblings and twins, and unrelated adolescents who reside in the same household. Socially, there was also a sample of relationship/social network patterns where all respondents were selected from two large schools (combined enrollment over 3,300) and 14 small schools (enrollment of each school fewer than 300). For $85.6 \%$ of the participating adolescents, at least one parent (usually a mother) completed a questionnaire. In the interest of this study a parent from each household was asked to report their socioeconomic status. The in-home interview included the following topics: health status, health-facility utilization, nutrition, peer networks, decision-making processes, family composition and dynamics, educational aspirations and expectations, employment experience, events leading to the formation of romantic partnerships, sexual partnerships, substance use, and criminal activities.

The second wave of the in-home interview took place from April 1996 to August 1996. No parent questionnaire was given during the second wave. The second wave in-home interview included the same topics as the first wave with exception of including one question related to sun exposure and more detailed nutritional questions. The mean interval between Wave I and Wave II data collection was 11.0 months (95\% confidence interval: 7.6-14.3 months; Resnick et al, 1997). Students in the $12^{\text {th }}$ grade that completed the in-home interview at Wave I did not participate in Wave II. 
Each participating school was also asked to complete a school administrator questionnaire during Wave I. A total of 164 self-administered school administrator questionnaires were completed. During the same time span as the in-home interview, this questionnaire was completed during year one of the first Wave. The questionnaire included the following topics: school policies and procedures, teacher characteristics, curriculum, health service provision or referral, school environment, and study body characteristics.

\section{Measures}

\section{Youth violence}

Youth violence was measured using a 7-item scale from the Add Health data that assessed a wide range of violent behaviors. Resnick et al. (1997), Dornbusch et al. (2001), and Resnick et al. (2004) used these 7 questions to measure the construct with strong internal consistency (alphas $=.82, .82$, and .83 , respectively). These questions assessed the use of weapons, physical altercations, and physical injury. The following are the 7 questions that were used in this study to measure youth violence (based on in the past 12 months "how often did you"):

1. "Pull a knife or gun on someone?"

2. "Shot or stabbed someone?"

3. "Get into a serious physical fight?"

4. "Use a weapon in a fight?"

5. "Hurt someone badly enough to need bandages or care from a doctor or nurse?”

6. "Use or threaten to use a weapon to get something from someone?" 
7. "Take part in a fight where a group of your friends was against another group?”

The first two questions were answered using a scale of never (o), once (1), and more than once (2). Questions 3 through 7 were answered using a scale of never (o), 1 or 2 times (1), 3 or 4 times (2), and 5 or more times (3). Because of the relative low frequencies of violence, the violent data were recoded as no violent acts a (0) and one or more violent acts a (1) (see Dornbusch et al., 2001; Resnick et al., 2004). However, although each question was treated as dichotomous there are multiple violence questions which provided scores varying from $0-7$ for each student. Similar to previous studies (Dornbusch et al., 2001; Resnick et al., 2004) the scale was transformed before analyses (i.e., log-log) because of the highly skewed distribution.

\section{School size}

School size was reported by the school administrators among many other school characteristic variables. School size was reported in increments of 100 students, while Add Health dataset identified the schools as small (1-400), medium (401-1000), or large (1001-4000). Thus, this predictor variable was coded categorically.

\section{School connectedness}

School connectedness was measured using Resnick et al.'s (1997) 8-item scale. Resnick et al.'s definition includes adolescents' need to feel respected and cared for, having a perception of belonging, and a sense of safety and fairness. In one of the first published studies examining school connectedness with Add Health data Resnick et al. used an 8-item scale (alpha $=.75)$ that included feelings of 
teacher support and respect, sense of safety, perception of belonging, perception of being treated fairly, and difficulty getting along with teachers and other students. Other studies have measured school connectedness with the same Add Health data with a range of 5-8 questions (e.g., Bonny et al., 2000; Brookmeyer et al., 2006; Henrich et al., 2005; McNeely, 2003; McNeely et al., 2002; McNeely \& Falci, 2004). Resnick et al.'s 8-item scale was selected because of its theoretical foundation, widely cited definition of school connectedness, and other studies citing similar internal consistency (e.g., Henrich et al., 2005; McNeely \& Falci, 2004). The following are the 8 questions that were used in this study to measure school connectedness as a predictor variable:

1. "You feel close to people at your school?"

2. "You feel like you are part of your school?"

3. "You are happy to be at your school?"

4. "The teachers at your school treat students fairly?"

5. "You feel safe in your school?"

6. Sense the start of the school year, how often have you had trouble "getting along with your teachers?”

7. Since the start of the school year, how often have you had trouble "getting along with other students?”

8. "How much do you feel that your teachers care about you?"

Questions 1-5 are answered using a scale of strongly agree (1) to strongly disagree (5). These responses were reverse-coded, consistent with other studies (Bonny et al., 2000; Dornbusch et al., 2001; McNeely et al, 2002), so higher scores reflected greater school connectedness. Questions 6 and 7 were answered 
using a scale of never (o) to everyday (3). These responses were also reversecoded to have a higher score reflect greater school connectedness. Finally, question 8 was answered on a scale of not at all (1) to very much (5). These scores were then standardized and summed for each student.

\section{Data Analysis}

All analyses in this study utilized sampling weights to adjust for stratification and oversampling of underrepresented groups. The use of sampling weights allows for the sample to be regarded as nationally representative of adolescents in grades 7 through 12.

Hierarchical linear models (HLM) with HLM 6 (Raudenbush, Bryk, Cheong, Congdon, \& du Toit, 2004) were used to estimate the effects of school connectedness and school size on youth violence over time. This statistical technique is appropriate for the multi-level nature of the research questions, and the school-based clustering (i.e., nested data) of Add Health, in which observations within schools are not independent. Thus, within-school (individual-level) and between-school (school-level) models were estimated simultaneously. Overall, the primary goal of HLM is to predict values of a dependent variable (i.e., youth violence) based on a function of predictor variables (i.e., school connectedness and school size) at more than one level (Luke, 2004). This study employed a two-level hierarchical linear model with youth violence and school connectedness on the first level nested within schools and school size on the second level. In order to test any possible mediation/moderation of school connectedness on the effects of school size on youth violence a logical stepwise process for testing the five hypotheses was 
implemented. This process of testing the possible mediation/moderation relationships followed Baron's and Kenny's (1986) regression recommendations in a similar manner, but with HLM processes.

The following is the primary two-level model for which analyses were used to test this study's hypotheses:

Level 1: $Y_{i j}=\beta_{0 j}+\beta_{1 j} X_{i j}+r_{i j}$

Level 2: $\beta_{o j}=Y_{o o}+Y_{o 1} W_{j}+u_{o j}$

$$
\beta_{1 j}=Y_{10}+Y_{11} W_{j}+u_{1 j}
$$

Where: $\mathrm{i}=$ student $(\mathrm{i}=1 . .11,777)$ level 1 units nested with $\mathrm{j}=\operatorname{school}(\mathrm{j}=$

$$
\text { 1...115) level } 2 \text { units }
$$

$\mathrm{Y}_{\mathrm{ij}}=$ level-1 outcome (youth violence)

$\beta_{\mathrm{oj}}=$ level-1 intercept in level-2 unit $\mathrm{j}$

$\beta_{1 \mathrm{j}}=$ level-1 slope in level-2 unit $\mathrm{j}$

$\mathrm{X}_{\mathrm{ij}}=$ level-1 predictor (school connectedness)

$\mathrm{r}_{\mathrm{ij}}=$ level-1 random effect

$\mathrm{Y}_{\mathrm{oo}}=$ mean value of level-1 outcome (youth violence), controlling for level-2 predictor (school size) [fixed effect]

$Y_{01}=$ effect (slope) of level-2 predictor (school size) [fixed effect]

$\mathrm{W}_{\mathrm{j}}=$ level-2 predictor (school size)

$\mathrm{u}_{\mathrm{oj}}=$ level-2 random effect

$Y_{10}=$ mean value of level-1 slope (school connectedness), controlling for the level-2 predictor (school size) [fixed effect]

$Y_{11}=$ effect (slope) of level-2 predictor (school size) [fixed effect]

$\mathrm{u}_{1 \mathrm{j}}=$ level-2 random effect

This primary model included the three key constructs of the study and was used to develop alternative, secondary models to test each hypothesis. The primary model was also able to include key available demographic variables that could be included in the secondary models. Level 1 demographic variables 
included gender, race/ethnicity, socioeconomic status. Level 2 demographic variables included urbanicity (i.e., rural, suburban, urban) and school type (public, private).

Furthermore, it should be noted that the above two equations for this study's model highlight why multilevel models are also called mixed models as they are always made up of both fixed and random effects (Luke, 2004). Thus, by combining these two equations it is possible to get a mixed-effects model:

$$
\begin{array}{cc}
Y_{i j}=\left[Y_{o o}+Y_{10} X_{i j}+Y_{01} W_{j}+Y_{11} W_{j} X_{i j}\right] & +\left[u_{o j}+u_{1 j} X_{i j}+r_{i j}\right] \\
\text { fixed } & \text { random }
\end{array}
$$

This single prediction equation allows for clearer indication of the fixed effects ( $Y s$ ) and random effects ( $u$ and $r$ ) of the model. Random effects in a multilevel model should be viewed as additional error terms or sources of variability (Raudenbush \& Bryk, 2002). Thus, a mixed effects model was selected with the assumption that both intercepts and slopes would vary across the Level 2 units.

This study focuses on issues of mediation and moderation. Baron and Kenny (1986) recommended a four step procedure for mediation. Although Baron and Kenny are often associated with mediation and moderation procedures in the social sciences, it is considered standard statistical practice (Zhang, Zyphur, \& Preacher, 2009). Furthermore, this procedure is also cited as an appropriate method for testing mediation with HLM (Baron \& Kenny, 1986; Krull \& MacKinnon, 2001; Zhang et al., 2009). The first step should be to test the predictor variable (school size) with the outcome variable (youth violence). This will help establish if there is an effect that can be mediated. The second step is to 
test the predictor variable by treating the mediator (school connectedness) as an outcome variable. The intent is to examine whether there was an effect between school size and school connectedness. The third step in testing for mediation is to test the mediator (now being treated as a predictor) with the outcome variable. However, Baron and Kenny stated that simply testing the mediator with the outcome would not be sufficient as the mediator and the outcome may be correlated because they are both caused by the predictor. Thus, school size must be controlled in order to establish the effect of school connectedness on youth violence. The fourth step has two parts. First, is to test the predictor variable on the outcome variable, controlling for the mediator. The purpose here is to determine if there is any effect between school size and youth violence while controlling for school connectedness. The effect should be zero or close to zero. The second part includes comparing this effect with the effect from the first step, which was school size with youth violence not controlling for school connectedness. This comparison is done to determine if the effect for school size with youth violence is reduced when school connectedness is controlled.

Baron and Kenny (1986) initially argued that all four steps should be met for a full mediation between the predictor variable and outcome variable. A partial mediation is also possible if the first three steps are met, but step four is not. However, Kenny, Kashy, and Bloger (1998) acknowledged that "most" analysts do not believe that step one is required. What is most important is if steps two and three are met because this implies a path from the predictor variable to the outcome variable. Moreover, step four does not have to be fully met unless the desired outcome is a complete mediation. It should also be noted 
that the steps are not in terms of statistical significance (Baron \& Kenny, 1986). Rather, the steps are stated in terms of zero and nonzero coefficients. This means p-values are not used to determine significance of a mediation model. A comparison of models is required. Ultimately, the appropriate manner to determine mediation is to consider the degree to which the relationship between the predictor variable and outcome variable decreases when the proposed mediator is controlled (Frazier, Tix, \& Baron, 2004).

Another common technique to statistically test significance with mediation is the Sobel test. The test is frequently used to test mediation in multiple regression (Baron \& Kenny, 1986; MacKinnon, Lockwood, Hoffman, West, \& Sheets, 2002;). The Sobel test is also occasionally used to test mediation in HLM (Krull \& MacKinnon, 1999; Krull \& MacKinnon, 2001). Thus, as a supportive statistical procedure to determine mediation significance, the Sobel test was also used. However, it should be noted that the Sobel test was originally developed to test mediation significance in multiple regression (Krull \& MacKinnon, 2001). Therefore, some authors caution about potential greater error variance, which can ultimately result in increased rates of Type I errors (Krull \& MacKinnon, 1999; Krull \& MacKinnon, 2001; MacKinnon et al., 2002). In this case, although no suggested $p$-value is provided as an ideal cutoff to curtail the confounding error variance effect, the smaller the $p$-value, the more desirable.

Testing for moderation with HLM is a rather simple procedure, relative to mediation. The moderator in HLM is the interaction term assigned to the selected slop in any given model (Davison, Kwak, Seo, Choi, 2002; Raudenbush \& Bryk, 2002; Raudenbush et al., 2004). This is referred to as a cross-level 
interaction. In this study, a cross level interaction exists between student level variable X (school connectedness) and school variable W (school size) if the effect $\mathrm{Y}_{11} \mathrm{Wj}$ is nonzero (i.e., statistically significant; Davison et al., 2002). Stated differently, $\mathrm{Wj}$ is the school variable hypothesized to account for variation in slopes and intercepts across schools. For example, in level-2 of Model E (see p.56 and Table 5) $Y_{10}$ represents school connectedness as a slope while $Y_{11}$ represents school size as an effect on the slope (i.e., cross-level interaction). The resulting $p$ value from $Y_{11}$ is used to determine statistical significance of a possible moderation effect. 


\section{Chapter 3}

\section{Results}

\section{Introduction}

This chapter begins with descriptive analyses of the data collected for each of the three primary variables and germane demographic variables. The outcome variable in this study is youth violence. The predictor variables are school size and school connectedness. The chapter includes a comparison of a series of multi-level models using Hierarchical Linear Modeling (HLM6) procedures available through the full edition of the Scientific Software International (SSI) statistical package (Raudenbush et al., 2004). Weightings were also used for all analyses at both levels. All multilevel model analyses in this study used the default setting of restricted maximum likelihood (REML) estimation. REML is the appropriate estimation for analyzing data output for HLM as it simultaneously estimates random and fixed effects. In other words, REML adjusts for the uncertainty about the fixed effects, which provides for more conservative hypothesis testing (Raudenbush \& Bryk, 2002). Furthermore, all fixed effect estimates are based on final estimation with robust standard errors. An explanation of each model will be provided on how the fixed and random effects relate to the research questions and corresponding hypotheses in this study.

\section{Descriptive Analyses}

The data for this study were analyzed using a two-level, hierarchical linear model. The sample consisted of 11,777 students that were measured on school connectedness at time 1 and youth violence at time 2 . The students were nested 
within 115 schools and school size was measured at time 1. The following describes the model variables and student and school demographic variables further.

\section{Outcome Variable: Youth Violence}

Youth violence was measured using 7 questions (see Chapter 2) in which participants indicated the number of violent incidents from o to 7. (See Chapter 2 for a list of the seven questions.) Initially each individual question in this scale were categorical based upon frequency (e.g., never [o], once [1], and more than once [2]), but because of low frequencies of violence, the seven questions were recorded as either yes/no for violence. The scale was then log-log transformed to compensate for a highly skewed distribution. Skewness pre log-log transformation was 4.592 and was 1.544 post log-log transformation (See Table 1). The mean youth violence score was 0.58 with a standard deviation of 1.17 . In addition, $71.7 \%$ of students reported $\mathrm{o}$ incidents of violence while $28.3 \%$ reported 1 or more incidents of violence.

\section{Predictor Variables}

School size. School size is a categorical variable rated by each school administrator. The categories were small (1-400), medium (401-1000), or large (1001-4000). Of the total school sample ( $N=115), 22.3 \%(n=26)$ were small schools, $46.9 \%(n=54)$ were medium schools, and $30.8 \%(n=35)$ were large schools.

School Connectedness. School connectedness is a continuous variable rated by each student on a 8-item scale based upon their perception of relationships with teachers and other individuals within their school. (See 
Chapter 2 for a list of the eight questions.) These feelings included feeling supported and respected by teachers and students, feeling safe, and a sense of belongingness. The eight questions were standardized to z-scores and summed for each student due to varying scales of the items (e.g., o-3; 1-5). Thus, the higher the score, the more connected to school. The mean school connectedness score was 0.077 with a standard deviation of 4.924 (range $=-21.66-9.48)$.

\section{Demographics}

Student Variables. The following includes additional data that was collected from the students and used in this study's models. The dispersion of grade level was as follows: $7^{\text {th }}(15.2 \% ; n=1790), 8^{\text {th }}(15.4 \% ; n=1814), 9^{\text {th }}$ $(20.0 \% ; n=2355), 10^{\text {th }}(22.6 \% ; n=2662), 11^{\text {th }}(22.2 \% ; n=2614), 12^{\text {th }}(4.2 \% ; n=$ 495), grade not given $(0.4 \% ; n=47)$. The reason for a low number of participants in $12^{\text {th }}$ grade is because only students in $12^{\text {th }}$ grade at time 1 were able to participate in time 2 if they had to repeat the grade (i.e., those in $12^{\text {th }}$ grade that graduate at time 1 were not part of time 2). Biological sex was as follows: male $(48.6 \% ; n=5724)$, female $(51.4 \% ; n=6053)$. Race/ethnicity was as follows: Hispanic origin (16.7\%; $n=1967)$, White $(63.5 \% ; n=7478)$, African American (22.0\%; $n=2591)$, American Indian (3.5\%; $n=412)$, Asian (7.5\%; $n=$ 883). The reason for the percentages totaling above $100 \%$ is because some students identified themselves as more than one race/ethnicity. Household income was also reported by many of the students' primary caregiver. Of those that reported income $(77.12 \% ; n=9082)$, the average household income was approximately $\$ 47,000$ (median $\$ 39,000$ ) with a standard deviation of 
approximately $\$ 54,000$. The range was $\$ 0$ - $\$ 999,000$ (the maximum income that could be reported).

School Variables. The following includes additional data that was collected from the school administrators and used in this study's models. The mean average class size was 25.61 with a standard deviation of 5.40 (range 10 to 39). The mean number of full-time teachers was 55.05 with a standard deviation of 32.26 (range 5 to 182). Average daily attendance level was reported categorically: $95 \%$ or more (42.2\%), 90-94\% (40.6\%), $85-89 \%$ (10.2\%), 80-84\% (5.5\%), 75-79\% (1.6\%). School type was as follows: private $(9.2 \% ; n=11)$, public (90.8\%; $\mathrm{n}=104)$. Urbanicity was as follows: $\operatorname{urban}(31.5 \% ; n=36)$, suburban (53.8\%; $n=62)$, rural $(14.6 \% ; \mathrm{n}=17)$.

\section{Research Questions, Hypothesis Models, and Data Analysis}

The broad research question of this study explored the interrelationships among school connectedness, school size, and youth violence. This broad research question resulted in three specific research questions. The first question explored whether school connectedness mediates the relationship between school size and youth violence. The second question explored whether differences in school connectedness moderated the relationship between school size and youth violence. The third question examined if any relationships found in the first two questions continued to hold after controlling for student and school characteristics. These questions resulted in ten hypotheses that required corresponding HLM models to be tested. 


\section{Level 1 and Level 2 Correlations}

Table 2 shows the correlations among all the Level 1 variables. Youth violence was significantly correlated with gender $(r=-0.178)$, school connectedness $(r=-0.209)$, income $(r=-0.058)$, and all races/ethnicities: Hispanic $(r=0.067)$, White $(r=-0.071)$, African American $(r=0.051)$, American Indian $(r=0.060)$, and Asian $(r=-0.020)$. Males were more likely to report engaging in violent behaviors than females. School connectedness and income was inversely related violence. Hispanics, African Americans, and American Indians were positively related to violence. Whites and Asians were inversely related to violence.

School connectedness was significantly correlated with gender $(r=-$ o.021), income $\left(r=0.05^{2}\right)$, and all races/ethnicities with the exception of Hispanics $(r=-0.002)$ : White $(r=0.021)$, African American $(r=-0.051)$, American Indian $(r=-0.053)$, and Asian $(r=0.032)$. Females were more likely to report higher levels of feeling connected to school. Income was positively related to school connectedness. African Americans and American Indians were inversely related to school connectedness. Whites and Asians were positively related to school connectedness.

Finally, income was inversely related to Hispanics $(r=-0.089)$, African Americans $(r=-0.103)$, and American Indians $(r=-0.029)$. Whites $(r=0.124)$ and Asians ( $r=0.021)$ were positively related to income. Overall, it should be noted that the correlations for all Level 1 variables were relatively small in size. Thus, although many relationships are significant, initial observation lends towards a small amount of variance explained. 
Table 3 shows the correlations among all the Level 2 variables. School type was positively related with school size $(r=0.255)$ and urbanicity $(r=0.171)$. Thus, public schools were more likely to have a larger school size and be in urban communities. Again, similar to the Level 1 variables, these correlations were small in size, reflecting a small amount of variance explained.

\section{Variance Explained for Key Variables}

As it can be observed in the provided data for the following Models the coefficient size for most variable relationships is relatively small. Thus, it is prudent to specify the variance explained (VE) for these variable relationships. However, it is not possible to obtain a true R-squared value in HLM (Kreft \& Leew, 1998). However, there are suggested statistical procedures that can provide a value of the total explainable variance, which are explained by the model. These statistics are referred to as "pseudo R-squared values". Kreft and de Leew (1998) and Singer (1998) both suggested a formula utilizes error terms in an unrestricted model and restricted model to obtain the proportion of variance explained:

(unrestricted error - restricted error) / unrestricted error The unrestricted model (or null model) contains only the dependent variable (i.e., only the desired variable of interest and no independent variables) and its level-1 random intercept. The restricted model is the same as the unrestricted model with exception of adding an independent variable. The error terms from these two models are then used in the above equation to provide a pseudo R-squared value. Table 9 shows the obtained pseudo R-squared values of the key variables in this study. Overall, few variable relationships showed a variance explained at 
$1 \%$ or greater as a pseudo R-squared value. With regard to youth violence, school connectedness (5.4\%), gender (3.1\%), and income (4.5\%) accounted for some of the variance. With regard to school connectedness, income (6.0\%) accounted for some of the variance. The variance explained for the three primary constructs are also indicated in Figures 1 and 2.

\section{Research Question One: Does school connectedness partially mediate the effects of school size on youth violence?}

A separate model corresponding to each hypothesis (see Figure 1) is necessary in order to test for the proposed mediation effect (Baron \& Kenny, 1986). Furthermore, this process of developing and testing four separate models allowed for the understanding of possible relationships between the two predictor variables and the outcome variable.

Hypothesis 1: School size would be positively associated with youth violence.

Consistent with Baron and Kenny (1986), Model A included youth violence as a level 1 outcome and school size as a level 2 predictor. The components of this HLM 2-level model, in terms of predictors, outcome, and error terms, are specified below (see Table 5 for Model summary and comparison):

\section{$\underline{\text { Model A }}$}

Level 1 (student): $Y_{i j}=\beta_{o j}+r_{i j}$

Level 2 (school): $\beta_{o j}=Y_{o o}+Y_{o 1} W_{j}+u_{o j}$

$\mathrm{Y}_{\mathrm{ij}}=$ level-1 outcome (youth violence)

$\beta_{\mathrm{oj}}=$ level-1 intercept in level-2 unit $\mathrm{j}$

$\mathrm{r}_{\mathrm{ij}}=$ level-1 random effect

$Y_{0 o}=$ mean value of level-1 outcome (youth violence), controlling 


$$
\begin{aligned}
& \text { for level-2 predictor (school size) [fixed effect] } \\
& Y_{01}=\text { effect (slope) of level-2 predictor (school size) [fixed effect] } \\
& \mathrm{W}_{\mathrm{j}}=\text { level-2 predictor (school size) } \\
& \mathrm{u}_{\mathrm{oj}}=\text { level-2 random effect }
\end{aligned}
$$

The fixed effect for school size on youth violence $\left(\mathrm{Y}_{01}\right)$ was not statistically significant $t(113)=0.913, p=0.363, \mathrm{VE}=0.000$. (See Table 6 for Model A parameter estimates.) Therefore, the hypothesis $\left(\mathrm{H}_{1}\right)$ that school size is positively associated with youth violence is not supported. The variance component of the random intercept $\left(\mathrm{u}_{\mathrm{oj}}\right)$, also referred to as the random effect on the youth violence variable from each school, had a significant $p$-value of $<.001\left(\mathrm{u}_{\mathrm{oj}}=0.034\right)$. This indicates that there was variability in the youth violence intercept $\left(\beta_{\mathrm{oj}}\right)$ among schools (i.e., un-modeled variability). In other words, there may be alternative school-level factors associated with violent behavior not accounted for in this model. It should be noted that the random effects of the outcome variables in all models showed significant variability.

Hypothesis 2: School size would be inversely associated with school connectedness.

The second step in testing this research question is to test the predictor variable (school size) by treating the mediator (school connectedness) as an outcome variable. The intent is to examine whether there was an effect between school size and school connectedness. Thus, Model B includes school connectedness as a level 1 outcome and school size as a level 2 predictor. The components of this HLM 2-level model, in terms of predictors, outcome, and 
error terms, are specified below (see Table 5 for Model summary and comparison):

Model B

Level 1 (student): $Y_{i j}=\beta_{o j}+r_{i j}$

Level 2 (school): $\quad \beta_{\mathrm{oj}}=\mathrm{Y}_{\mathrm{oo}}+\mathrm{Y}_{\mathrm{o} 1} \mathrm{~W}_{\mathrm{j}}+\mathrm{u}_{\mathrm{oj}}$

$$
\begin{aligned}
& \mathrm{Y}_{\mathrm{ij}}=\text { level-1 outcome (school connectedness) } \\
& \beta_{\mathrm{oj}}=\text { level-1 intercept in level-2 unit } \mathrm{j} \\
& \mathrm{r}_{\mathrm{ij}}=\text { level-1 random effect } \\
& \mathrm{Y}_{\mathrm{oo}}=\text { mean value of level-1 outcome (school connectedness), } \\
& \quad \text { controlling for level-2 predictor (school size) [fixed effect] } \\
& Y_{\mathrm{o} 1}=\text { effect (slope) of level-2 predictor (school size) [fixed effect] } \\
& \mathrm{W}_{\mathrm{j}}=\text { level-2 predictor (school size) } \\
& \mathrm{u}_{\mathrm{oj}}=\text { level-2 random effect }
\end{aligned}
$$

The fixed effect for school size on school connectedness $\left(Y_{01}\right)$ was statistically significant $t(113)=-3.448, p<.001, \mathrm{VE}=0.000$. (See Table 6 for Model B parameter estimates.) Therefore, the hypothesis $\left(\mathrm{H}_{2}\right)$ that school size is inversely associated with school connectedness was supported.

Hypothesis 3: $\mathrm{H}_{3 \mathrm{a}}$ : School connectedness would be inversely associated with youth violence. $\mathrm{H}_{3 \mathrm{~b}}$ : School connectedness would be inversely associated with youth violence, while controlling for the effects of school size.

The third step in testing this research question is broken down into two separate hypotheses $\left(\mathrm{H}_{3 \mathrm{a}}\right.$ and $\left.\mathrm{H}_{3 \mathrm{~b}}\right)$ and models ( $\mathrm{C}$ and $\left.\mathrm{D}\right)$. The primary purpose for this hypothesis was to test the mediator (school connectedness - also a predictor variable) with the outcome variable (youth violence). Thus, Model C included youth violence as a level 1 outcome and school connectedness as a level 1 predictor. Model D included youth violence as a level 1 outcome, school 
connectedness as a level 1 predictor, and school size as a level 2 predictor. However, in this model, school size was not included as a slope/predictor for school connectedness (i.e., no interaction); only as a slope/predictor for youth violence in order to control for school size. Both models were used because Model C provided information about the relationship between school connectedness and youth violence and model D was part of the process of testing the mediation effects of school connectedness between school size and youth violence. The following are the Model $\mathrm{C}$ components in terms of predictors, outcome, and error terms (see Table 5 for Model summary and comparison):

\section{Model C}

Level 1 (student): $Y_{i j}=\beta_{o j}+\beta_{1 j} X_{i j}+r_{i j}$

Level 2 (school): $\quad \beta_{o j}=Y_{o o}+u_{o j}$

$$
\beta_{1 j}=Y_{10}
$$

$$
\begin{aligned}
& \mathrm{Y}_{\mathrm{ij}}=\text { level-1 outcome (youth violence) } \\
& \beta_{\mathrm{oj}}=\text { level-1 intercept in level-2 unit } \mathrm{j} \\
& \beta_{1 \mathrm{j}}=\text { level-1 slope in level-2 unit } \mathrm{j} \\
& \mathrm{X}_{\mathrm{ij}}=\text { level-1 predictor (school connectedness) } \\
& \mathrm{r}_{\mathrm{ij}}=\text { level-1 random effect } \\
& \left.\mathrm{Y}_{\mathrm{oo}}=\text { mean value of level-1 outcome (youth violence) [fixed effect }\right] \\
& \mathrm{u}_{\mathrm{oj}}=\text { level-2 random effect } \\
& \mathrm{Y}_{10}=\text { mean value of level-1 slope (school connectedness) [fixed } \\
& \quad \text { effect }] \\
& \mathrm{u}_{1 \mathrm{j}}=\text { level-2 random effect }
\end{aligned}
$$

The fixed effect for school connectedness on youth violence $\left(Y_{10}\right)$ was statistically significant $t(11775)=-11.178, p<.001, \mathrm{VE}=0.054$. (See Table 6 for Model C parameter estimates.) Therefore, the hypothesis $\left(\mathrm{H}_{3 \mathrm{a}}\right)$ that school connectedness is inversely associated with youth violence was supported. 
The following are the Model D components in terms of predictors, outcome, and error terms (see Table 5 for Model summary and comparison):

\section{$\underline{\text { Model D }}$}

Level 1 (student): $Y_{i j}=\beta_{0 j}+\beta_{1 j} X_{i j}+r_{i j}$

Level 2 (school): $\quad \beta_{o j}=Y_{o o}+Y_{o 1} W_{j}+u_{o j}$

$$
\beta_{1 j}=Y_{10}
$$

$\mathrm{Y}_{\mathrm{ij}}=$ level-1 outcome (youth violence)

$\beta_{\mathrm{oj}}=$ level-1 intercept in level-2 unit $\mathrm{j}$

$\beta_{1 \mathrm{j}}=$ level-1 slope in level-2 unit $\mathrm{j}$

$\mathrm{X}_{\mathrm{ij}}=$ level-1 predictor (school connectedness)

$\mathrm{r}_{\mathrm{ij}}=$ level-1 random effect

$Y_{\mathrm{oo}}=$ mean value of level-1 outcome (youth violence), controlling for level-2 predictor (school size) [fixed effect]

$Y_{01}=$ effect (slope) of level-2 predictor (school size) [fixed effect]

$\mathrm{W}_{\mathrm{j}}=$ level-2 predictor (school size)

$\mathrm{u}_{\mathrm{oj}}=$ level-2 random effect

$Y_{10}=$ mean value of level-1 slope (school connectedness), controlling for thelevel-2 predictor (school size) [fixed effect]

The fixed effect for school connectedness on youth violence $\left(\mathrm{Y}_{10}\right)$ was statistically significant $t(11774)=-9.764, p<.001, \mathrm{VE}=0.054$. (See Table 6 for Model D parameter estimates.) Therefore, the hypothesis $\left(\mathrm{H}_{3 \mathrm{~b}}\right)$ that school connectedness is inversely associated with youth violence, while controlling for school size, was supported.

Hypothesis 4: School connectedness would partially mediate the effects of school size on youth violence. (See Figure 1.)

Models $\mathrm{H}_{3 \mathrm{~b}}$ (Model D) of step 3 and $\mathrm{H}_{1}$ (Model A) of step 1 are used together for the fourth step in determining any possible mediating relationship of school connectedness between school size and youth violence. The effect of the 
predictor (school size) on the outcome (youth violence), controlling for the mediator (school connectedness), should be zero or close to zero. This effect was almost obtained in Model D ( $\left.\mathrm{Y}_{01}\right)$ of step 3 as demonstrated by a parameter (i.e., coefficient) for school size at $0.007 t(113)=0.150, p=0.882$. Additionally, the results from Model A $\left(Y_{01}\right)$ of step 1 show that the parameter for school size (school connectedness not controlled as a mediator) was $0.049 t(113)=0.913$, $p=0.363$. What is observed here is that the parameter estimate for school size was reduced when school connectedness was added (controlled) to Model D. Thus, school size had almost no effect by itself, but any effect that it did have was in conjunction with school connectedness. Furthermore, it should not be forgotten that Model B of step2 showed a significant inverse relationship between school size and school connectedness.

As discussed earlier, what is most important to indicate a possible mediation is if steps 2 and 3 are met because this implies a path from the predictor variable to the outcome variable. Moreover, step 4 does not have to be fully met unless the desired outcome is a complete mediation. Baron and Kenny (1986) also pointed out that the steps are stated in terms of zero and nonzero coefficients, not in terms of statistical significance. With mediation there is no single $p$-value (yes/no) to determine if there is mediation/significance. There needs to be a comparison among models. Frazier et al. (2004) indicated that mediation is determined by the degree to which the relationship between the predictor and outcome decreases when the proposed mediator is controlled. The results of this analysis indicated that the relationship between school size 
(predictor) and youth violence (outcome) decreased to almost no effect when school connectedness (mediator) was controlled.

As a supportive statistical measure to confirm the mediation relationship of school connectedness on school size and youth violence a Sobel Test was performed. Baron and Kenny (1996) and MacKinnon et al. (2002) state that the $t$-test statistic from the relationship between the independent variable (school size) and mediator (school connectedness; Model B) and the $t$-test statistic from the relationship between the mediator (school connectedness) and outcome (youth violence; Model D), while controlling for the independent variable (school size), are required to determine possible statistical significance. (It should also be noted that the use of these two $t$-test statistics corresponds with the above stated steps 2 and 3 for mediation.) Thus, the required t-test statistics from Model B ( $t=-3.448)$ and Model D ( $t=-9.764)$ provided a Sobel Test statistic of 3.251 ( $p=0.001)$. As stated earlier, some authors caution on potential increased rates of Type I errors using the Sobel Test with HLM (Krull \& MacKinnon, 1999; Krull \& MacKinnon, 2001; MacKinnon et al., 2002). However, the statistically significant small p-value provides greater confidence for avoiding Type I error concerns. Therefore, the results of this study tentatively support that school connectedness partially mediates the effects of school size on youth violence.

\section{Research Question Two: Does school connectedness moderate the effects of school size on youth violence?}

Hypothesis 5: Student connectedness would moderate the effect of school size on youth violence. (See Figures 1 and 2.) 
The analysis for this hypothesis is to test both predictor variables (school size and school connectedness) with the outcome variable (youth violence). Of most interest is the interaction, or effect, of school size on the slope of school connectedness. Thus, Model E included youth violence as a level 1 outcome, school connectedness as a level 1 predictor, and school size as a level 2 predictor. The components of this HLM 2-level model, in terms of predictors, outcome, and error terms, are specified below (see Table 5 for Model summary and comparison):

\section{Model E}

Level 1 (student): $Y_{i j}=\beta_{0 j}+\beta_{1 j} X_{i j}+r_{i j}$

Level 2 (school): $\quad \beta_{o j}=Y_{o o}+Y_{o 1} W_{j}+u_{o j}$

$$
\beta_{1 j}=Y_{10}+Y_{11} W_{j}
$$

$\mathrm{Y}_{\mathrm{ij}}=$ level-1 outcome (youth violence)

$\beta_{\mathrm{oj}}=$ level-1 intercept in level-2 unit $\mathrm{j}$

$\beta_{1 j}=$ level-1 slope in level-2 unit $\mathrm{j}$

$\mathrm{X}_{\mathrm{ij}}=$ level-1 predictor (school connectedness)

$\mathrm{r}_{\mathrm{ij}}=$ level-1 random effect

$Y_{o o}=$ mean value of level-1 outcome (youth violence), controlling for level-2 predictor (school size) [fixed effect]

$Y_{01}=$ effect (slope) of level-2 predictor (school size) [fixed effect]

$\mathrm{W}_{\mathrm{j}}=$ level-2 predictor (school size)

$\mathrm{u}_{\mathrm{oj}}=$ level-2 random effect

$Y_{10}=$ mean value of level-1 slope (school connectedness), controlling for the level-2 predictor (school size) [fixed effect]

$Y_{11}=$ effect (slope) of level-2 predictor (school size) [fixed effect]

The fixed effect for school size (slope) on school connectedness $\left(Y_{11}\right)$ was not statistically significant $t(11773)=-0.715, p=.475, \mathrm{VE}=0.000$, indicating no interaction between school size and school connectedness (See Table 6 for Model 
E parameter estimates.) Therefore, the hypothesis $\left(\mathrm{H}_{5}\right)$ that student connectedness moderates the effect of school size on youth violence was not supported.

\section{Research Question Three: Will the relationships found in the first two research questions still hold after controlling for pertinent student and school characteristics?}

As student variables and school variables may influence the relationships among school size and connectedness, it is also important to control for certain student and school demographic variables in order to determine whether the effects observed in $\mathrm{H}_{1-5}$ still hold. Thus, the following includes the associated hypotheses and models including noted student and school demographic variables. More specifically, biological sex, Hispanic origin, White, African American, American Indian, and income were the level 1 controls. School type and urbanicity were add to level 2 controls. The components of the HLM 2-level models, in terms of predictors/controls, outcome, and error terms, are specified for each model (labels of each variable are included in model for ease comprehension due to length of equations; see Table 7 for Model summary and comparison).

Hypothesis 6: School size would be positively associated with youth violence controlling for student and school characteristics.

$\underline{\text { Model F }}$

Level 1 (student): $Y_{\mathrm{ij}}=\beta_{\mathrm{oj}}+\beta_{\mathrm{ij}}($ biological sex $)+\beta_{2 \mathrm{j}}($ Hispanic origin $)+$

$$
\begin{aligned}
& \beta_{3 \mathrm{j}}(\text { White })+\beta_{4 \mathrm{j}}(\text { African American })+ \\
& \beta_{5 \mathrm{j}}(\text { American Indian })+\beta_{6 \mathrm{j}}(\text { Asian })+\beta_{7 \mathrm{j}}(\text { Income })+ \\
& \mathrm{r}_{\mathrm{ij}}
\end{aligned}
$$


Level 2 (school): $\quad \beta_{\mathrm{oj}}=\mathrm{Y}_{\mathrm{oo}}+\mathrm{Y}_{\mathrm{o} 1}(\mathrm{school}$ size $)+\mathrm{Y}_{\mathrm{o} 2}(\mathrm{school}$ type $)+$

$$
Y_{\mathrm{o} 3} \text { (urbanicity) }+\mathrm{u}_{\mathrm{oj}}
$$

$\beta_{1 j}=Y_{10}$

$\beta_{2 j}=Y_{20}$

$\beta_{3 j}=Y_{30}$

$\beta_{4 j}=Y_{40}$

$\beta_{5 j}=Y_{50}$

$\beta_{6 j}=Y_{60}$

$\beta_{7 \mathrm{j}}=\mathrm{Y}_{70}$

$\mathrm{Y}_{\mathrm{ij}}=$ level-1 outcome (youth violence)

$\beta_{\mathrm{oj}}=$ level-1 intercept in level-2 unit $\mathrm{j}$

$\beta_{1 \mathrm{j}-\mathrm{j}}=$ level-1 slopes (controls) in level-2 unit $\mathrm{j}$

$\mathrm{r}_{\mathrm{ij}}=$ level-1 random effect

$Y_{\mathrm{oo}}=$ mean value of level-1 outcome (youth violence), controlling for level-2 predictors/controls [fixed effect]

$Y_{01}=$ effect (slope) of level-2 predictor (school size) [fixed effect]

$\mathrm{Y}_{\text {02-03 }}=$ effect (slope) of level-2 controls [fixed effect]

$\mathrm{u}_{\mathrm{oj}}=$ level-2 random effect

$\mathrm{Y}_{10-70}=$ mean value of level-1 slopes

The fixed effect for school size on youth violence $\left(Y_{01}\right)$ was not statistically significant $t(111)=0.365, p=.716, \mathrm{VE}=0.000$. (See Table 8 for Model $\mathrm{F}$ parameter estimates.) Therefore, the hypothesis $\left(\mathrm{H}_{1}\right)$ that school size is positively associated with youth violence remained unsupported with the inclusion of control variables.

Hypothesis 7: School size would be inversely associated with school connectedness controlling for student and school characteristics.

\section{Model G}

Level 1 (student): $Y_{\mathrm{ij}}=\beta_{\mathrm{oj}}+\beta_{1 \mathrm{j}}($ biological sex $)+\beta_{2 \mathrm{j}}($ Hispanic origin $)+$

$$
\beta_{3 j}(\text { White })+\beta_{4 j}(\text { African American })+
$$


$\beta_{5 j}($ American Indian $)+\beta_{6 j}($ Asian $)+\beta_{7 j}($ Income $)+$

$\mathrm{r}_{\mathrm{ij}}$

Level 2 (school): $\quad \beta_{\mathrm{oj}}=\mathrm{Y}_{\mathrm{oo}}+\mathrm{Y}_{\mathrm{o} 1}($ school size $)+\mathrm{Y}_{\mathrm{O} 2}($ school type $)+$ $\mathrm{Y}_{\mathrm{o} 3}$ (urbanicity) $+\mathrm{u}_{\mathrm{oj}}$

$$
\begin{aligned}
& \beta_{1 j}=Y_{10} \\
& \beta_{2 j}=Y_{20} \\
& \beta_{3 j}=Y_{30} \\
& \beta_{4 j}=Y_{40} \\
& \beta_{5 j}=Y_{50} \\
& \beta_{6 j}=Y_{60} \\
& \beta_{7 j}=Y_{70}
\end{aligned}
$$

$\mathrm{Y}_{\mathrm{ij}}=$ level-1 outcome (school connectedness)

$\beta_{\mathrm{oj}}=$ level-1 intercept in level-2 unit $\mathrm{j}$

$\beta_{1 \mathrm{j}-\mathrm{j} j}=$ level-1 slopes (controls) in level-2 unit $\mathrm{j}$

$\mathrm{r}_{\mathrm{ij}}=$ level-1 random effect

$Y_{\mathrm{oo}}=$ mean value of level-1 outcome (school connectedness), controlling for level-2 predictors/controls [fixed effect]

$Y_{01}=$ effect (slope) of level-2 predictor (school size) [fixed effect]

$\mathrm{Y}_{\mathrm{O} 2-03}=$ effect (slope) of level-2 controls [fixed effect]

$\mathrm{u}_{\mathrm{oj}}=$ level-2 random effect

$\mathrm{Y}_{10-70}=$ mean value of level-1 slopes

The fixed effect for school size on school connectedness $\left(\mathrm{Y}_{01}\right)$ was statistically significant $t(111)=-2.129, p=.035, \mathrm{VE}=0.000$. (See Table 8 for Model G parameter estimates.) Therefore, the hypothesis $\left(\mathrm{H}_{2}\right)$ that school size is inversely associated with school connectedness was supported with the inclusion of control variables.

Hypothesis 8: School connectedness would be inversely associated with youth violence controlling for student and school characteristics. 
This hypothesis was initially broken down into two separate components in order to test school connectedness' relationship with school size while not controlling for school size and controlling for school size. In this case, $\mathrm{H}_{3 \mathrm{~b}}$ and $\mathrm{H}_{3 \mathrm{a}}$ are essentially one hypothesis tested with the controls. School size is already included as a control variable in $\mathrm{H}_{3 \mathrm{~b}}$ and it would not be appropriate to exclude school size from $\mathrm{H}_{3 \mathrm{a}}$ because it also considered a control. (In other words, testing both hypotheses separately in this context would be unnecessarily redundant when considering the outcomes and determination of any possible mediation effect.)

\section{Model H}

Level 1 (student): $Y_{i j}=\beta_{o j}+\beta_{1 j}($ school connectedness $)+\beta_{2 j}$ (biological sex) $+\beta_{3 \mathrm{j}}($ Hispanic origin $)+\beta_{4 \mathrm{j}}($ White $)+\beta_{5 \mathrm{j}}($ African American $)+\beta_{6 \mathrm{j}}($ American Indian $)+\beta_{7 \mathrm{j}}($ Asian $)+$ $\beta_{8 j}($ Income $)+r_{i j}$

Level 2 (school): $\quad \beta_{\mathrm{oj}}=\mathrm{Y}_{\mathrm{oo}}+\mathrm{Y}_{\mathrm{o} 1}(\mathrm{school}$ size $)+\mathrm{Y}_{\mathrm{o} 2}($ school type $)+$

$$
\begin{gathered}
Y_{{ }_{0}}(\text { urbanicity })+u_{o j} \\
\beta_{1 j}=Y_{10} \\
\beta_{2 j}=Y_{20} \\
\beta_{3 j}=Y_{30} \\
\beta_{4 j}=Y_{40} \\
\beta_{5 j}=Y_{50} \\
\beta_{6 j}=Y_{60} \\
\beta_{7 j}=Y_{70} \\
\beta_{8 j}=Y_{80} \\
Y_{i j}=\text { level-1 outcome (youth violence) } \\
\beta_{0 j}=\text { level-1 intercept in level-2 unit } j \\
\beta_{1 j}=\text { level-1 slope (school connectedness) in level-2 unit } j \\
\beta_{2 j-8 j}=\text { level-1 slopes (controls) in level-2 unit j }
\end{gathered}
$$




$$
\begin{aligned}
& \mathrm{r}_{\mathrm{ij}}=\text { level-1 random effect } \\
& \mathrm{Y}_{\mathrm{Oo}}=\text { mean value of level-1 outcome (youth violence), controlling } \\
& \quad \text { for level-2 predictors/controls [fixed effect] } \\
& Y_{01}=\text { effect (slope) of level-2 predictor (school size) [fixed effect] } \\
& Y_{02-03}=\text { effect (slope) of level-2 controls [fixed effect] } \\
& \mathrm{u}_{0 \mathrm{j}}=\text { level-2 random effect } \\
& Y_{10}=\text { mean value of level-1 slope (school connectedness), } \\
& \quad \text { controlling for level-2 predictors/controls [fixed effect] } \\
& Y_{20-80}=\text { mean value of level-1 slopes }
\end{aligned}
$$

The fixed effect for school connectedness on youth violence $\left(Y_{10}\right)$ was statistically significant $t(8969)=-8.387, p<.001, \mathrm{VE}=0.054$. (See Table 9 for Model $\mathrm{H}$ parameter estimates.) Therefore, the hypothesis $\left(\mathrm{H}_{3}\right)$ that school connectedness is inversely associated with youth violence was supported with the inclusion of control variables.

Hypothesis 9: School connectedness would partially mediate the effects of school size on youth violence controlling for student and school characteristics. (See Figure 1.)

Models $\mathrm{H}_{3}$ (Model $\mathrm{H}$ ) of step 3 and $\mathrm{H}_{1}$ (Model $\mathrm{F}$ ) of step 1 are used together for the fourth step in determining any possible mediating relationship of school connectedness between school size and youth violence. The effect of the predictor (school size) on the outcome (youth violence), controlling for the mediator (school connectedness), should be zero or close to zero. This effect was almost obtained in Model $\mathrm{H}\left(\mathrm{Y}_{\mathrm{ol}}\right)$ of step 3 as demonstrated by a parameter (i.e., coefficient) for school size at $0.003 t(111)=0.078, p=0.938$. Additionally, the results from Model $\mathrm{F}\left(\mathrm{Y}_{\mathrm{O} 1}\right)$ of step 1 showed that the parameter for school size (school connectedness not controlled as a mediator) was $0.032 t(111)=0.365, p$ 
$=.716$. What is observed here is that the parameter estimate for school size was reduced when school connectedness was added (controlled) to Model H. Thus, with inclusion of control variables, school size had almost no effect by itself, but any effect that it did have was in conjunction with school connectedness.

Therefore, the results of this study tentatively support that school connectedness partially mediates the effects of school size on youth violence with the inclusion of control variables.

As a supportive statistical measure to confirm the mediation relationship of school connectedness on school size and youth violence a Sobel Test was performed. The required t-test statistics from Model G ( $t=-2.129)$ and Model H $(t=-8.387)$ provided a Sobel Test statistic of $2.064(p=0.039)$. As stated earlier, caution should be taken in interpreting the Sobel Test statistic with HLM due to increased rates of Type I errors. The statistically significant $p$-value tentatively supports that school connectedness partially mediates the effects of school size on youth violence with the inclusion of control variables. However, this significance is not as robust relative to hypothesis $4(p=0.001)$, which does not control for student and school variables. Thus, some caution should be taken in interpreting the significance of this statistic.

Hypothesis 10: Student connectedness would moderate the effect of school size on youth violence controlling for student and school characteristics. (See Figures 1 and 2.)

\section{$\underline{\text { Model I }}$}

Level 1 (student): $Y_{\mathrm{ij}}=\beta_{\mathrm{oj}}+\beta_{\mathrm{ij}}($ school connectedness $)+\beta_{2 \mathrm{j}}($ biological sex $)$

$$
+\beta_{3 j}(\text { Hispanic origin })+\beta_{4 j}(\text { White })+\beta_{5 j}(\text { African }
$$$$
\text { American })+\beta_{6 j}(\text { American Indian })+\beta_{7 j}(\text { Asian })+
$$ 


$$
\beta_{8 j}(\text { Income })+r_{i j}
$$

Level 2 (school): $\beta_{\mathrm{oj}}=\mathrm{Y}_{\mathrm{oo}}+\mathrm{Y}_{\mathrm{o} 1}($ school size $)+\mathrm{Y}_{\mathrm{o} 2}($ school type $)+$

$$
\begin{aligned}
& \quad Y_{03} \text { (urbanicity) }+u_{0 j} \\
& \beta_{1 j}=Y_{10}+Y_{11} \text { (school size) } \\
& \beta_{2 j}=Y_{20} \\
& \beta_{3 j}=Y_{30} \\
& \beta_{4 j}=Y_{40} \\
& \beta_{5 j}=Y_{50} \\
& \beta_{6 j}=Y_{60} \\
& \beta_{7 j}=Y_{70} \\
& \beta_{8 j}=Y_{80}
\end{aligned}
$$

$\mathrm{Y}_{\mathrm{ij}}=$ level-1 outcome (youth violence)

$\beta_{\mathrm{oj}}=$ level-1 intercept in level-2 unit $\mathrm{j}$

$\beta_{1 \mathrm{j}}=$ level-1 slope (school connectedness) in level-2 unit $\mathrm{j}$

$\beta_{2 \mathrm{j}-8 \mathrm{j}}=$ level-1 slopes (controls) in level-2 unit $\mathrm{j}$

$\mathrm{r}_{\mathrm{ij}}=$ level-1 random effect

$\mathrm{Y}_{\mathrm{oo}}=$ mean value of level-1 outcome (youth violence), controlling for level-2 predictors/controls [fixed effect]

$Y_{01}=$ effect (slope) of level-2 predictor (school size) [fixed effect]

$\mathrm{Y}_{\mathrm{O} 2-\mathrm{O} 3}=$ effect (slope) of level-2 controls [fixed effect]

$\mathrm{u}_{\mathrm{oj}}=$ level-2 random effect

$Y_{10}=$ mean value of level-1 slope (school connectedness), controlling for level-2 predictors/controls [fixed effect]

$Y_{11}=$ effect (slope/interaction) of level-2 predictor (school size)

[fixed

effect]

$\mathrm{Y}_{20-80}=$ mean value of level-1 slopes

The fixed effect for school size (slope) on school connectedness $\left(Y_{11}\right)$ was not statistically significant $t(8968)=-0.492, p=.695, \mathrm{VE}=0.00$, indicating no interaction between school size and school connectedness (See Table 9 for Model 
I parameter estimates.) Therefore, the hypothesis $\left(\mathrm{H}_{5}\right)$ that student connectedness moderates the effect of school size on youth violence was not supported with the inclusion of control variables. 


\section{Chapter 4}

\section{Discussion}

\section{Introduction}

The goal of this study was to consider an alternative, multivariable approach towards preventing youth violence utilizing longitudinal data. This study takes into consideration the calls of numerous researchers to expand this research domain (e.g., Blum et al., 2002; Crosnoe et al., 2004; Hoagwood, 2000; Jenkins, 1997; Loukas et al., 2006). The research questions associated with the present study emerged as an unexplored area within the larger ecological context of research related to youth violence, school connectedness, and school size. Although there is a growing body of literature on the relationship between school connectedness and youth violence, very few have considered school size and no known study has examined school connectedness as a mediator or moderator. The findings from this study expand the existing knowledge on the preventative role of school connectedness on youth violence and associated contextual role of school size.

Add Health data was used to longitudinally measure school connectedness and school size at time 1 and youth violence at time 2. Hierarchical linear modeling was used to test 9 Models as students $(N=11,777)$ were nested in schools $(N=115)$. Students self-reported their acts of violence and perceived school connectedness through answering multiple questions as part of larger inhome interview. School personnel reported school size as part of a larger school administrator survey. 
Three research questions were posed, and corresponding hypotheses about those questions were postulated. This chapter includes: (a) review of the findings related to each question, (b) discussion of any convergent findings or divergent findings relevant to the current literature, (c) study limitations, (d) implications for practice, (e) and recommendations for future research.

\section{Mediation of School Connectedness}

No known study has directly examined both school size and school connectedness concurrently in terms of their role in predicting youth violence as an outcome. This is somewhat surprising considering the robust literature demonstrating relationships between school connectedness, school size, and other outcomes. With all the attention and emphasis currently being placed on the need for more preventative efforts, examining a possible mediator and/or moderator role of school connectedness between school size and youth violence was a logical area of inquiry. Such an approach is based upon not only the demonstrated literature supporting the relationship among these constructs but also on recommendations of scholars in this field (e.g., Blum et al., 2002;; Hoagwood, 2000; Loukas et al., 2006).

The hypothesis that school connectedness would partially mediate the effects of school size on youth violence was supported $\left(\mathrm{H}_{4}\right)$, including controlling for student and school characteristics $\left(\mathrm{H}_{9}\right)$. Baron and Kenny's (1986) mediation four step process was followed and the necessary fixed effects from the Models to determine the first three hypotheses were obtained. Overall, there was no relationship between school size and youth violence $\left(\mathrm{H}_{1} \& \mathrm{H}_{6}\right)$, but there was a relationship between school connectedness and youth violence $\left(\mathrm{H}_{3} \& \mathrm{H}_{8}\right)$, and 
school size and school connectedness $\left(\mathrm{H}_{2} \& \mathrm{H}_{7}\right)$. Furthermore, the relationship between school size and youth violence decreased to almost no effect when school connectedness was controlled. The only connection school size had with youth violence was through school connectedness - a mediator. A Sobel Test was also conducted to provide statistical support of a mediation relationship. Therefore, given the results, one can cautiously conclude that school connectedness appears to partially mediate the effects of school size on youth violence. Additionally, the relatively small amount of variance explained should also be taken into consideration. Although there is tentative support for a mediation effect it should be noted that the largest variance explained was between school connectedness and youth violence was only 5.4\%. Thus, caution should also be taken in over interpreting the results knowing that approximately $95 \%$ of the variance explained is not accounted for.

In one of the few studies to look at school connectedness as a mediator, Loukas et al. (2006) found school connectedness to mediate the relationship between three school climate variables (i.e., perceived friction, perceived cohesion, and overall class satisfaction) and future conduct problems one year later. Jenkins (1997) also found school connectedness to mediate the relationships of personal background characteristics and family involvement in schooling with delinquent/violent school behaviors. Thus, school connectedness not only appears to have a direct relationship with youth violence, but also may have an indirect or mediation effect. Multiple researchers have called for further examination of school connectedness as a possible mediator/moderator between youth violence and other school variables, including school size (Blum et al., 
2002; Crosnoe et al., 2004; Hoagwood, 2000; Jenkins, 1997; Loukas et al., 2006). This study was initiated to respond to these calls, at least in part, within the ecological context of school size, school connectedness, and youth violence. Overall, it appears that while school size may not have a direct relationship to youth violence, school size may have an impact on youth violence through school connectedness. This finding provides needed information regarding school violence prevention as school connectedness is a malleable construct that can be changed through the training of school personnel.

All mediation (and moderation) hypotheses were examined while controlling for specific student and school characteristics. More specifically, student characteristics included biological sex, race/ethnicity, socio-economic status and school characteristics included urbanicity and school type. These characteristics were included in these analyses because they have been previously shown to have their own unique effects on the outcome of youth violence (Crouch et al., 2000; Ferris \& West, 2004; Leventhal \& Brooks-Gunn, 2000). However, some studies, including those using Add Health data (e.g., Blum et al., 2002; Brookmeyer et al., 2006; McNeely et al., 2002), did not control for most or all of the characteristics controlled in this study. Those studies that did control for such characteristics when examining school size, school connectedness, and youth violence still found significance in their findings (e.g., Bonny et al., 2000; Crosnoe et al., 2004; Dornbusch et al., 2001; Franke, 2000; Henrich et al., 2005; McNeely, 2003; McNeely \& Falci, 2004; Resnick et al., 2004; Resnick et al., 1997). For example, Resnick et al. (2004) stated that school connectedness is a "potent predictor" of youth violence; even more than socioeconomic status and 
race/ethnicity. Thus, the findings from this study support the current literature with regard to the effects of school connectedness and school size on youth violence still holding after controlling for multiple student and school characteristics.

During the process of examining the possible meditational role of school connectedness other relationships were also examined, which contribute to the expanding literature on this topic. The first hypothesis $\left(\mathrm{H}_{1}\right)$ concerning whether school size would be positively associated with youth violence was not supported, including controlling for student and school characteristics $\left(\mathrm{H}_{6}\right)$. Initially, this finding was surprising considering earlier literature linking increasing student population to acts of violence (Brookmeyer et al., 2006; Ferris \& West, 2004; Kaiser, 2005; Leung \& Ferris, 2005). However, upon further examination of these studies (Ferris \& West, 2004; Kaiser, 2005; Leung \& Ferris, 2005), they were most likely measuring slightly different constructs from this study. For example, Ferris and West examined "serious violent incidents" (e.g., from physical altercations to use of guns/knives) and Kaiser's (2005) conclusions were largely based on 17 school shootings. The discrepancy in findings may be due to how the construct of "youth violence" was measured in terms of intensity. Although physical altercations with a weapon were included in this study's youth violence variable, so were other incidents such as physical fights or threats to use violence. Additionally, this study explicitly assessed violence both in the school and community, whereas the previous research primarily examining school size and violence assessed violence in the schools. 
The other contradiction in the literature was Brookmeyer et al. (2006) who found school size to be a predictor of youth violence with Add Health data. However, there are two possible reasons for this discrepancy. First, Brookmeyer et al. trimmed their data to 6,397 from 125 schools, which was most likely done to incorporate a variety of other variables not examined in this study. Second, Brookmeyer et al. do not state that weighted data was used for analyses, which Add Health recommends for accurate interpretations. Thus, keeping these two points in mind, the difference between Brookmeyer et al.'s and this study's may account for the contradictory findings. Overall, this study's finding that school size was not a predictor of youth violence contradicts previous research, which may likely be due to differences in measuring and analyzing this construct.

The second hypothesis (H2) that school size would be inversely associated with school connectedness was supported, including controlling for student and school characteristics $\left(\mathrm{H}_{7}\right)$. This finding was consistent with previous research examining relationships of students with school personnel, including studies examining Add Health data. Although many studies have examined the effects of school size on a variety of outcomes, few have specifically examined the relationship between school size and school connectedness. Before the term "school connectedness" received wide attention in the literature, Bowen et al. (2000) and Fowler and Walberg (1991) both reported school size to be an inverse predictor of what they called "school satisfaction," which was used as a more broad term beyond student-school personnel relationships. Other studies have found the construct of school connectedness to be inversely related to school size (Kearney, 2008; Thompson et al., 2006). Furthermore, two Add Health studies 
have also found inverse relationships between school connectedness and school size (Crosnoe et al., 2004; McNeely et al., 2002). Thus, this hypothesis further confirms the other literature on the existing inverse relationship between these two key variables. Overall, it appears to be increasingly difficult for students to establish substantial quality relationships with teachers and other school personnel as the size of the school increases.

The third hypothesis $\left(\mathrm{H}_{3 \mathrm{a}}, \mathrm{H}_{3 \mathrm{~b}}\right)$ that school connectedness would be inversely associated with youth violence, including controlling for the effects of school size, was supported, $\left(\mathrm{H}_{8}\right)$. This finding was consistent with previous research examining school connectedness and a variety of violence outcomes. Students with high levels of school connectedness as compared to students with low levels of school connectedness have been found to be less likely to be perpetrators, or victims, of violence (Smith \& Sandhu, 2004; Wilson, 2004). Resnick et al.'s (1997) seminal study of a cross-sectional examination of Add Health data found that students with high levels of school connectedness had an inverse relationship with aggressive behaviors. Other Add Health studies have also found that high levels of school connectedness have a role in preventing youth violence (Brookmeyer et al., 2006; Dornbush et al., 2001; Franke, 2000; Henrich et al., 2005). Resnick et al.' s (2004) Add Health study found that students reporting high levels of school connectedness at Wave 1, reported lower reports of violent behavior at Wave 2 (one year later). Resnick et al.' study is similar to this study in that it explicitly used longitudinal data to examine school connectedness as a predictor of violence over time. However, the Resnick et al.'s study utilized multiple linear regression to analyze their data while this study 
incorporated hierarchical linear modeling to account for student data being nested within schools. Thus, this hypothesis further confirms and expands the existing literature on the inverse relationship between these two key variables. Overall, it appears that the stronger the relationships students form with teachers and school personnel, the less likely they are to engage in negative, disruptive, aggressive behaviors.

\section{Moderation of School Connectedness}

The hypothesis that school connectedness would moderate the effects of school size on youth violence was not supported $\left(\mathrm{H}_{5}\right)$, including controlling for student and school characteristics $\left(\mathrm{H}_{10}\right)$. The fixed interaction effect between school size and school connectedness was not significant. This lack of support was found with and without controlling for student and school characteristics. Therefore, school connectedness did not influence the relationship between school size and youth violence. However, the lack of school connectedness moderation between school size and youth violence is somewhat deceiving because it assumes that there is an initial relationship between school size and youth violence. The first four hypotheses, especially hypothesis one, which indicated no direct relationship between school size and youth violence, showed initial indications that there may not be an interaction effect. In other words, it appeared that there was no school size to youth violence relationship to begin with. Nevertheless, it was still important to test for a possible interaction effect between school size and school connectedness without assuming there was no relationship. 
The current call for youth violence prevention has resulted in the need to examine contextual relationships of youth and school characteristics with youth violence, which ultimately involves examining potential mediating and moderating effects. Although this study did not support a moderator effect of school connectedness, this finding in conjunction with a possible mediation effect of school connectedness provides some indication of the ecological role school size and school connectedness may have in youth violence prevention efforts. These two findings respond to, and expand upon, the call for greater understanding of contextual factors that may play a role in preventing youth violence. These results can further inform future youth violence prevention practices and research measurement and design.

Overall, school connectedness appears to have meditational relationship between school size and youth violence, but does not have any moderational role. This conclusion appears to largely come from the finding that school size did not show any relationship with youth violence. In fact, there was no variance explained between school size and youth violence. School size did have a relationship with school connectedness, which in turn had a relationship with youth violence. Furthermore, school connectedness had one of the strongest variance explained with you youth violence at $5.4 \%$. The only other variables that had an explained variance of $1 \%$ or greater were gender (3.1\%) and income (4.5\%) on youth violence, and income (6.0\%) on school connectedness. These results show that although school connectedness may be a factor in preventing youth violence, its role is relatively small. However, the small impact is consistent with other pertinent variables in which the impact is also small. Interestingly, income 
appeared to explain more variance on youth violence and school connectedness than any other variable. Although race/ethnicity showed initial relationships with youth violence and school connectedness (see Table 2 for correlation matrix level 2) it appears income is what truly drives these relationships. This finding actually supports previous studies investigating race/ethnicity and socioeconomic status (Crouch et al., 2000; Foster et al., 2007). It is not unreasonable to speculate from these findings that the school connectedness and school size has a limited impact on youth violence. However, it should be noted that there are multitude of other school and student variables that were not available to be examined in this study. What is known is that school size by itself does not appear to have any effect on youth violence. However, other student variables such as school connectedness, do have a relationship with youth violence. Although an explained variance of $5.4 \%$ may be relatively small, it may be that no single school or individual variable has a grand impact on youth violence. Also, there are many variables that cannot be changed by mental health and school counselors (e.g., gender, income), but at least the relationships that influence school connectedness provides a point of entry to prevent youth violence.

\section{Study Limitations}

The use of an existing database like Add Health has many advantages, including use of a nationally representative sample of adolescent students, large sample size, and longitudinal data collection. This study attempted to utilize these advantages and build upon previous research through the use of hierarchical linear modeling [HLM], appropriate weights, and examination of the potential mediating and moderating role of school connectedness. However, like 
using many existing databases, there were some limitations. For this study, the limitations concern measuring the key constructs and lack of consideration for alternative variables.

The questions used to measure youth violence from the Add Health inhome interview appeared to lack sensitivity to the frequency and intensity of violent behaviors. This study used a total of seven questions with such scales as “never (o), 1 or 2 times (1), 3 or 4 times (2), and 5 or more times (3)." However due to there being such low frequencies, the violent data were recoded as " $n o$ violent acts a (0) and one or more violent acts a (1).” This resulted in totaling each question to obtain a score varying from 0-7 for each student. The concern with using such a scale resulted in the possibility of one violent incident receiving a "yes" response to most of the seven questions and multiple incidents receiving a "yes" response to one or two questions. Thus, there is a significant possibility to misrepresent the true number of violent incidents. Furthermore, the intensity of violent incidents is also lost. For example, a student responding "yes" to getting into a "physical fight" is weighted the same as another student responding "yes" to "shot or stabbed someone." Although both are acts of violence, the resulting outcomes may be considerably different. Unlike developing or utilizing another violence questionnaire, the use of the Add Health violence questions limited the contextual nature of violence assessed in this study.

Similar to the concerns of limited options in measuring youth violence, measurement of school size was also limited. The Add Health data set only provided categorical data of school size, including small (1-400), medium (4011000), or large (1001-4000). The categorical nature of school size may have 
reduced the possibility of some findings that might have been possible with continuous data. Furthermore, an alternative approach to measure school size would have been student-teacher ratio, especially considering the importance of the key construct of school connectedness which largely relies upon studentteacher relationships. The categorical nature of school size precluded any possible option to transform number of students and number of teachers for each school into a student-teacher ratio construct.

A potential limitation with measuring school connectedness has less to do with the use of Add Health data, but more with actual participation in completing the questions related to this construct. There may be differences in perceptions of school connectedness between those students who did not participate to those who did participate; thus, restricting the variance in responses. School connectedness measured a level of positive student perception about their school, especially with school personnel. Thus, a student who does not have a positive perception of school may not only have an increased proclivity to avoid attending school, but also participate in any study that asks a multitude of questions about their thoughts and feelings of school and related relationships.

This study only measured two key constructs and controlled for a few student and school variables that may be related to youth violence. There are most likely many other variables, interaction effects, and contextual factors that have direct and/or mediating or moderating relationships with youth violence. In fact, the small portion of variance/effect size of school connectedness in this study only confirms that there are other variables that contribute to the youth violence relationship. Therefore, although this study used a longitudinal dataset, 
causal inferences to youth violence with these findings is limited. Even though it is impossible for any study to account and control for the many mediating and moderating effects on a model for youth violence, consideration of alterative variables should not be ignored, especially when findings are associated with small effect sizes.

\section{Implications for Practice}

The findings from this study provide information concerning preventing school violence. The findings reflect that school connectedness mediates the relationship between school size and youth violence. Thus, school connectedness may have an effect on youth violence, and school size appears to only influence youth violence through school connectedness. This is considered a positive finding because school connectedness is malleable to change whereas changing school size requires significant systemic efforts beyond mental health professionals. School connectedness' malleability to change gives it potential for effective prevention efforts (Bonne et al., 2000). School connectedness' meditational role helps understand the link between processes of prevention and youth violence from an ecological and multilevel approach (Brookmeyer et al., 2006). This finding provides promise for preventative efforts of establishing quality relationships between students and school personnel that can generalize to adolescent life outside of school and into the community.

Other researchers have called schools to develop preventative and early intervention programs for youth violence that go beyond typical school health efforts (Dornbush et al., 2001; Henrich et al., 2005). As McNeely et al. (2002) states, "the concept of school health promotion should be expanded beyond 
health education, physical education, and health services" (p. 146). School connectedness appears to be at least one significant domain that can be changed and improved upon through systemic and interdisciplinary efforts by mental health professionals and school personnel. As alluded to earlier, some researchers believe that the field of violence prevention is evolving toward an ecological perspective (e.g., Centers for Disease Control and Prevention, 2010; Resnick et al., 2004), which includes more concerted efforts to instill programs that foster and facilitate school connectedness.

Currently, the findings from this study and other studies (e.g,. Brookmeyer et al., 2006; Dornbush et al., 2001; Franke, 2000; Henrich et al., 2005; Resnick et al.' s (2004) indicate that improving school personnel's interactions with students may have an effect on increasing levels of students' perceptions of school connectedness and preventing youth violence. Catalano et al. (2004) found that prevention/early intervention efforts that focused on classroom instruction and management, and child skill development showed an increase in self-reports of positive school climate and reducing school behavioral problems, six and nine years after the intervention. School counselors can have a role in improving relationships between students and school personnel through teacher education and basic relational skill development. Fostering strengths, providing hope, responding to bullying, and instilling personal insight are some recommended avenues to foster student connectedness between students and teachers. (e.g., Bonny et al., 2000; Ericson, 2001; Ozer, 2005; Shochet et al., 2006). One avenue that is gaining increasing attention as vital components of student-teacher relationships is student self-reports of being treated with dignity 
and respect by their teachers (Daniels et al., 2007; Daniels et al., 2010). These approaches seem to cultivate a sense of fitting in, or belonging, rather than feeling rejected.

A word of caution should also be noted to school counselors who may attempt to assess levels of school connectedness within their schools. When measuring such constructs as school connectedness the data is often presented as the average score/level within a school or group of schools. The average level of school connectedness may represent a component of school climate, but individual reports should also be addressed on a case-by-case process, when necessary. For example, a school as a whole could have above average levels of school connectedness, but this does not rule out that there could be individual students feelings significantly isolated. Stated differently, students reporting low levels of school connectedness while many of their peers are reporting high levels of school connectedness could be at risk for further isolation. In fact, students that feel isolated and do not "fit in" with fellow peers are the individuals who teachers and school counselors should especially be reaching out to for relational support. Overall, the school setting appears to be a rich area of practice for school counselors and other mental health professionals to implement and foster positive student-teacher relationships as a vehicle for youth violence prevention into the community.

\section{Recommendations for Future Research}

This study's research design and findings highlight a few areas in this research domain in need of further research consideration. Considerations for 
use of Add Health data and research design, measurement of key constructs, and alternative mediator/moderator models are discussed.

Add Health is a nationally representative and large sample of students with a longitudinal design. Therefore, it seems prudent for further Add Health research to take advantage of this design and implement it into further studies whenever necessary, rather than cross-sectional. Although the results of such studies arguably may not always be able to do demonstrate "causality," it does provide variances for possible effects (Raudenbush \& Bryk, 2002).

Current statistical approaches are now sophisticated enough to take into account individual and organizational differences. Many of the studies cited in this paper used multiple regressions, or other variations, when examining relationships of students nested within a school setting. However, hierarchical linear modeling (HLM) is most appropriate for multi-level research questions, including school-based clustering (i.e., nested data) of Add Health data where observations within schools are not independent. In fact, Add Heath specifically recommends the use of HLM for such analyses in order to account for effects on estimates of totals, estimates of ratios, and estimates of variances, standard errors, and confidence intervals (Harris et al., 2009). Simply stated, not using HLM analyses with nested data can result in inaccurate hypothesis testing.

Some of the previous studies in this literature domain using Add Health data either neglected to incorporate sampling weights, or did not explicitly mention the use of weights. It is important to use the appropriate weight to the corresponding research design and included Waves in order to assure a nationally representative sample with unbiased population estimates and 
standard errors. Not using weights when necessary limits the generalizability of the findings. This could have a potential negative unseen impact by way of limiting the effectiveness of applied preventative efforts.

The investigative process of this study has also highlighted the significance of how the constructs youth violence, school size, and school connectedness are measured. First, future measurement of youth violence should have response categories that are sensitive to the frequency of violent behaviors. For example, using the questions from the Add Health database, one violent incident may receive a "yes" response to all of the seven questions, where a series of violent incidents may only receive a "yes" response to one or two questions. Such counting of "yes's" and "no's" may be deceptive in being relied upon as an accurate assessment of "more" versus "less" violence for each individual and overall violence indicators. Similarly, sensitivity to the intensity of violence should also be taken into consideration. For example, should a physical altercation resulting in a bruise be weighted the same as knife wound requiring medical attention? The use of weapon(s) and physical outcome may be more reliable indicators for intensity and severity of violence. Regardless of how the construct is measured, researchers should be explicit in their studies on not only how youth violence is operationally defined, but also on how it is measured (i.e., questions) and weighted. Otherwise, there should be caution in comparing youth violence findings between studies with such varying measurement strategies. It may be that school connectedness has varying degrees of effectiveness on preventing youth violence depending upon the context. 
Future research considering other alternatives on how school size is measured may provide additional insights for the relationship among school size, school connectedness, youth violence, and other variables. For example, using number of school employees (i.e., personnel available to an organization) rather than number of students may show a different pattern/relationship of school connectedness and school violence. Furthermore, it may be even more fruitful to use multiple measures of organizational size within the same study and compare the combined effects. More specifically, looking at both number of students and number of school teachers might result in formulating a unique type of organizational size measure: student-teacher ratio. Although a student-teacher ratio is nothing new by itself, it appears that none of the aforementioned studies used this ratio as a measure of organizational size. (This approach was not an option in this study because Add Health data categorized school size into small, medium, and large, rather than providing total student population.) Therefore, student-teacher ratio may provide added insight into the potential mediating/moderating role of school connectedness and violence. For example, the negative effects of increasing school size (by way of number of students) may not be as significant in schools with a smaller gap in the student to teacher ratio. It would seem such a ratio would be especially important in assessing the effects of school connectedness because of the strong role of teacher skills in forming positive relationships with students. In other words, perhaps, on average, it is less challenging to form positive student relationships with an average class size of 20, rather than 40. The same can also be said for the student to school counselor ratio. It is not unreasonable to speculate that a school counselor 
assigned to 30 students would be more efficient and interpersonally connected than a school counselor assigned to 60 students. In both cases, the emphasis should be more on quality of relationships, rather than number of students served.

In the current research school connectedness is measured as a global relationship between students and teachers/school personnel, and sometimes peers. Although this approach has shown its effectiveness in measuring school connectedness and determining relationships with other variables, measuring levels of connectedness more specifically may provide clearer outcomes and further inform practice. For example, preventative efforts may be given clearer direction by distinguishing from connectedness with teachers, peers, and even learning (McNeely \& Falci, 2004). An overarching level of school connectedness can still be measured, but also include different levels of connectedness subtypes. Research on specific identification of connectedness subtypes could provide insight to mental health professionals the target areas in need of more development and consultation.

As stated earlier, many researchers have called for expanding upon the knowledge base of means to understand and prevent youth violence, including the role of school connectedness. Many of these calls have stated the need for further examination of the meditational and moderation role of preventative factors, such as school connectedness. However, the present literature shows few studies examining this construct within a larger ecological context through mediator or moderator models. As this present study demonstrated, the role of school size and school connectedness are interconnected, which has provided 
added insight into further areas of research and expanded practice options for mental health professionals and other professionals within school settings. However, the testing of this study's meditational and moderator models is by no means exhaustive. In fact, the lack of variance explained for school size and the small amount of variance explained for school connectedness only confirms that there are other variables that contribute to the youth violence relationship. There certainly is room for future research to consider alternative mediator/moderator models, including variables beside school connectedness and alternative social ecologies (e.g., neighborhood risk factors). Overall, further examination of such contextual relationships appears to have promise in further expanding effective preventative approaches to youth violence both in schools and the community.

\section{Summary and Conclusions}

This study used Add Health longitudinal data with multilevel modeling to examine the interrelationship of school size, school connectedness, and youth violence. The findings from this study tentatively support a partial mediation effect of school connectedness between school size and youth violence, including controlling for specific student and school variables. The prediction of a moderation effect of school connectedness between school size and youth violence was not supported. This study also provides empirical support for an inverse relationship between school size and school connectedness, and an inverse relationship between school connectedness and youth violence. Increasing school student population appears to play a role in creating challenges in the development of quality relationships between students and school personnel, which in turn impedes prevention of youth violence. Overall, the 
findings from this study highlight how student-teacher relationships can be a key factor in preventing youth violence. Furthermore, the malleability of school connectedness provides mental health professionals a primary target area for change. Mental health professionals can both create programs that improve student-teacher relationships and also have a means to assess individual student perceptions of safety and relationships with others. Finally, in addition to contributing to the literature on preventing youth violence, this study also underscores the need for future research to take caution in research design and measurement with Add Health data, and further exploration in alternative contextual relationships that may prevent youth violence. 


\section{References}

Baron, R. M., \& Kenny, D. A. (1986). The moderator-mediator variable distinction in social psychological research: Conceptual, strategic, and statistical considerations. Journal of Personality and Social Psychology, $51,1173-1182$.

Battistich, V., \& Hom. (1997). The relationship between students' sense of their school as a community and their involvement in problem behaviors. American Journal of Public Health, 87, 1997-2001.

Baumeister, R. F., \& Leary, M. R. (1995). The need to belong: Desire for interpersonal attachments as a fundamental human motivation. Psychological Bulletin, 117, 497-529.

Blum, R. W., McNeely, C. A., \& Rinehart, P. M. (2002). Improving the odds: The untapped power of schools to improve the health of teens. Minneapolis, MN: Center for Adolescent Health and Development, University of Minnesota.

Blum, R. W., \& Libbey, H. P. (2004). Executive Summary. Journal of School Health, 74, 231-232.

Bonny, A. E., Britto, M. T., Klostermann, B. K., Hornung, R. W., \& Slap, G. B. (2000). School disconnectedness: Identifying adolescents at risk. Pediatrics, 106, 1017-1021.

Bowen, G. L., Bowen, N. K., \& Richman, J. M. (2000). School size and middle school students' perceptions of the school environment. Social Work in Education, 22, 69-82.

Brookmeyer, K. A., Fanti, K. A., \& Henrich, C. C. (2006). Schools, parents, and 
youth violence: A multilevel, ecological analysis. Journal of Child and Adolescent Psychology, 35, 504-514.

Buka, S. L., Stichick, T. L., Birdthistle, I., \& Earls, F. J. (2001). Youth exposure to violence: Prevalence, risks, and consequences. American Journal of Orthopsychiatry, 71, 298-310.

Catalano, R. F., Haggerty, K. P., Oesterle, S., Fleming, C. B., \& Hawkins, J. D. (2004). The importance of bonding to school for healthy development: Findings from the social development research group. Journal of School Health, 74, 252-261.

Centers for Disease Control and Prevention. (2010). Youth risk behavior surveillance - United States, 2009. Morbidity and Mortality Weekly Report, 59(Suppl. 5), 1-108.

Centers for Disease Control and Prevention. (2009). Web-Based Injury Statistics Query and Reporting System (WISQARS). Retrieved October 19, 2010, from http://www.cdc.gov/injury/wisqars/nonfatal.html.

Chávez, V. (1999). Operational definitions of youth violence in empirical research. International Quarterly of Community Health Education, 18, 237-261.

Cohen, M. A. (1998). The monetary value of saving a high-risk youth. Journal of Quantitative Criminology, 14, 5-33.

Cohn, E. (1975). A proposal for school size incentives in state aid to education. Journal of Education Finance, 1, 216-225.

Conant, J. (1959). The American high school today: A first report to interested citizens. New York, NY: McGraw-Hill. 
Cotton, K. C. (1996a). School size, school climate, and student performance. Close-up \#20. Portland, OR: Northwest Regional Education Laboratory.

Cotton, K. C. (1996b). Affective and social benefits of small-scale schooling. ERIC Digest: 401-088. Charleston, WV: Clearinghouse on Rural Education and Small Schools.

Crosnoe, R., Johnson, M. K., \& Elder, G. H. (2004). School size and the interpersonal side of education: An examination of race/ethnicity and organizational context. Social Science Quarterly, 85, 1259-1274.

Crouch, J. L., Hanson, R. F., Saunders, B. E., Kilpatrick, D. G., \& Resnick H. S. (2000). Journal of Community Psychology, 28, 625-641.

Daniels, J. A., Bradley, M. C., Cramer, D. P., Winkler, A., Kinebrew, K., \& Crockett, D. (2007). The successful resolution of armed hostage/barricade events in schools: A qualitative analysis. Psychology in the schools, 44, 601-613.

Daniels, J. A., Bradley, M. C., Hays, M. (2007). The impact of school violence on school personnel: Implications for psychologists. Professional Psychology: Review and Practice, 38, 652-659.

Daniels, J. A., Volungis, A., Pshenishny, E., Gandhi, P., Winkler, A., Cramer, D. P. et al. (2010). A qualitative investigation of averted school rampages. The Counseling Psychologist, 38, 69-95.

Davison, M. L., Kwak, N., Seo, Y. S., \& Choi, J. (2002). Using hierarchical linear models to examine moderator effects: Person-by-organization interactions. Organizational Research Methods, 5, 231-254.

Derzon, J. H. (2001). Antisocial behavior and the prediction of violence: A meta- 
analysis. Psychology in the Schools, 38, 93-106.

Devoe, J. F., Peter, K., Kaufman, P., Ruddy, S. A.., Miller, A. K., Planty, M., et al. (2003). Indicators of school crime and safety. Washington, DC: U. S. Departments of Education and Justice.

Dornbusch, S. M., Erickson, K. G., Laird, J., \& Wong, C. A. (2001). The relation of family and school attachment to adolescent deviance in diverse groups and communities. Journal of Adolescent Research, 16, 296-422.

Dunbar, R. I. M. (1992). Neocortex size a constraint on group size in primates. Journal of Human Evolution, 22, 469-493.

Dunbar, R. I. M. (1993). Coevolution of neocortical size, group size and language in humans. Behavioral and Brian Sciences, 16, 681-735.

Edwards, C. H. (2001). Student violence and the moral dimensions of education. Psychology in the Schools, 38, 249-257.

Ericson, N. (2001). Addressing the problem of juvenile bullying. OJJDP Fact Sheet \#27. U. S. Department of Justice, Office of Justice Programs, Office of Juvenile Justice and Delinquency Prevention: Washington, DC: U.S. Government Printing Office.

Farrington, D. (2004). Conduct disorder, aggression, and delinquency. In R. Lerner \& S. Steinberg (Eds.), Handbook of adolescent psychology (pp. 627-664). New York: Wiley.

Federal Bureau of Investigation. (1999). Uniform crime reports for the United States. Washington, DC: U.S. Government Printing Office.

Ferris, J. S., \& West, E. G. (2004). Economies of scale, school violence and the optimal size of schools. Applied Economics, 36, 1677-1684. 
Fowler, W. J., \& Walberg, H. J. (1991). School size, characteristics, and outcomes. Educational Evaluation and Policy Analysis, 13, 189-202.

Franke, T. M. (2000). The role of attachment as a protective factor in adolescent violent behavior. Adolescent and Family Health, 1, 40-57.

Frazier, P. S., Barron, K. E., \& Tix, A. P. (2004). Testing moderator and mediator effects in counseling psychology. Journal of Counseling Psychology, 51, $115-134$.

Furlong, M., \& Morrison, G. (2000). The school in school violence: Definitions and facts. Journal of Emotional and Behavioral Disorders, 8, 71-80.

Galletti, S. (1999). School size counts. Education Digest, 64(9), 15-17.

Hammond, W. R., Haegerich, T. M., \& Saul, J. (2009). The public health approach to youth violence and child maltreatment prevention at the Centers for Disease Control and Prevention. Psychological Science, 6, 253263.

Hammond, W. R., Whitaker, D. J., Lutzker, J. R., Mercy, J., \& Chin, P. M. (2006). Setting a violence prevention agenda at the Centers for Disease Control and Prevention. Aggression and Violent Behavior, 11, 112-119.

Harris, K. M. (2009). The National Longitudinal Study of Adolescent Health (Add Health), Waves I \& II, 1994-1996; Wave III, 2001-2002; Wave IV, 2007-2009 [machine-readable data file and documentation]. Chapel Hill, NC: Carolina Population Center, University of North Carolina at Chapel Hill.

Harris, K. M., Halpern, C. T., Whistsel, E., Hussey, J., Tabor, J., Entzel, P., et al. (2009). The National Longitudinal Study of Adolescent Health: Research 
design. Retrieved October 27, 2010, from http://www.cpc.unc.edu/projects/addhealth/design.

Hart, S. D., Webster, C. D., \& Menzies, R. J. (1993). A note on portraying the accuracy of violence predictions. Law and Human Behavior, 17, 695-700. Hawkins, J. D., Herrenkohl, T. I., Farrington, D. P., Brewer, D., Catalano, R. F., Harachi, T. W. et al. (2000). Predictors of youth violence. Juvenile Justice Bulletin. Washington, DC: U.S. Department of Justice, Office of Juvenile Justice and Delinquency Prevention.

Henrich, C. C., Brookmeyer, K. A., \& Shahar, G. (2005). Weapon violence in adolescence: Parent and school connectedness as protective factors. Journal of Adolescent Health, 37, 306-312.

Herrenkohl, T. I., Hill, K. G., Chung, I-J., Guo, J., Abbott, R. D., \& Hawkins, J. D. (2003). Protective factors against serious violent behavior in adolescence: A prospective study of aggressive children. Social Work Research, 27, 179191.

Hoagwood, K. (2000). Research on youth violence: Progress by replacement, not addition. Journal of Emotional and Behavioral Disorders, 8, 67-70.

Foster, H., Brooks-Gunn, J., \& Martin, A. (2007). Poverty/socioeconomic status and exposure to violence in the lives of children and adolescents. In D. J. Flannery, A. T. Vazsonyi, \& I. D. Waldman (Eds.), The Cambridge handbook of violent behavior and aggression (pp. 664-687). New York, NY: Cambridge University Press.

Hunt, M. H., Meyers, J., Davies, G., Meyers, B., Grogg, K. R., \& Neel, J. (2002). A 
comprehensive needs assessment to facilitate prevention of school dropout and violence. Psychology in the Schools, 39, 399-416.

Hyman, I., Cohen, I., \& Mahon, M. (2003). Student alienation syndrome: A paradigm for understanding the relation between school trauma and school violence. The California School Psychologist, 8, 73-86.

Hyman, I. A., \& Perone, D. D. (1988). The other side of school violence: Educator policies and practices that may contribute to student misbehavior. Journal of School Psychology, 36, 7-27.

Hyman, I. A., Zelikoff W., \& Clarke, J. (1988). Psychological and physical abuse in the schools: A paradigm for understanding post-traumatic stress disorder in children. Journal of Traumatic Stress, 1, 243-267.

Jenkins, P. H. (1997). School delinquency and the school social bond. Journal of Research in Crime and Delinquency, 34, 337-367.

Jimerson, S. R., Morrison, G. M., Pletcher, S. W., \& Furlong, M. J. (2006). Youth engaged in antisocial and aggressive behaviors: Who are they? In S. R. Jimerson \& M. J. Furlong (Eds.), Handbook of school violence and school safety: From research to practice (pp. 3-19). Mahwah, NJ: Lawrence Erlbaum.

Jones, J. T., Toma, E. F., \& Zimmer, R. W. (2008). School attendance and district school size. Economics of Education Review, 27, 140-148.

Kaiser, D. A. (2005). School shootings, high school size, and neurobiological considerations. Journal of Neurotherapy, 9, 101-115.

Karcher, M. J. (2004). Connectedness and school violence: A framework for 
developmental interventions. In E. R. Gerler (Ed.), Handbook of school violence (pp. 7-39). New York: Haworth.

Kearney, C. A. (2008). School absenteeism and school refusal behavior in youth: A contemporary review. Clinical Psychology Review, 28, 451-471.

Kenny, D. A.., Kashy, D. A., \& Bolger, N. (1998). Data analysis in social psychology. In D. Gilbert, S. Fiske, \& G. Lindzey (Eds.), The handbook of social psychology (4th ed., Vol. 1, pp. 233-265). Boston, MA: McGraw-Hill.

Kia-Keating, M., \& Ellis, B. H. (2007). Belonging and connection to school in resettlement: Young refugees, school belonging, and psychosocial adjustment. Clinical Child Psychology and Psychiatry, 12, 29-43.

Kimberly, J. R. (1976). Organizational size and the structuralist perspective: A review, critique, and proposal. Administrative Science Quarterly, 21, 571597.

Kreft, I., \& De Leeuw, J. (1998). Introducing multilevel modeling. London: Sage Publicaions.

Krug, E. G., Dahlberg, L. L., Mercy, J. A., Zwi, A. B., \& Lozaneo, R. (2002). World Report on Violence and Health. Geneva: World Health Organization.

Krull, J. L., \& MacKinnon, D. P. (1999). Multilevel mediation modeling in groupbased intervention studies. Evaluation Review, 23, 418-444.

Krull, J. L., \& MacKinnon, D. P. (2001). Multilevel modeling of individual and group level mediated effects. Multivariate Behavioral Research, 36, 249277.

Leung, A., \& Ferris, J. S. (2008). School size and youth violence. Journal of Economic Behavior \& Organization, 65, 318-333. 
Leventhal, T., \& Brooks-Gunn, J. (2000). The neighborhoods they live in: The effects of neighborhood residence on child and adolescent outcomes. Psychological Bulletin, 126, 309-337.

Libbey, H. P. (2004). Measuring student relationships to school: Attachment, bonding, connectedness, and engagement. Journal of School Health, 74, 274-283.

Lindsay, P. (1982). The effect of high school size on student participation, satisfaction, and attendance. Educational Evaluation and Policy Analysis, $4,57-65$.

Loeber, R., \& Hay, D. (1997). Key issues in the development of aggression and violence from childhood to early adulthood. Annual Review of Psychology, 48, 371-410.

Loukas, A., Suzuki, R., \& Horton, K. D. (2006). Examining school connectedness as a mediator of school climate effects. Journal of Research on Adolescence, 16, 491-502.

Ludwig, K. A., \& Warren, J. S. (2009). Community violence, school-related protective factors, and psychosocial outcomes in urban youth. Psychology in the Schools, 46, 1061-1073.

Luke, D. A. (2004). Multilevel modeling. Sage University Papers Series on Quantitative Applications in the Social Sciences. Thousand Oaks, CA: Sage.

MacKinnon, D. P., Lockwood, C. M., Hoffman, J. M., West, S. G., \& Sheets, V. (2002). A comparison of methods to test mediation and other intervening variable effects. Psychological Methods, 7, 83-104. 
Maddox, S. J., \& Prinz, R. J. (2003). School bonding in children and adolescents: Conceptualization, assessment, and associated variables. Clinical Child and Family Psychology Review, 6, 31-49.

Martinez, P., \& Richters, J. E. (1993). The NIMH community violence project: II. Children's distress symptoms associated with violence exposure. Psychiatry, 56, 22-35.

McNeely, C. A. (2003, March). Connection to school as an indicator of positive development. Paper presented at the meeting of the Indicators of Positive Development Conference, Washington, DC.

McNeely, C. A., \& Falci, C. (2004). School connectedness and the transition into and out of health-risk behavior among adolescents: A comparison of social belonging and teacher support. Journal of School Health, 74, 284-292.

McNeely, C. A., Nonnemaker, J. M., \& Blum, R. W. (2002). Promoting school connectedness: Evidence from the national longitudinal study of adolescent health. Journal of School Health, 72, 138-146.

Miller, G. E., Breham, K., \& Whitehouse, S. (1998). Reconceptualizing schoolbased prevention for antisocial behavior within a resiliency framework. School Psychology Review, 27, 364-379.

Modzeleski, W., Feucht, T., Rand, M., Hall, J. E., Simon, T. R., Butler, L. et al. (2008). School-associated student homicides: United States, 1992-2006. Morbidity and Mortality Weekly Report, 57(2), 33-36. Atlanta, GA: U. S. Department of Health \& Human Services, Centers for Disease Control and Prevention.

Mulvey, E. P., \& Cauffman, E. (2001). The inherent limits of predicting school 
violence. American Psychologist, 56, 797-802.

Nation, M., Crusto, C., Wandersman, A., Kumpfer, K. L., Seybolt, D., MorrisseyKane, E., et al. (2003). What works in prevention: Principles of effective prevention programs. American Psychologist, 58, 449-456.

O’Donnell, J., Hawkins, J. D., \& Abbott, R. D. (1995). Predicting serious delinquency and substance use among aggressive boys. Journal of Consulting and Clinical Psychology, 63, 529-537.

Osofsky, J. D., Werers, S., Hann, D. M., \& Fick, A. C. (1993). Chronic community violence: What is happening to our children? Psychiatry, 56, 36-45.

O’Toole, M. (2000). The school shooter: A threat assessment perspective. Quantico, VA: Federal Bureau of Investigation.

Ozer, E. J. (2005). The impact of violence on urban adolescents: Longitudinal effects of perceived school connection and family support. Journal of Adolescent Research, 20, 167-192.

Pastore, A. L., \& Maguire, K. (Eds.). (2002). Sourcebook of criminal justice statistics 2001. Washington, DC: U.S. Department of Justice.

Pittman, R. B., \& Haughwout, P. (1987). Influence of high school size on dropout rate. Educational Evaluation and Policy Analysis, 9, 337-343.

Ready, D. D., Lee, V. E., \& Welner, K. G. (2004). Educational equity and school structure: School size, overcrowding, and schools-within-schools. Teachers College Record, 106, 1989-2014.

Raudenbush, S. \& Bryk. A. (2002). Hierarchical linear models: Applications and data analysis methods ( $2^{\text {nd }}$ ed.). Thousand Oaks, CA: Sage Publications. Raudenbush, S., Bryk, A., Cheong, Y. F., Congdon, R., \& du Toit, M. (2004). HLM 
6: Hierarchical linear and nonlinear modeling. Lincolnwood, IL: Scientific Software International, Inc.

Reddy, M., Borum, R., Berglund, J., Vossekuil, B., Fein, R., \& Modzeleski, W. (2001). Evaluating risk for targeted violence in schools: Comparing risk assessment, threat assessment, and other approaches. Psychology in the Schools, 38, 157-172.

Resnick, M. D., Bearman, P. S., Blum, R. W., Bauman, K. E., Harris, K. M., Jones, J., et al. (1997). Protecting adolescent from harm: Findings from the national longitudinal study on adolescent health. Journal of the American Medical Association, 278, 823-832.

Resnick, M. D., Harris, L., \& Blum, R. (1993). The impact of caring and connectedness on adolescent health and well-being. Journal of Pediatrics \& Child Health, 28, S3-S9.

Resnick, M. D., Ireland, M., \& Borowsky, I. (2004). Youth violence perpetration: What protects? What predicts? Finding from the national longitudinal study of adolescent health. Journal of Adolescent Health, 35, 424-433.

Rosenblatt, J. A., \& Furlong, M. J. (1997). Assessing the reliability and validity of student self-reports of campus violence. Journal of Youth and Adolescence, 26, 187-202.

Rotherham, A. (1999). When it comes to school size, smaller is better. Education Week, $18,76-77$.

Sampson, R. J., \& Laub, J. H. (1990). Crime and deviance over the life course: The salience of adult social bonds. American Sociological Review, 55, $609-627$ 
Schwab-Stone, M., Chen, C., Greenberger, E., Silver, D., Lichtman, J., \& Voyce, C. (1999). No safe haven II: The effects of violence exposure on urban youth. Journal of the American Academy of Child and Adolescent Psychiatry, $38,359-367$.

Shochet, I. M., Dadds, M. R., Ham, D., \& Montague, R. (2006). School connectedness is an underemphasized parameter in adolescent mental health: Results of a community prediction study. Journal of Clinical Child and Adolescent Psychology, 35, 170-179.

Singer, J. (1998). Using SAS PROC MIXED to fit multilevel models, hierarchical models, and individual growth models. Journal of Education and Behavioral Statistics, 24, 323-355.

Skiba, R. J., \& Peterson, R. L. (1999). The dark side of zero tolerance: Can punishment lead to safe schools? Phi Delta Kappan, 8o, 372-376.

Smith, D. C., \& Sandhu, D. S. (2004). Toward a positive perspective on violence prevention in schools: Building connections. Journal of Counseling \& Development, 82, 287-293.

Sullivan, T. N., Farrell, A. D., Bettencourt, A. F., \& Helms, S. W. (2008). Core competencies and the prevention of youth violence. New Directions for Child and Adolescent Development, 122, 33-46.

Thomas S. P., \& Smith, H. (2004). School connectedness, anger behaviors, and relationships of violent and nonviolent American youth. Perspectives in Psychiatric Care, 40, 135-148.

Thompson, D. R., Iachan, R., Overpeck, M., Ross, J. G., \& Gross, L. A. (2006). 
School connectedness in the health behavior in school-aged children study: The role of student, school, and school neighborhood connectedness. Journal of School Health, 76, 379-386.

Townsend, K. C., \& McWhirter, B. T. (2005). Connectedness: A review of the literature with implications for counseling, assessment, and research. Journal of Counseling \& Development, 83, 191-201.

U.S. Department of Health and Human Services. (2001). Youth violence: A report of the Surgeon General. Retrieved May 11, 2009, from http://www.surgeongeneral.gov/library/youthviolence

Vossekuil, B., Fein, R., Reddy, M., Borum, R., \& Modzeleski, W. (2002). The finalreport and findings of the safe school initiative: Implications for the prevention of school attacks in the United States. Washington, DC: U.S. Secret Service, National Threat Assessment Center.

Whitlock, J. L. (2006). Youth perceptions of life at school: Contextual correlates of school connectedness in adolescence. Applied Developmental Science, $10,13-29$.

Wilson, D. (2004). The interface of school climate and school connectedness and relationships with aggression and victimization. Journal of School Health, 74, 293-299.

World Health Organization Global Consultation on Violence and Health. (1996). Violence: A public health priority (WHO/EHA/SPI.POA.2). Geneva: World Health Organization.

Zhang, Z., Zyphur, M. J., \& Preacher, K. J. (2009). Testing multilevel mediation 
using hierarchical linear models: Problems and solutions. Organizational Research Methods, 12, 695-719. 
Appendix A Tables 
Table 1

Skweness Pre/Post Log-Log Transformation

\begin{tabular}{lcccc} 
& Std. Deviation & Variance & Skewness & Kurtosis \\
\hline Pre Youth Violence & 1.170 & 1.368 & 4.592 & 7.473 \\
Post Youth Violence & 0.507 & 0.258 & 1.544 & 1.237 \\
\hline
\end{tabular}


Table 2

Correlations Between Level-1 Variables

\begin{tabular}{lcccccccc}
\hline & Sex & YV & Conect & Hisp. & White & AA & AI & Asian \\
\hline Youth Violence & $-0.178^{* *}$ & & & & & & & \\
Connectedness & $0.021^{*}$ & $-0.209^{* *}$ & & & & & & \\
Hispanic & -0.010 & $0.067^{* *}$ & -0.002 & & & & & \\
White & -0.010 & $-0.071^{* *}$ & $0.021^{*}$ & $\mathrm{n} / \mathrm{a}$ & & & \\
African American & 0.011 & $0.051^{* *}$ & $-0.051^{* *}$ & $\mathrm{n} / \mathrm{a}$ & $\mathrm{n} / \mathrm{a}$ & & & \\
American Indian & 0.013 & $0.060^{* *}$ & $-0.053^{* *}$ & $\mathrm{n} / \mathrm{a}$ & $\mathrm{n} / \mathrm{a}$ & $\mathrm{n} / \mathrm{a}$ & & \\
Asian & -0.016 & $-0.020^{*}$ & $0.032^{* *}$ & $\mathrm{n} / \mathrm{a}$ & $\mathrm{n} / \mathrm{a}$ & $\mathrm{n} / \mathrm{a}$ & $\mathrm{n} / \mathrm{a}$ & \\
Income & -0.004 & $-0.058^{* *}$ & $0.052^{* *}$ & $-0.089^{* *}$ & $0.124^{* *}$ & $-0.103^{* *}$ & $-0.029^{* *}$ & $0.021^{*}$ \\
\hline${ }^{*} \mathrm{p}<.05,^{* *} \mathrm{p}<.01$ & & & & & & & &
\end{tabular}


Table 3

Correlations Between Level-2 Variables

\begin{tabular}{lcc}
\hline & School Type & School Size \\
\hline School Size & $0.255^{* *}$ & \\
Urbanicity & $0.171^{*}$ & 0.133 \\
\hline${ }^{*} \mathrm{p}<.05,{ }^{* *} \mathrm{p}<.01$ & &
\end{tabular}


Table 4

Variance Explained for Key Variables

\begin{tabular}{lcc}
\hline & Youth Violence & School Connectedness \\
\hline Youth Violence & $0.054^{*}$ & $0.054^{*}$ \\
School Connectedness & 0.000 & \\
School Size & $0.031^{*}$ & 0.000 \\
Gender & 0.004 & 0.008 \\
Race & 0.001 & 0.005 \\
Hispanic & 0.000 & 0.003 \\
White & 0.000 & 0.000 \\
African American & 0.003 & 0.000 \\
American Indian & 0.001 & 0.001 \\
Asian & $0.045^{*}$ & 0.000 \\
Income & 0.000 & 0.060 \\
School Type & 0.000 & 0.000 \\
Urbanicity & Daoo & 0.000 \\
\hline
\end{tabular}

*Variance Explained at 1\% or greater as a pseudo R-squared value 
Table 5

Hypothesis Model Equations Without Controls (A-E)

Model A: Youth Violence and School Size

Level 1: $\quad$ Yij[youth violence] $=\beta_{\mathrm{oj}}+\mathrm{r}_{\mathrm{ij}}$

Level 2: $\quad \beta_{o j}=Y_{o o}+Y_{o 1}[$ school size $]+u_{o j}$

Model B: School Connectedness and School Size

Level 1: $\quad$ Yij[school connectedness $]=\beta_{\mathrm{oj}}+\mathrm{r}_{\mathrm{ij}}$

Level 2: $\quad \beta_{\mathrm{oj}}=\mathrm{Y}_{\mathrm{oo}}+\mathrm{Y}_{\mathrm{o} 1}[\mathrm{school}$ size $]+\mathrm{u}_{\mathrm{oj}}$

Model C: Youth Violence and School Connectedness

Level 1: $\quad Y_{\mathrm{ij}}[$ youth violence $]=\beta_{\mathrm{oj}}+\beta_{\mathrm{ij}}[$ school connectedness $]+\mathrm{r}_{\mathrm{ij}}$

Level 2: $\quad \beta_{\mathrm{oj}}=\mathrm{Y}_{\mathrm{oo}}+\mathrm{u}_{\mathrm{oj}}$

$\beta_{1 j}=Y_{10}$

Model D: Youth Violence and School Connectedness (School Size Controlled)

Level 1: $\quad Y_{\mathrm{ij}}\left[\right.$ youth violence] $=\beta_{\mathrm{oj}}+\beta_{\mathrm{ij}}$ [school connectedness $]+\mathrm{r}_{\mathrm{ij}}$

Level 2: $\quad \beta_{\mathrm{oj}}=Y_{\mathrm{oo}}+\mathrm{Y}_{\mathrm{o} 1}[\mathrm{school}$ size $]+\mathrm{u}_{\mathrm{oj}}$

$\beta_{1 j}=Y_{10}$

Model E: Youth Violence and School Connectedness (Interaction)

Level 1: $\quad Y_{\mathrm{ij}}\left[\right.$ [youth violence] $=\beta_{\mathrm{oj}}+\beta_{\mathrm{j} j}$ [school connectedness] $+\mathrm{r}_{\mathrm{ij}}$

Level 2: $\quad \beta_{\mathrm{oj}}=\mathrm{Y}_{\mathrm{oo}}+\mathrm{Y}_{\mathrm{o} 1}[\mathrm{school}$ size $]+\mathrm{u}_{\mathrm{oj}}$

$\beta_{1 j}=Y_{10}+Y_{11}[$ school size $]$ 
Table 6

Hypothesis Models without Controls (A-E) Final Estimation of Fixed Effects

\begin{tabular}{|c|c|c|c|c|c|c|}
\hline & & Coefficient & $\mathrm{SE}$ & T-ratio & df & $p$-value \\
\hline \multicolumn{7}{|l|}{ Fixed Effects Model $A$} \\
\hline Youth Violence (Int.)a & $Y_{\text {oo }}$ & 0.568 & 0.037 & 15.232 & 113 & $0.000^{* * *}$ \\
\hline School Size & $Y_{01}$ & 0.050 & 0.054 & 0.913 & 113 & 0.363 \\
\hline \multicolumn{7}{|l|}{ Fixed Effects Model B } \\
\hline School Connect (Int.) ${ }^{\mathrm{a}}$ & $Y_{\text {oo }}$ & 0.474 & 0.157 & 3.017 & 113 & $0.004^{* *}$ \\
\hline School Size & $Y_{01}$ & -0.796 & 0.231 & -3.448 & 113 & $0.001^{* *}$ \\
\hline \multicolumn{7}{|l|}{ Fixed Effects Model C } \\
\hline Youth Violence (Int.)a & $Y_{o o}$ & 0.593 & 0.031 & 19.159 & 114 & $0.000^{* * *}$ \\
\hline School Connect (Slope) & $Y_{10}$ & -0.052 & 0.005 & -11.178 & 11775 & $0.000^{* * *}$ \\
\hline \multicolumn{7}{|c|}{ Fixed Effects Model D } \\
\hline Youth Violence (Int.)a & $Y_{\text {oo }}$ & 0.591 & 0.035 & 16.831 & 113 & $0.000^{* * *}$ \\
\hline School Size & $Y_{01}$ & 0.007 & 0.050 & 0.150 & 113 & 0.882 \\
\hline School Connect (Slope) & $Y_{10}$ & -0.050 & 0.050 & -9.764 & 11774 & $0.000^{* * *}$ \\
\hline \multicolumn{7}{|c|}{ Fixed Effects Model E } \\
\hline Youth Violence (Int.)a & $Y_{\text {oo }}$ & 0.572 & 0.033 & 16.004 & 113 & $0.000^{* * *}$ \\
\hline School Size & $Y_{01}$ & 0.007 & 0.048 & 0.146 & 113 & 0.884 \\
\hline School Connect (Slope) & $Y_{10}$ & -0.046 & 0.051 & -6.876 & 11773 & $0.000^{* * *}$ \\
\hline School Size & $Y_{11}$ & 0.001 & 0.014 & -0.715 & 11773 & 0.475 \\
\hline
\end{tabular}

Note. Output generated by HLM6 with REML.

Run-time deletion reduced number of level-1 units to 8981

a Intercept

${ }^{*} \mathrm{p}<.05,{ }^{* *} \mathrm{p}<.01,{ }^{* * *} \mathrm{p}<.001$ 
Table 7

Hypothesis Model Equations with Controls (F-I)

Model F: Youth Violence and School Size

Level 1: $\quad Y_{\mathrm{ij}}$ [youth violence] $=\beta_{\mathrm{oj}}+\beta_{1 \mathrm{j}}[$ biological sex $]+\beta_{2 \mathrm{j}}[$ Hispanic origin $]$

$+\beta_{3 j}[$ White $]+\beta_{4 j}[$ African American $]+\beta_{5 j}[$ American Indian $]$

$+\beta_{6 j}[$ Asian $]+\beta_{7 \mathrm{j}}$ [Income $]+\mathrm{r}_{\mathrm{ij}}$

Level 2: $\quad \beta_{\mathrm{oj}}=\mathrm{Y}_{\mathrm{oo}}+\mathrm{Y}_{\mathrm{o} 1}$ [school size $]+\mathrm{Y}_{\mathrm{o} 2}[$ school type $]+\mathrm{Y}_{\mathrm{o} 3}$ [urbanicity $]$

$+\mathrm{u}_{\mathrm{oj}}$

$\beta_{1 j}=Y_{10} ; \beta_{2 j}=Y_{20} ; \beta_{3 j}=Y_{30} ; \beta_{4 j}=Y_{40} ; \beta_{5 j}=Y_{50} ; \beta_{6 j}=Y_{60} ; \beta_{7 j}=Y_{70}$

Model G: School Connectedness and School Size

Level 1: $\quad Y_{\mathrm{ij}}[$ school connectedness $]=\beta_{\mathrm{oj}}+\beta_{1 \mathrm{j}}[$ biological sex $]+\beta_{2 \mathrm{j}}[$ Hispanic origin $]+\beta_{3 \mathrm{j}}[$ White $]+\beta_{4 \mathrm{j}}[$ African American $]+\beta_{5 \mathrm{j}}[$ American Indian $]+\beta_{6 \mathrm{j}}[$ Asian $]+\beta_{7 \mathrm{j}}[$ Income $]+\mathrm{r}_{\mathrm{ij}}$

Level 2: $\quad \beta_{\mathrm{oj}}=\mathrm{Y}_{\mathrm{oo}}+\mathrm{Y}_{\mathrm{o} 1}[$ school size $]+\mathrm{Y}_{\mathrm{o} 2}$ [school type $]+\mathrm{Y}_{\mathrm{o} 3}[$ urbanicity $]+$ $\mathrm{u}_{\mathrm{oj}}$

$\beta_{1 j}=Y_{10} ; \beta_{2 j}=Y_{20} ; \beta_{3 j}=Y_{30} ; \beta_{4 j}=Y_{40} ; \beta_{5 j}=Y_{50} ; \beta_{6 j}=Y_{6 o} ; \beta_{7 j}=Y_{70}$

Model H: Youth Violence and School Connectedness

Level 1: $\quad Y_{i j}$ [youth violence] $=\beta_{\mathrm{oj}}+\beta_{1 \mathrm{j}}$ [school connectedness] $+\beta_{2 \mathrm{j}}[$ biological sex $]+\beta_{3 j}$ [Hispanic origin $]+\beta_{4 j}[$ White $]+\beta_{5 j}[$ African American $]$ $+\beta_{6 j}[$ American Indian $]+\beta_{7 \mathrm{j}}[$ Asian $]+\beta_{8 \mathrm{j}}[$ Income $]+\mathrm{r}_{\mathrm{ij}}$

Level 2: $\quad \beta_{\mathrm{oj}}=\mathrm{Y}_{\mathrm{oo}}+\mathrm{Y}_{\mathrm{o} 1}$ [school size $]+\mathrm{Y}_{\mathrm{o} 2}$ [school type $]+\mathrm{Y}_{\mathrm{o} 3}$ [urbanicity] $+\mathrm{u}_{\mathrm{oj}}$

$\beta_{1 j}=Y_{10} ; \beta_{2 j}=Y_{20} ; \beta_{3 j}=Y_{30} ; \beta_{4 j}=Y_{40} ; \beta_{5 j}=Y_{50} ; \beta_{6 j}=Y_{6 o} ;$

$\beta_{7 \mathrm{j}}=Y_{70} ; \beta_{7 \mathrm{j}}=Y_{80}$

Model I: Youth Violence and School Connectedness (Interaction)

Level 1: $\quad Y_{i j}$ [youth violence] $=\beta_{\mathrm{oj}}+\beta_{1 \mathrm{j}}$ [school connectedness] $+\beta_{2 \mathrm{j}}[$ biological sex $]+\beta_{3 j}[$ Hispanic origin $]+\beta_{4 j}[$ White $]+\beta_{5 j}[$ African American $]$

$+\beta_{6 \mathrm{j}}[$ American Indian $]+\beta_{7 \mathrm{j}}[$ Asian $]+\beta_{8 \mathrm{j}}[$ Income $]+\mathrm{r}_{\mathrm{ij}}$

Level 2: $\quad \beta_{\mathrm{oj}}=\mathrm{Y}_{\mathrm{oo}}+\mathrm{Y}_{\mathrm{o} 1}[$ school size $]+\mathrm{Y}_{\mathrm{o} 2}[$ school type $]+\mathrm{Y}_{\mathrm{o} 3}$ [urbanicity]

$+\mathrm{u}_{\mathrm{oj}}$

$\beta_{1 j}=Y_{10}+Y_{11}[$ school size $]$

$\beta_{2 \mathrm{j}}=Y_{20} ; \beta_{3 \mathrm{j}}=Y_{30} ; \beta_{4 \mathrm{j}}=Y_{40} ; \beta_{5 \mathrm{j}}=Y_{50} ; \beta_{6 \mathrm{j}}=Y_{60} ; \beta_{7 \mathrm{j}}=Y_{70} ; \beta_{7 \mathrm{j}}=Y_{80}$ 
Table 8

Hypothesis Models with Controls (F \& G) Final Estimation of Fixed Effects

\begin{tabular}{|c|c|c|c|c|c|c|}
\hline & & Coefficient & SE & T-ratio & $\mathrm{df}$ & $p$-value \\
\hline \multicolumn{7}{|l|}{ Fixed Effects Model F } \\
\hline Youth Violence (Int.)a & $Y_{\mathrm{oo}}$ & 1.397 & 0.223 & 6.267 & 111 & $0.000^{* * *}$ \\
\hline School Size & $\mathrm{Y}_{01}$ & 0.032 & 0.060 & 0.365 & 111 & 0.716 \\
\hline School Type & $\mathrm{Y}_{02}$ & 0.083 & 0.070 & 1.181 & 111 & 0.240 \\
\hline Ubranicity & $\mathrm{Y}_{\mathrm{O} 3}$ & 0.080 & 0.071 & 1.122 & 111 & 0.264 \\
\hline Biological Sex (Slope) & $Y_{10}$ & -0.378 & 0.091 & -4.169 & 8970 & $0.000^{* * *}$ \\
\hline Hispanic Origin (Slope) & $\mathrm{Y}_{20}$ & 0.198 & 0.084 & 2.363 & 8970 & $0.018 *$ \\
\hline White (Slope) & $\mathrm{Y}_{30}$ & -0.101 & 0.179 & -0.565 & 8970 & 0.572 \\
\hline African American (Slope) & ) $Y_{40}$ & 0.068 & 0.177 & 0.383 & 8970 & 0.702 \\
\hline American Indian (Slope) & $Y_{50}$ & 0.287 & 0.120 & 2.399 & 8970 & $0.017^{*}$ \\
\hline Asian (Slope) & $\mathrm{Y}_{60}$ & -0.251 & 0.156 & -1.610 & 8970 & 0.107 \\
\hline Income (Slope) & $Y_{70}$ & -0.001 & 0.001 & -2.713 & 8970 & $0.007^{* *}$ \\
\hline \multicolumn{7}{|l|}{ Fixed Effects Model G } \\
\hline School Connect (Int.) ${ }^{\mathrm{a}}$ & $Y_{\text {oo }}$ & 1.520 & 0.833 & 1.825 & 111 & 0.071 \\
\hline School Size & $Y_{01}$ & -0.401 & 0.150 & -2.129 & 111 & $0.035^{*}$ \\
\hline School Type & $Y_{02}$ & -0.789 & 0.727 & -1.085 & 111 & 0.280 \\
\hline Ubranicity & $\mathrm{Y}_{\mathrm{O} 3}$ & 0.587 & 0.442 & 1.329 & 111 & 0.187 \\
\hline Biological Sex (Slope) & $Y_{10}$ & 0.618 & 0.270 & 2.286 & 8970 & $0.022^{*}$ \\
\hline Hispanic Origin (Slope) & $\mathrm{Y}_{20}$ & -0.144 & 0.334 & -0.432 & 8970 & 0.666 \\
\hline White (Slope) & $\mathrm{Y}_{30}$ & -0.643 & 0.546 & -1.177 & 8970 & 0.239 \\
\hline African American (Slope) & e) $Y_{40}$ & -0.944 & 0.581 & -1.624 & 8970 & 0.104 \\
\hline American Indian (Slope) & $\mathrm{Y}_{50}$ & -1.465 & 0.722 & -2.030 & 8970 & $0.042^{*}$ \\
\hline Asian (Slope) & $\mathrm{Y}_{60}$ & -0.446 & 0.637 & -0.699 & 8970 & 0.485 \\
\hline Income (Slope) & $Y_{70}$ & 0.008 & 0.003 & 2.616 & 8970 & $0.009^{* *}$ \\
\hline
\end{tabular}

Note. Output generated by HLM6 with REML.

Run-time deletion reduced number of level-1 units to 8981

a Intercept

${ }^{*} \mathrm{p}<.05,{ }^{* *} \mathrm{p}<.01,{ }^{* * *} \mathrm{p}<.001$ 
Table 9

Hypothesis Models with Controls (H \& I) Final Estimation of Fixed Effects

\begin{tabular}{|c|c|c|c|c|c|c|}
\hline & & Coefficient & $\mathrm{SE}$ & T-ratio & df & $p$-value \\
\hline \multicolumn{7}{|l|}{ Fixed Effects Model H } \\
\hline Youth Violence (Int.)a & $Y_{\mathrm{oo}}$ & 1.407 & 0.235 & 6.256 & 111 & $0.000^{* * * *}$ \\
\hline School Size & $Y_{01}$ & 0.003 & 0.042 & 0.078 & 111 & 0.938 \\
\hline School Type & $Y_{02}$ & -0.063 & 0.051 & -1.233 & 111 & 0.220 \\
\hline Ubranicity & $\mathrm{Y}_{\mathrm{O} 3}$ & 0.071 & 0.047 & 1.523 & 111 & 0.131 \\
\hline School Connect (Slope) & $Y_{10}$ & -0.048 & 0.006 & -8.387 & 8969 & $0.000^{* * *}$ \\
\hline Biological Sex (Slope) & $Y_{20}$ & -0.378 & 0.090 & -4.201 & 8969 & $0.000^{* * *}$ \\
\hline Hispanic Origin (Slope) & $Y_{30}$ & 0.184 & 0.089 & 2.071 & 8969 & $0.038^{*}$ \\
\hline White (Slope) & $\mathrm{Y}_{40}$ & -0.097 & 0.176 & -0.551 & 8969 & 0.582 \\
\hline African American (Slope) & $\mathrm{Y}_{50}$ & 0.067 & 0.175 & 0.387 & 8969 & 0.699 \\
\hline American Indian (Slope) & $Y_{60}$ & 0.282 & 0.115 & 2.444 & 8969 & $0.015^{*}$ \\
\hline Asian (Slope) & $Y_{70}$ & -0.253 & 0.153 & -1.652 & 8969 & 0.099 \\
\hline Income (Slope) & $Y_{80}$ & -0.001 & 0.000 & -2.687 & 8969 & $0.007^{* *}$ \\
\hline \multicolumn{7}{|l|}{ Fixed Effects Model I } \\
\hline Youth Violence (Int.) a & $Y_{\text {oo }}$ & 1.554 & 0.248 & 6.252 & 111 & $0.000^{* * *}$ \\
\hline School Size & $Y_{01}$ & 0.003 & 0.041 & 0.072 & 111 & 0.943 \\
\hline School Type & $\mathrm{Y}_{\mathrm{O} 2}$ & -0.048 & 0.060 & -0.803 & 111 & 0.0424 \\
\hline Ubranicity & $Y_{\mathrm{O} 3}$ & 0.031 & 0.055 & 0.564 & 111 & 0.574 \\
\hline School Connect (Slope) & $Y_{10}$ & -0.053 & 0.011 & -6.082 & 8968 & $0.000^{* * *}$ \\
\hline School Size & $Y_{11}$ & -0.006 & 0.012 & -0.492 & 8968 & 0.623 \\
\hline Biological Sex (Slope) & $Y_{20}$ & -0.377 & 0.090 & -4.199 & 8968 & $0.000^{* * *}$ \\
\hline Hispanic Origin (Slope) & $Y_{30}$ & 0.180 & 0.092 & 1.988 & 8968 & $0.047^{*}$ \\
\hline White (Slope) & $\mathrm{Y}_{40}$ & -0.097 & 0.174 & -0.560 & 8968 & 0.576 \\
\hline African American (Slope) & ) $Y_{50}$ & 0.072 & 0.171 & 0.418 & 8968 & 0.676 \\
\hline American Indian (Slope) & $Y_{60}$ & 0.278 & 0.113 & 2.462 & 8968 & $0.014^{*}$ \\
\hline Asian (Slope) & $Y_{70}$ & -0.260 & 0.154 & -1.674 & 8968 & 0.094 \\
\hline Income (Slope) & $Y_{80}$ & -0.001 & 0.000 & -2.712 & 8968 & $0.007^{* *}$ \\
\hline
\end{tabular}

Note. Output generated by HLM6 with REML.

Run-time deletion reduced number of level-1 units to 8981

${ }^{a}$ Intercept

${ }^{*} \mathrm{p}<.05,{ }^{* *} \mathrm{p}<.01,{ }^{* * *} \mathrm{p}<.001$ 
Appendix B: Figures 
Figure 1. Predicted mediating effect of school connectedness between school size and youth violence.

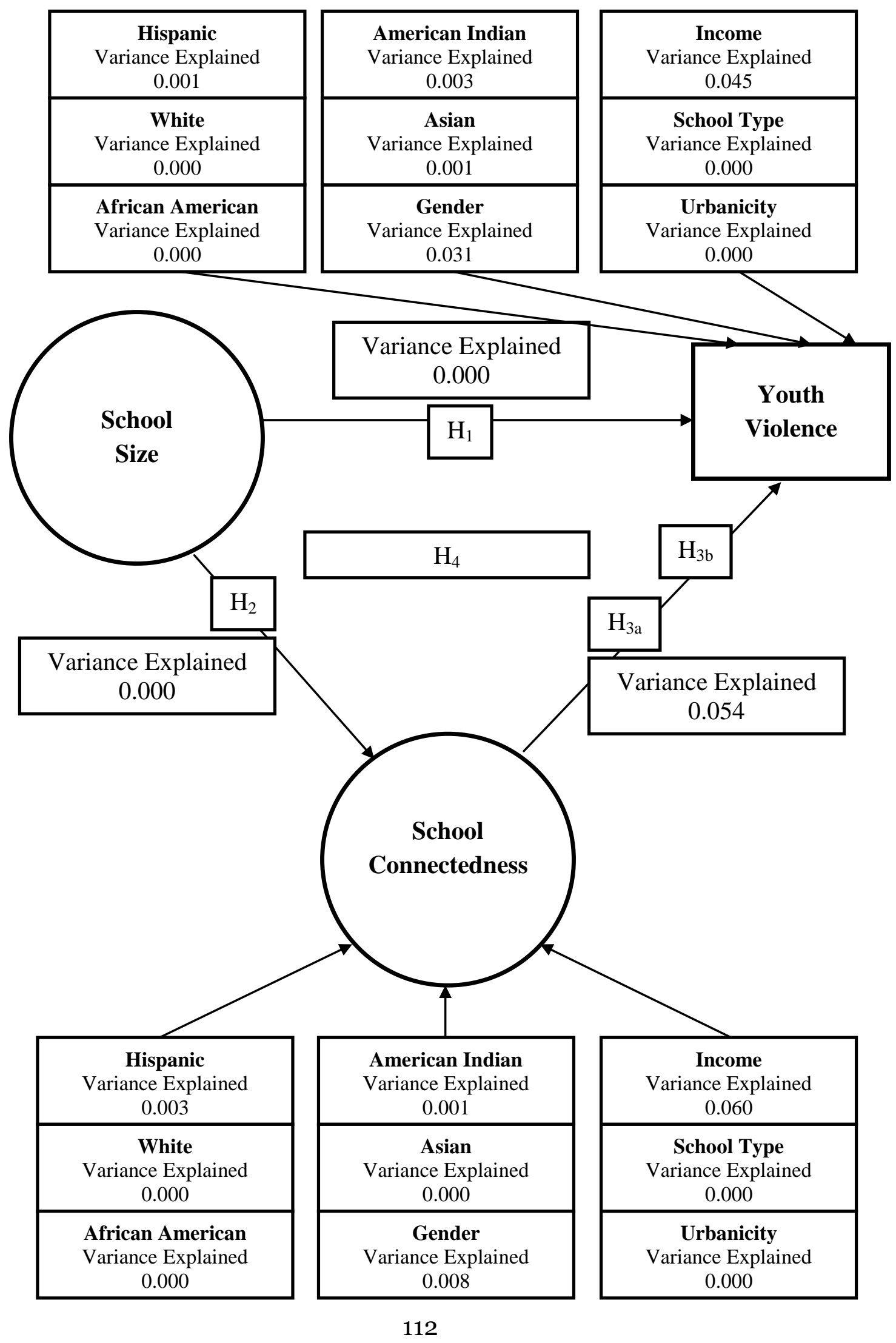


Figure 2. Predicted moderating effect of school connectedness between school size and youth violence. (Note: The variance explained for the controls are the same as Figure 1.)

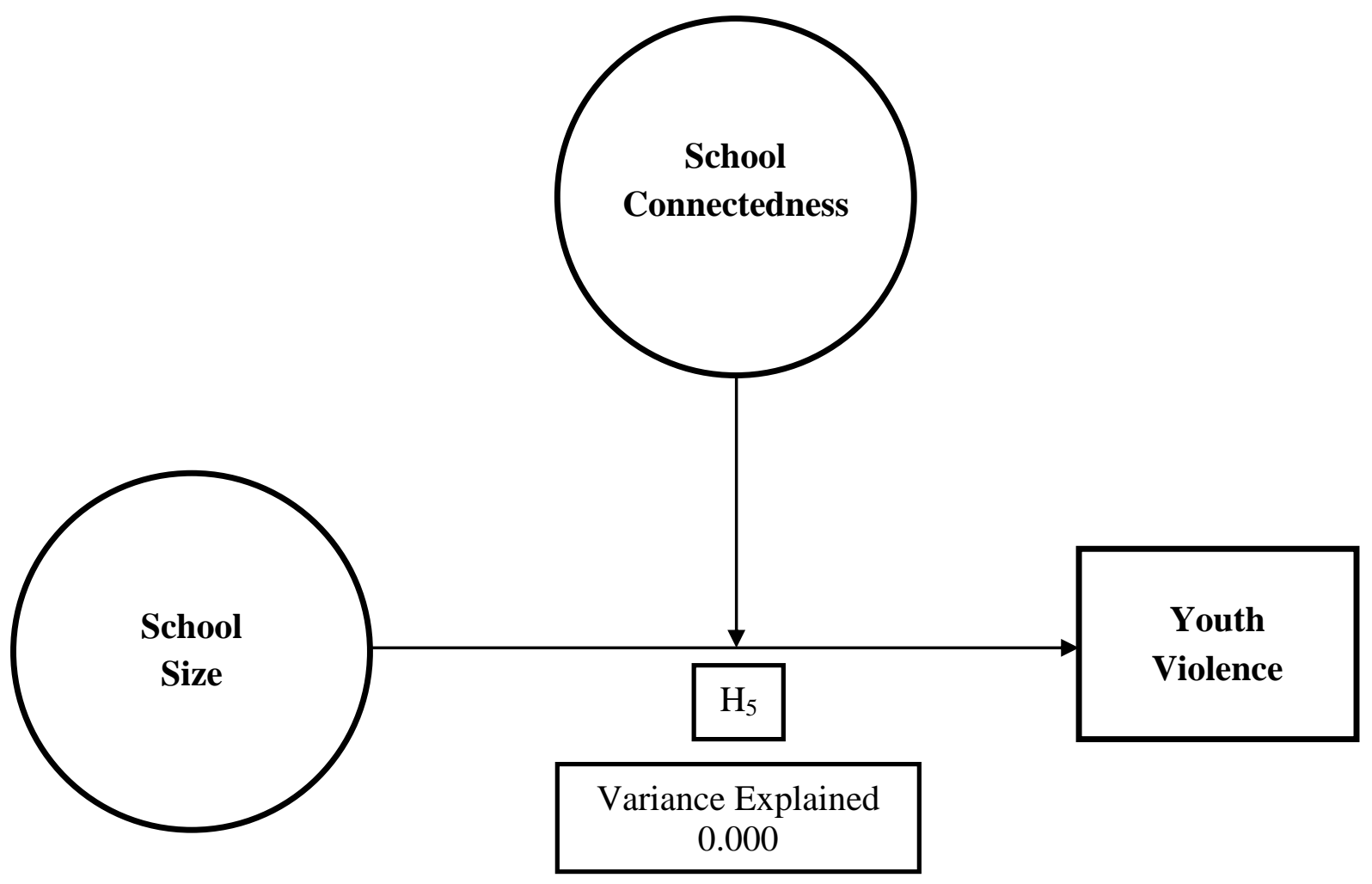


Figure 3. Predicted interaction effect resulting school connectedness moderation

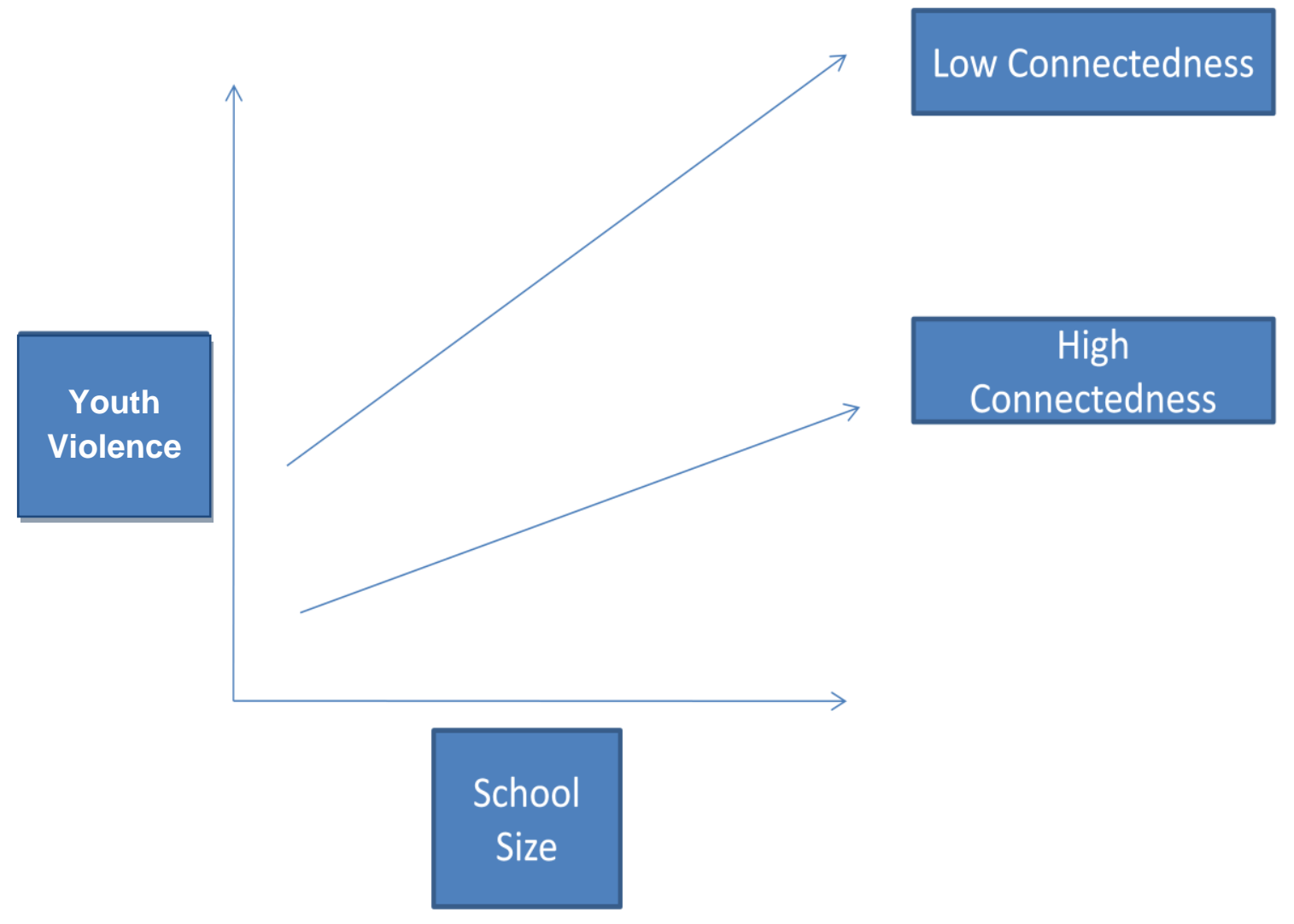


Appendix C: Curriculum Vita 


\section{Adam M. Volungis, MA, LMHC}

Department of Counseling \& Educational Psychology

201 N. Rose Avenue

Bloomington, IN 47405

avolungi@indiana.edu

\section{EDUCATION}

\section{Ph.D. Candidate, Counseling Psychology \\ Indiana University - Bloomington, IN (APA \\ Accredited) (Anticipated January, 2011)}

Minor: Organizational Management (Kelley School of Business)

Dissertation Title: School Size \& Youth Violence: Potential Mediating \& Moderating Role of School Connectedness

APA Accredited Clinical Internship: Casa Pacifica - Camarillo, CA (http://www.casapacifica.org)

\section{M.A., Counseling Psychology}

Assumption College - Worcester, MA (5/2003)

\section{Concentrations: Cognitive-Behavioral Therapies (Aaron T. Beck Institute)}

Child and Family Interventions

\section{B.A., Psychology - Magna Cum Laude \\ Saint Anselm College - Manchester, NH (5/2001)}

Senior Thesis: Coping Strategies and Social Support in HIV-Positive Gay Men:

The Relationship to Depression and Anxiety

Thesis can be viewed at: http://www.anselm.edu/internet/psych/theses/SR2001.htm/volungis/volungis.html

LICENSURE

\section{HONORS/AWARDS}

\section{Paul F. Munger Award}

Spring 2009

(Nominated and awarded by faculty for demonstrating "high promise in the areas of

clinical practice, research, teaching, and community-building" - Indiana University)

APAGS' Outstanding Professional Development Program Award (APA-APAGS)

Department of Counseling \& Educational

Psychology Research Fellowship Award

Spring 2008

(Awarded by faculty in support of "outstanding student research" - Indiana University)

Trentham Conference Travel Award (for APA)

(Indiana University) 
(National Scholastic Honor Society for Catholic

Colleges)

Psi-Chi Induction

(National Psychology Honor Society)

Dean's List of Scholars

1997-2001

(Saint Anselm College)

Presidential Scholarship Award

(Saint Anselm College)

1997-2001

TEACHING EXPERIENCE

\section{DEPARTMENT OF COUNSELING PSYCHOLOGY - ASSUMPTION COLLEGE -} WORCESTER, MA

Adjunct Professor

Department Chair: Leonard Doerfler, Ph.D.

Spring 2011

- Psychology of Measurement (1 section)

- A master's course focusing on an introduction to the instruments and the methods used in the measurement and evaluation of the psychological characteristics of human beings, including elementary principles of statistical analysis

- Topics will be approached by means of lecture, class discussion, and readings

- Student performance will be evaluated through examinations and presentations

- Cognitive Assessment and Psychotherapy (1 section)

- A master's course focusing on providing a psychotherapeutic understanding of cognitive structure and content as it influences the client's perceptions, emotional states, and behavior; personal construct assessment, cognitive modification, stress inoculation training, self-instructional methods, and cognitive restructuring techniques are emphasized

- Topics approached by means of lecture, class discussion, demonstration, observation, and readings

- Student performance will be evaluated through class participation, presentations, and two term papers

DEPARTMENT OF PSYCHOLOGY - IVY TECH COMMUNITY COLLEGE OF INDIANA BLOOMINGTON, IN

Adjunct Faculty

Fall 2007 - Fall 2009

Department Chair: Martin Wolfger, M.A., LMHC

- Introduction to Psychology (5 sections; 4 in-class / 1 online)

○ An undergraduate course focusing on biological foundations, learning processes, research methodologies, personality, human development, social psychology, and abnormal behavior

- Topics approached by means of lecture, class discussion, demonstration, and readings

- Evaluated student performance through examinations and written reflection assignments 
- Abnormal Psychology (2 sections)

- An undergraduate course focusing on theories and research related to abnormal behavior with a primary emphasis on psychological disorders and treatment methods

- Topics approached by means of lecture, class discussion, demonstration, and readings

$\circ$ Evaluated student performance through examinations, quizzes, and case studies

DEPARTMENT OF COUNSELING AND EDUCATIONAL PSYCHOLOGY - INDIANA UNIVERSITY, BLOOMINGTON

Guest Lectures

Fall 2006 - Fall 2008

- Doctoral Practicum (fall 2006, 2007, 2008) (Instructor: Rex Stockton, Ed.D.)

- Presented the "Indiana Change Model" (and personal change model), which is the counseling psychology program's espoused concept of therapeutic change; this approach incorporates the program's philosophy of training and emphasizes change through the integration of science and practice through a variety of mechanisms and across units

- Psychoeducational Consultation (graduate) (fall 2007) (Instructor: Jeff Daniels, Ph.D.)

- Presented on direct-care staff burnout in adolescent residential service settings within the theme of prevention and intervention through organizational citizenship behaviors

- Counseling lab (graduate) (fall 2007) (Instructor: Jeff Daniels, Ph.D.)

$\circ$ Lectured on the counseling skills of interpretations and self-disclosures

- Psychoeducational Consultation (graduate) (summer 2007) (Instructor: Charles Ridley, Ph.D.)

- Lectured on: non-classical organizational theories, criticisms of classical/non-classical organizational theories, matrix designs, theory $\mathrm{z}$, and analyzing supra-systems

\section{DEPARTMENT OF COUNSELING AND EDUCATIONAL PSYCHOLOGY - INDIANA} UNIVERSITY, BLOOMINGTON

Associate Instructor

Fall 2005 - Spring 2006; Fall 2008 - Spring 2009

Department Supervisors: Jack Cummings, Ph.D. / Sue Whiston, Ph.D.

- Communication in the Classroom (5 sections)

- An undergraduate course primarily for education majors covering interpersonal communication skills, group dynamics, and multicultural issues

○ Topics approached by means of class discussion, demonstration, application through role-plays, observation, and readings

- Evaluated student performance through examinations, written assignments, quizzes, mock parent-teacher conferences, and a final group project presentation

- Individual Appraisal: Principles and Procedures (1 section)

- A graduate (master's and doctoral) assessment course focusing on statistical, psychometric, sociometric, and clinical principles crucial to professional standardized and informal data regarding interpretation of individual clients

- Topics approached by means of lecture, class discussion, demonstration, observation, and readings

- Evaluated student performance through examinations, presentations, and term paper 
DEPARTMENT OF COUNSELING AND EDUCATIONAL PSYCHOLOGY - INDIANA UNIVERSITY, BLOOMINGTON

Research Assistant

Supervisor: Jeff Daniels, Ph.D.

October 2005 - August 2009

- Examined the concern of school safety from a positive psychology perspective. Attempted to understand school violence prevention from the perspective of school personnel who intervened to avert deadly shooting rampages. Duties included qualitative process of "blocking" and "domaining" transcripts of individuals interviewed and manuscript preparation.

\section{YOUTH OPPORTUNITES UPHELD (YOU) INC. - SOUTHBRIDGE, MA}

Research Consultant

October 2002 - May 2003

Supervisor: Owen Ryan, MSW, LICSW

- Assisted in creating and administering a Social Norms questionnaire at local area high schools, in an attempt to gain greater knowledge of student alcohol and drug use along with student's perceptions of alcohol and drug use among their peers. Results used towards a grant proposal to provide science-based substance abuse prevention programs in communities throughout the Commonwealth. Potential Purchasing Department: Department of Public Health \& Bureau of Substance Abuse Services.

\section{UMASS MEDICAL SCHOOL - WORCESTER, MA}

Research Assistant

Supervisors: Daniel Connor, M.D. \& Leonard Doerfler, Ph.D.

July 2002 - August 2005

- Duties included research, data analysis, and manuscript preparation of "emotionally disturbed" children and adolescents from a Devereux residential program and a psychopharmacology database of outpatients at the medical school. Some specific areas of interest included aggression (e.g., proactive - reactive), expression of anxiety (e.g., panic, agoraphobia) and other comorbid disorders, impact of physical/sexual abuse and parental alcoholism/violence, other influences on adaptive functioning, and general characteristics.

\section{DEPARTMENT OF PSYCHOLOGY - ASSUMPTION COLLEGE - WORCESTER, MA}

Research Assistant May 2001 - May 2003

Supervisor: Peter Toscano, Ph.D.

- Duties included research and data analysis on adopted children and adolescents in a general mental health clinic (e.g., differences in externalizing/internalizing pathology, ADHD comorbidity, family history).

\section{DEPARTMENT OF PSYCHOLOGY - SAINT ANSELM COLLEGE - MANCHESTER, NH}

Research Assistant January 2001 - March 2003

Supervisor: Laurie Geck, Ph.D.

- Duties included transcribing bereavement tapes of HIV-positive gay men, data analysis, and manuscript preparation. Examined how emotional disclosure of a traumatic event (i.e., bereavement of a lost "loved-one") affects psychological and immune processes and whether supportive feedback would influence such effects. 
CASA PACIFICA - CAMARILLO, CA (APA Accredited)

Pre-Doctoral Residential Clinical Intern

August 2009 - August 2010

Primary Supervisor: Lori Kaplan, Ph.D.

(40-50 hours weekly)

Secondary Supervisor: Michael Marquez, Ph.D.

Group Supervisor: Laureen Worden, Ph.D.

- Clinician at a Residential Level-14 cottage for 14 boys aged 11 to 18 with severe mental illness (e.g., trauma, bipolar, major depression), learning disabilities, challenging behaviors (e.g., conduct disorder, antisocial personality traits), and substance abuse

- Primary duties included providing evidenced based individual, family, and group therapy for adolescents and their families: CBT, TF-CBT, Interpersonal, DBT, Collaborative Problem Solving (CPS), Life Space Crisis Intervention (LSCI)

- Associated responsibilities included facilitating treatment team meetings, intakes, formal treatment planning and interventions, emotional and behavior contributions to IEPs, discharge summaries, and case management

- Completed full battery psychological/cognitive assessments and psychosocial assessments; testing highlights: CBCL, CRS-R, BASC-2, CDI, MASC, WISC-IV, WAIS-IV, WJ-IIICog/Ach, MMPI-II, MMPI-A, MACI, MCMI-III, NEPSY-2, TOVA, HTP, Roberts, Sentence Completion

- Provided intensive crisis and suicide assessment and intervention

- Such duties and responsibilities were completed in conjunction with other departments (e.g., psychiatry, nursing, education, residential) and other outside providers (e.g., Child Protective Services, Juvenile Justice/Probation Officers, Ventura County Behavioral Health)

- Participated in weekly individual and group supervision, staff meetings, and didactics

- Provided case presentations of select clients to program staff

\section{CENTER FOR HUMAN GROWTH - INDIANA UNIVERSITY, BLOOMINGTON}

\section{Assistant Director}

Training Director: Rex Stockton, Ed.D.

Interim-Director: Kimberly Wagner, Ph.D.

- Accountable for the day-to-day operation of a university department counseling center open to students and the community at large; worked in conjunction with other Assistant Director and Director of the center

- Supervised and consulted intake interviews of master's and doctoral level counselors

- Provided crisis supervision of student counseling

- Provided weekly direct individual supervision for 4 master's level counselors (2 fall 2006 spring 2007; 2 fall 2007 - spring 2008) (separate from supervision practicum)

- Co-facilitated weekly counselor staff meetings

- Attended weekly administration meetings

- Planed and conducted orientation and training sessions for new counselors each semester

- Assisted in the supervision and administration of outreach activities

- Assisted and coordinated national screening days

- Planed and conducted community relations activities to market center services

- Co-facilitated master's practicum interviews for placement at the center 
CENTER FOR ADOLESCENT \& FAMILY STUDIES - BLOOMINGTON, IN

Advanced Practicum Family Counselor

Training Supervisor: Thomas L. Sexton, Ph.D., ABPP
July 2006 - October 2007

(10-15 hours weekly)

- Provided Functional Family Therapy (FFT), an evidence-based intervention for at-risk adolescents and their families who have been court mandated or referred by county juvenile probation through the state funded Indiana Family Project

- Conducted pre-treatment and post-treatment assessment, including administration and interpretation of the OQ ${ }^{\circledR}-45.2$, YOQ, YOQ-SR, and other instruments specific to outcome assessment of FFT

- Consulted with and provided progress updates to probation officers as needed

- Participated in weekly group supervision

- Participated in FFT training seminars and workshops

- Maintained current progress notes and case information using an online database tracking therapist adherence and outcome of therapy

\section{CENTER FOR HUMAN GROWTH - INDIANA UNIVERSITY, BLOOMINGTON}

Advanced Practicum Counselor

Training Director: Rex Stockton, Ed.D.

Training Supervisor: Thomas L. Sexton, Ph.D., ABPP

- Provided individual counseling services for both university students and the surrounding community population within the university department counseling center - provided services for children, adolescents, adults, and families

- Clients presented with a wide range of clinical issues including depression, anxiety, externalized behavioral/emotional problems such as ADHD or ODD, career management, phase of life and identity development issues, relationship and marital problems, bereavement, communication/social skills, and stress/time management

- Conducted pre-treatment and post-treatment assessment, including treatment planning and administration and interpretation of the OQ®-45.2, YOQ, YOQ-SR

- Maintained weekly crisis and walk-in hours

- Participated in weekly individual supervision and weekly staff meetings

- Communicated with outside providers and other community agencies regarding client transfer of care when necessary, including outside referrals for psychiatric consultation

- Participated in campus outreach activities including national screening days and dormitory programs

\section{MEADOWRIDGE BEHAVIORAL HEALTH CENTER (JUSTICE RESOURCE INSTITUTE) - SWANSEA, MA}

\section{Clinician}

Clinical Supervisor: James Isidorio, M.A., LMHC

Program Director: Stephanie Ward, M.Ed., LMHC

May 2003 - August 2005

(40 hours weekly)

- Clinician for a COA-accredited treatment center and residential school for 27 adolescent boys and girls aged 12 to 22 with moderate to severe mental illness (e.g., trauma, bipolar, early onset psychosis), learning disabilities, and challenging behaviors (e.g., conduct disorder, borderline personality traits) (Chapter 766 approved and EEC licensed)

- Duties included providing individual, family, and group therapy (e.g., CBT, DBT) for adolescents and their families 
- Associated responsibilities included intakes, cognitive and behavioral assessments (e.g., BDI-II, CBCL), interpretation of intelligence/achievement assessments (WISC-III/IV, WAIS-III, WJ-III), assistance with personality assessments (e.g., MMPI-A, MMPI-II, MACI, MCMI-III) and integrated reports, formal treatment planning and interventions, emotional and behavior contributions to IEPs, discharge summaries, and case management

- Provided intensive crisis and suicide assessment and intervention

- Such duties and responsibilities were completed in conjunction with other departments (e.g., program psychiatrist, nursing, education, residential) and other outside providers (e.g., court appointed attorneys, Department of Social Services, Department of Youth Services, Department of Mental Health)

- Participated in weekly individual and group supervision, and daily staff meetings

- Provided monthly case presentations of select clients to program staff

- Implemented interdepartmental client specific and general program-wide behavioral assessments and interventions

\section{YOUTH OPPORTUNITES UPHELD (YOU) INC. - SOUTHBRIDGE, MA}

\section{Intern School-Based \& Outpatient Therapist \\ September 2002 - May 2003}

Site Supervisor: Owen Ryan, MSW, LICSW

Department Supervisors: Lynn Dowd, Psy.D. \& Peter Toscano, Ph.D.

(20 hours weekly)

- Completed master's internship as a school-based and outpatient therapist

- Duties included providing assessment and therapy for children, adolescents, adults, and families utilizing local school facilities, the Family Services/Outpatient Clinic, and occasionally in the homes of the clients

- Specific areas of treatment included depression, anxiety, anger management, family and relationship problems, as well as other externalized behavioral/emotional problems such as ADHD, ODD, etc.

- Associated responsibilities included intakes, request for services from managed care, formal treatment planning and interventions, termination planning, and case management

- Participated in weekly individual and group supervision

\section{YOUTH OPPORTUNITES UPHELD (YOU) INC. - WORCESTER, MA}

\section{Practicum Counselor}

Site Supervisor: Nathan Peterson, M.A., LMHC
May 2002 - August 2002

(10 hours weekly)

Department Supervisors: Lynn Dowd, Psy.D. \& Peter Toscano, Ph.D.

- Completed master's practicum as a counselor with predominately latency aged children

- Duties included assisting in facilitating a "life skills" program for court referred/mandated children and assisting with fire-starting assessment and integrated reports

- Other responsibilities included participating in an "anger management" program for children with a prior history of aggressive behaviors by providing therapeutic support (e.g., counseling, modeling, coping skills, social skills)

- Participated in weekly individual supervision 
WORCESTER STATE HOSPITAL - MA

Transitions Counselor

July 2001 - September 2003

Supervisor: Steve Phaneuf, M.S.

Program Director: Andrew Benedetti, M.Ed.

(24-40 hours weekly)

- "Transitions" counselor for a JCAHO accredited intensive residential treatment program (IRTP) for severely emotionally disturbed abused and neglected adolescents ranging from eating disorders to early onset psychosis; affiliated with UMass Medical - Psychiatry

- Population deemed committable under state law to a psychiatric treatment facility predominately referred through the Department of Mental Health

- Duties included interacting with each adolescent during their daily activities in a "lockeddown" milieu while participating in their individualized treatment plans (e.g., daily logs, weekly treatment team evaluations)

\section{WESTBORO STATE HOSPITAL - MA}

Connections Counselor

Supervisor: Harry Poirier, M.S.

July 2001 - September 2003

(on-call weekly)

Program Director: Andrew Benedetti, M.Ed.

- "Connections" counselor for a JCAHO accredited behavioral intensive residential treatment (BIRT) program for severely behaviorally disturbed abused and neglected adolescents ranging from suicidal ideation/behaviors to severe conduct disordered behaviors; affiliated with UMass Medical - Psychiatry

- Population deemed committable under state law to a psychiatric treatment facility predominately referred through the Department of Youth Services

- Duties included interacting with each adolescent during their daily activities in a "lockeddown" milieu while participating in their individualized treatment plans (e.g., daily logs, weekly treatment team evaluations)

SUPERVISION EXPERIENCE

CENTER FOR ADOLESCENT \& FAMILY STUDIES - BLOOMINGTON, IN

Interim Lead Family Supervisor

Support Supervisor: Thomas L. Sexton, Ph.D., A.B.P.P.

- Provided weekly group supervision to master's (3) and doctoral (3) level counselors providing Functional Family Therapy (FFT)

- Followed clinical supervision model of the FFT Service Delivery System; this system includes an evidence-based family intervention, client assessment system, integrated clinical supervision and quality assurance protocol, and systematic training

- Provided developmental and professional feedback on counseling and case conceptualization of clients through utilizing clinical experience, integrated theory, and empirical evidence produced by process and outcome studies

- Acted as case management liaison between counselors and juvenile probation system 
DEPARTMENT OF COUNSELING AND EDUCATIONAL PSYCHOLOGY - INDIANA UNIVERSITY, BLOOMINGTON

Advanced Practicum Supervisor

May 2007 - August 2007

Training Director: Rex Stockton, Ed.D.

Interim-Director: Kimberly Wagner, Ph.D.

- Provided weekly individual supervision to 2 master's counseling students providing services within the Center for Human Growth (CHG) and 2 counseling students providing services within the local community (separate from Assistant Director supervision)

- Emphasized theme of developing a knowledge base related to supervision theory, research, and practice

- Reviewed audio and video recordings of each supervisee's clinical work

- Provided developmental and professional feedback/support on counseling of clients, case management related activities, and conduct within the center

- Completed midterm and final evaluations for each supervisee

- Participated in weekly supervision-of-supervision and weekly class/peer supervision

OTHER RELATED VOLUNTEER ACTIVITIES

\section{PINE HAVEN CENTER FOR BOYS - ALLENSTOWN, NH}

Classroom Assistant/Counselor

September 1999 - May 2000; January 2001 - May 2001

Supervisor: Mike Maroni, M.A.

- Volunteered and completed an undergraduate internship as a "classroom assistant/counselor" in a class of six latency aged students at a residential facility for abused and neglected boys. Duties included participating in the student's behavior program as set forth in their treatment plan and assisting in instructing students, individually or in small groups, according to the students' identified needs and learning styles (e.g., IEP).

SAINT ANSELM COLLEGE - MANCHESTER, NH

Big Brother

Fall 1998 - Summer 2001

- Mentor to a 13-year-old boy in Manchester, NH; through Saint Anselm College

AMERICA READS - MANCHESTER, NH

Volunteer

Spring 1998

- Assisted in an after school program at the local Salvation Army designed to assist grades

K-6 students with their homework and other living skills

PROFESSIONAL ACTIVITIES

DEPARTMENT OF COUNSELING AND EDUCATIONAL PSYCHOLOGY - INDIANA UNIVERSITY, BLOOMINGTON

Doctoral Student Representative

October 2006 - September 2007

Training Directors: Charles R. Ridley, Ph.D. \& Rex Stockton, Ed.D.

- Elected by peers as doctoral student representative to the faculty of the counseling psychology program. Primary duties included attendance and participation in monthly faculty meetings and assistance in APA accreditation process spring 2007. Presented doctoral students' interests and concerns to put on the agenda in order to provide voice of 
the student body as a whole, and communicated to all doctoral students important and relevant items from the faculty meetings.

\section{DEPARTMENT OF COUNSELING AND EDUCATIONAL PSYCHOLOGY - INDIANA} UNIVERSITY, BLOOMINGTON

Policy Committee Member

May 2006 - May 2007

Chair: Charles R. Ridley, Ph.D.

- Primary member in the development and completion of the first and current working document of the counseling psychology program's policy statement. Components included preamble, program values, operational guidelines, and accountability.

\section{SAINT ANSELM COLLEGE - MANCHESTER, NH}

Psychology Club

Fall 1998 - Spring 2001

Chair: Paul Finn, Ph.D.

- Vice President (Fall 2000 - Spring 2001)

- Junior Class Representative (Fall 1999 - Spring 2000)

\section{PROFESSIONAL AFFILIATIONS}

American Psychological Association (APA) - Graduate Student Affiliate 2003 - Present

Div. 12 - Clinical Psychology

Div. 17 - Counseling Psychology

Div. 37 - Child \& Family Policy \& Practice (Section on Child Maltreatment)

Association for Behavioral \& Cognitive Therapies (ABCT) - Member

2003 - Present

Delta Epsilon Sigma - Member

Psi Chi - Member

2000 - Present

1999 - Present

\section{PUBLICATIONS}

Volungis, A. M., \& Steinfeldt, J. (2010). Direct-care staff burnout in residential service settings: A theoretical approach through the lens of organizational citizenship behaviors. Manuscript in preparation.

Volungis, A. M. (2010). Strategic planning in nonprofit mental health service settings: A review of unique obstacles, problems, and recommendations for future research. Manuscript in preparation.

Volungis, A. M. (2010). School size \& school violence: Potential mediating and moderating role of school connectedness. Manuscript in preparation.

Volungis, A. M., Arany, J. G., \& Gilman, L. (2010). Doctoral students' experience of multiple relationships supervising master's students: Implications for training, practice, and research. Manuscript submitted for review.

Daniels, J. A., Volungis, A. M., Pshenishny, E., Ghandi, P., Winkler, A., Bradley, M. C., \& Cramer, D. P. (2010). A qualitative investigation of averted school rampages. The Counseling Psychologist,38, 69-95.

Volungis, A. M. \& Whiston, S. C. (2009). Instructor's manual for principles and applications of assessment in counseling ( $3^{\text {rd }}$ ed.). Belmont, CA: Brooks/Cole. 
Volungis, A. M. (2008). Preventing school violence through establishing school connectedness. Prevention in Counseling Psychology: Theory, Research, Practice and Training, 2, 17-21.

Doerfler, L. A., Connor, D. F., Volungis, A. M., \& Toscano, P. F. (2007). Panic disorder in clinically referred children and adolescents. Child Psychiatry and Human Development, 38, 57-71.

Connor, D. F., Doerfler, L. A., Toscano, P. F., Volungis, A. M., \& Steingard, R. J. (2004). Characteristics of children and adolescents admitted to a residential treatment center. Journal of Child and Family Studies, 13, 497-510.

Connor, D. F., Doerfler, L., Volungis, A. M., \& Melloni, R. H. (2003). Aggressive behavior in abused children. Annals of the New York Academy of Sciences, 1008, 79-90.

\section{PRESENTATIONS}

Volungis, A. M. (2008, August). Implementing empirically supported treatments: Keys to promoting success. Paper presented at the $116^{\text {th }}$ annual conference of the American Psychological Association, Boston, MA.

Volungis, A. M. (2008, August). Doctoral students' supervision experiences of multiple relationships. In L. Gilman \& A. M. Volungis (Co-Chairs), Doctoral students supervising master's students: Addressing training in multiple relationships. APAGS Symposium conducted at the $116^{\text {th }}$ annual conference of the American Psychological Association, Boston, MA. [Recipient of the 2008 APAGS' Outstanding Professional Development Award.]

Volungis, A. M., \& Rahardja, D. (2008, June). Systemic considerations and micro-level application for school violence prevention. In A. M. Volungis (Chair), Enhancing student mental health \& school violence prevention: Fostering school connectedness through interpersonal relationships. Symposium conducted at the Paul Munger Conference for Youth-Serving Professionals, Bloomington, IN.

Volungis, A. M. (2008, March). General constructs and approaches in implementing counseling based programs. Poster session presented at the International Counseling Psychology Conference, Chicago, IL.

Volungis, A. M. (2007, August). Consultation on burnout within organizations. In C. Ridley (Chair), Emerging issues in organizational consultation. Symposium conducted at the $115^{\text {th }}$ annual conference of the American Psychological Association, San Francisco, CA.

Daniels, J. A., Volungis, A. M., Pshenishny, E., Ghandi, P., \& Winkler, A. (2007, August). A qualitative investigation of averted school rampages: Preliminary findings. Paper presented at the $115^{\text {th }}$ annual conference of the American Psychological Association, San Francisco, CA.

Volungis, A. M., \& Tai, W. (2007, June). Best practices through manualized treatments: Debunking myths and how it "really" works. Workshop conducted at the Best Practices Summer Institute: Population-Based Services, Bloomington, IN

Volungis, A. M. (2007, March). Transportation of manualized treatments. In, Can manualized treatments promote the integration of practice and research, art and science? Symposium conducted at the $20^{\text {th }}$ annual American Psychological Association Division 17 Great Lakes Regional Conference, Akron, $\mathrm{OH}$. 
Volungis, A. M. (2006, April). Insufficient services and systems. In J. Daniels (Chair), The impact of school violence on school personnel: Implications for counselors. Symposium conducted at the $19^{\text {th }}$ annual American Psychological Association Division 17 Great Lakes Regional Conference, West Lafayette, IN.

${ }^{2}$ Geck, L. C., Doyle, K. A., Volungis, A. M., \& DiDio, A. A. (2003, March). HIV-Related bereavement and repeated disclosure: How do topic and listener support affect disclosure content? Poster session presented at the Eastern Psychological Association, Baltimore, MD.

${ }^{2}$ Geck, L. C., Doyle, K. A., DiDio, A. A., \& Volungis, A. M. (2002, October). HIV-Related bereavement disclosure to a supportive listener vs. no listener: Does support matter? Poster session presented at the New England Psychological Association, Nashua, NH.

${ }^{1}$ Volungis, A. M., \& Geck, L. C. (2002, March). Optimism and perceived stress in HIV-Positive gay men: The relationship to depression and anxiety. Poster session presented at the Eastern Psychological Association, Boston, MA.

${ }^{2}$ Geck, L. C., Volungis, A. M., Doyle, K. A., \& DiDio, A. (2002, March). Content and process of HIV-Related bereavement disclosure to a supportive listener. Poster session presented at the Eastern Psychological Association, Boston, MA.

${ }^{1}$ Volungis, A. M., \& Geck, L. C. (2001, April). Coping strategies and social support in HIVPositive gay men: The relationship to depression and anxiety. Psi-Chi poster session presented at the Eastern Psychological Association, Washington, DC.

*(see link above to view web page of senior thesis) 